University of Louisville

ThinkIR: The University of Louisville's Institutional Repository

Electronic Theses and Dissertations

$5-2017$

\title{
The role of the planetarium in students' attitudes, learning, and thinking about astronomical concepts.
}

William Raymond Thornburgh

University of Louisville

Follow this and additional works at: https://ir.library.louisville.edu/etd

Part of the Curriculum and Instruction Commons, and the Science and Mathematics Education Commons

\section{Recommended Citation}

Thornburgh, William Raymond, "The role of the planetarium in students' attitudes, learning, and thinking about astronomical concepts." (2017). Electronic Theses and Dissertations. Paper 2684.

https://doi.org/10.18297/etd/2684

This Doctoral Dissertation is brought to you for free and open access by ThinkIR: The University of Louisville's Institutional Repository. It has been accepted for inclusion in Electronic Theses and Dissertations by an authorized administrator of ThinkIR: The University of Louisville's Institutional Repository. This title appears here courtesy of the author, who has retained all other copyrights. For more information, please contact thinkir@louisville.edu. 
THE ROLE OF THE PLANETARIUM IN STUDENTS' ATTITUDES, LEARNING, AND THINKING ABOUT ASTRONOMICAL CONCEPTS

\author{
By \\ William Raymond Thornburgh \\ B.S., Butler University, 1998 \\ M.S., Montana State University, 2010

\begin{abstract}
A Dissertation
Submitted to the Faculty of the

College of Education and Human Development of the University of Louisville In Partial Fulfillment of the Requirements

For the Degree of
\end{abstract}

Doctor of Philosophy in Curriculum and Instruction

Department of Middle and Secondary Education

University of Louisville

Louisville, Kentucky

May, 2017 
Copyright 2017 by William Raymond Thornburgh

All Rights Reserved 

THE ROLE OF THE PLANETARIUM IN STUDENTS' ATTITUDES, LEARNING, AND THINKING ABOUT ASTRONOMICAL CONCEPTS

\author{
By \\ William Raymond Thornburgh \\ B.S., Butler University, 1998 \\ M.S., Montana State University, 2010 \\ A Dissertation Approved on
}

April 17, 2017

By the following Dissertation Committee:

Dissertation Director - Dr. Tom Tretter

Committee Member - Dr. Sherri Brown

Committee Member - Dr. James Chisholm

Committee Member - Dr. Justin McFadden

Committee Member - Dr. William Ingle 


\section{DEDICATION}

This dissertation is dedicated to my parents - Edward and Janice - for their support of my academic endeavors over the years. They have always encouraged me to follow my dreams and to work hard. I appreciate your love and support, thank you. This is as much for you as it is for me... I love you! Also, to my children - Isabella, Asher, and Hadley who have allowed me to pursue my goals and endured many hours, days, months, and years of daddy reading, writing, and sitting at the computer while completing this degree. Thank you for your patience and love during this long and tiresome program. I love you and I hope daddy has made you proud. Finally, I owe thanks to a great group of friends that have been my support group for years. Although we are separated by distance, we are connected by a special bond - \#sixstrong. 


\section{ACKNOWLEDGMENTS}

I would like to say thank you to the faculty members I have worked with while at the University of Louisville - Dr. Tretter, Dr. Brown, Dr. Chisholm, Dr. Jett, Dr. Choi, Dr. Adelson, Dr. Valentine, Dr. Ronau, Dr. Evans-Andris, Dr. Carter (Weiland), Dr. McFadden, Dr. Mark, and Dr. Ingle. The guidance, advice, and opportunities have been appreciated and I have grown as a person and student since my arrival on campus. Go Cards! 


\title{
ABSTRACT \\ THE ROLE OF THE PLANETARIUM IN STUDENTS' ATTITUDES, LEARNING, AND THINKING ABOUT ASTRONOMICAL CONCEPTS
}

\author{
William R. Thornburgh
}

April 17, 2017

The purpose of this study was to examine the role of the planetarium on students while learning astronomy. The main goals of this study were to evaluate changes in students' attitudes towards astronomy, whether students learned and retained more knowledge due to planetarium-enriched instruction, and how the planetarium helped students think about astronomical concepts.

The framework that guided this study was the Contextual Model of Learning (CML) (Falk \& Dierking, 1992; 2000), which includes three overlapping contexts that contribute to the overall learning experience in informal science venues - the personal, physical, and sociocultural contexts. The planetarium program was successful in reaching students in all three contexts of the CML, which contributed to students' positive experiences during this study.

The results of this study showed that the immersive environment and unique capabilities of a digital planetarium positively influenced students' attitudes, learning, retention, and thinking. This study has important implications for planetariums, informal science education researchers, and schools. 


\section{TABLE OF CONTENTS}

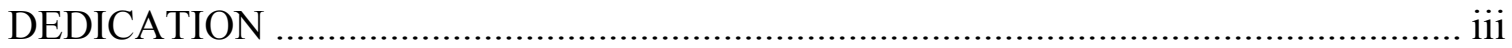

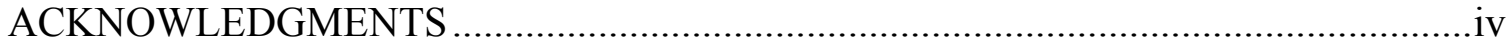

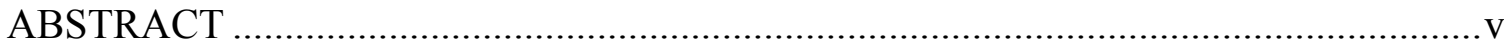

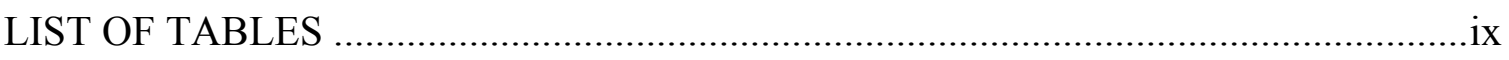

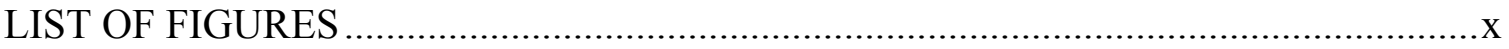

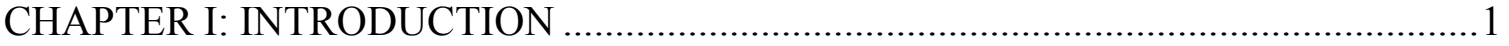

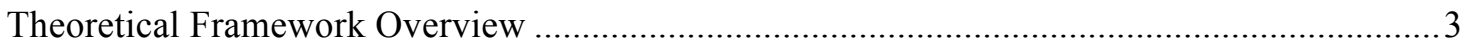

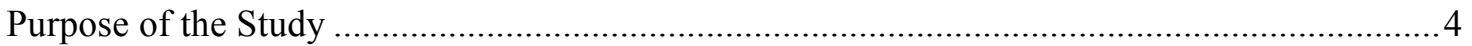

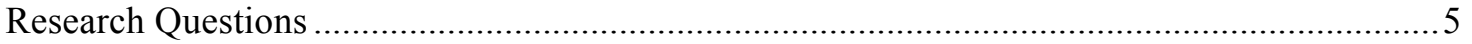

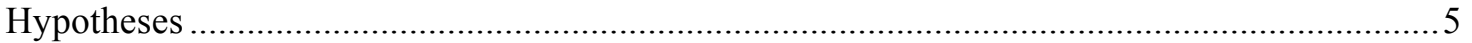

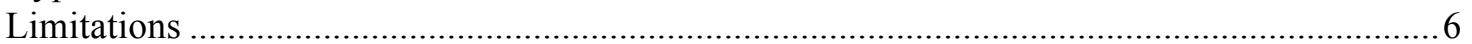

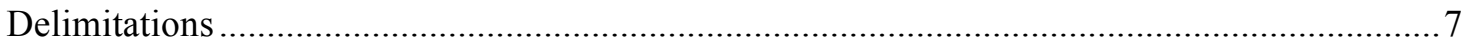

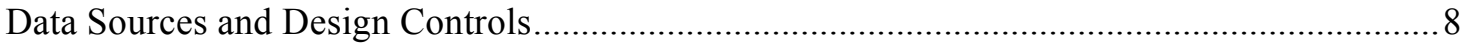

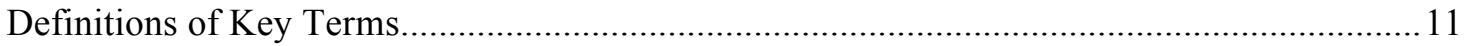

Organization of Remaining Chapters …………………………………………………....13

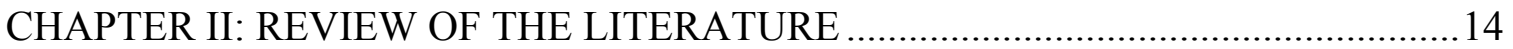

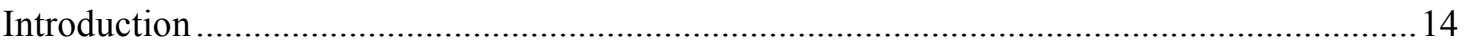

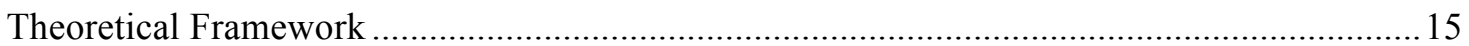

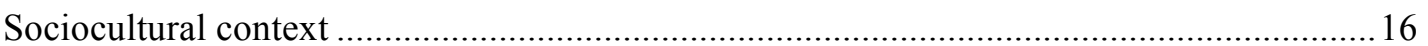

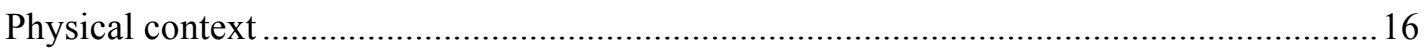

Personal context ...................................................................................................

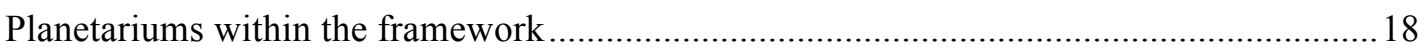

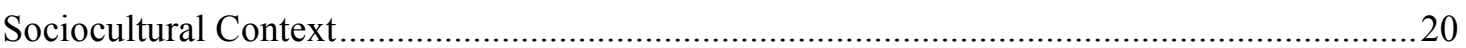

Changing views of informal science education ...............................................................2

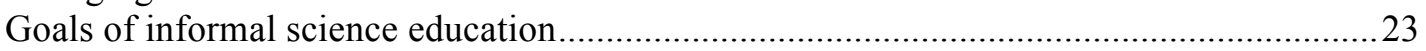

Informal science education aligned with formal curriculum ..............................................24

Informal science education program structure....................................................................2

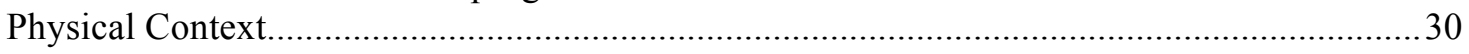

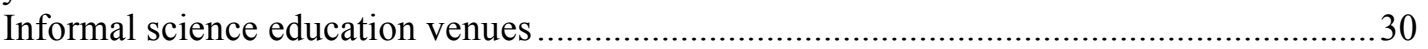

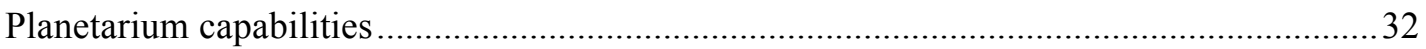

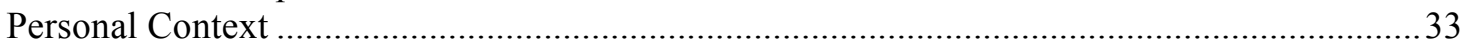

Informal science education: education vs. learning ……………………………………..... 34

Formal and informal science learning ………………………......................................

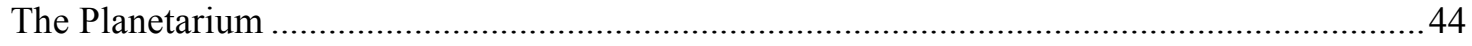

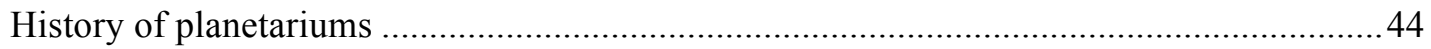

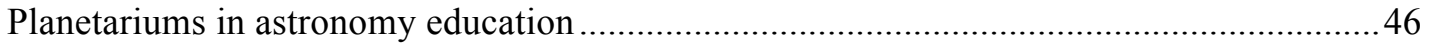

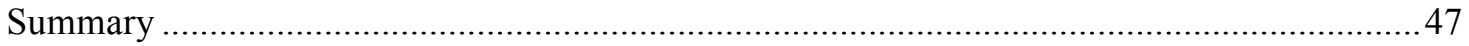

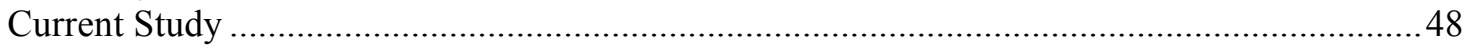




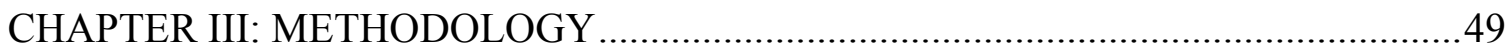

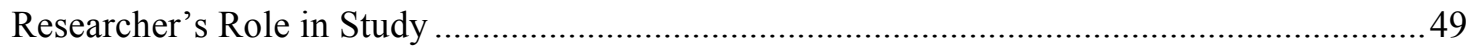

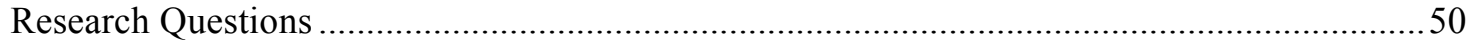

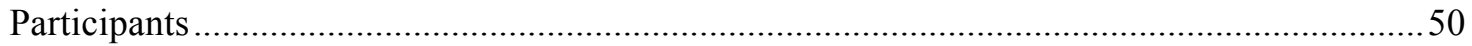

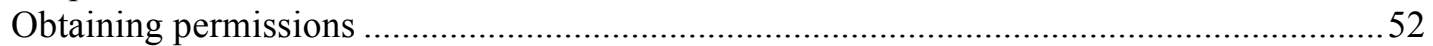

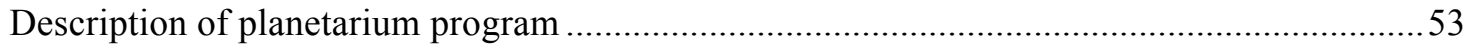

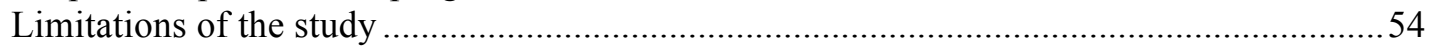

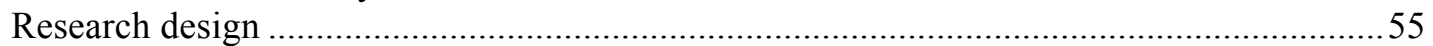

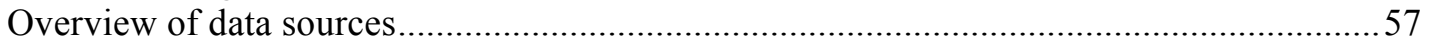

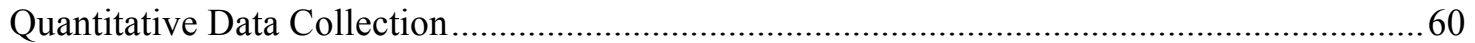

Survey of attitudes towards astronomy …………………………………………………...60

Pre-unit content assessment ...........................................................................................6

District Benchmark Assessment …………………………………………………....61

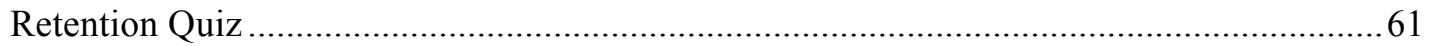

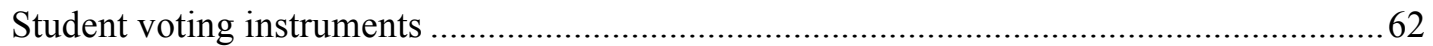

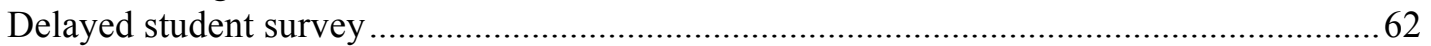

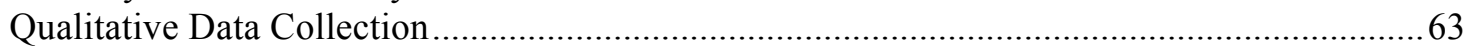

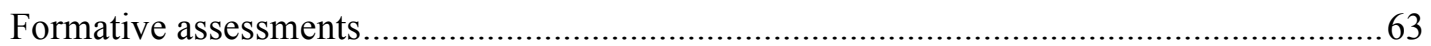

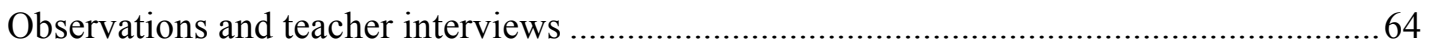

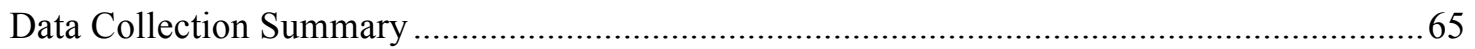

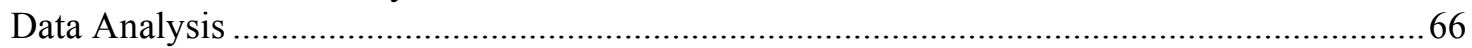

Survey of attitudes towards astronomy $(S A T A)$...............................................................66

Delayed student survey and teacher interview questions ………………………………......67

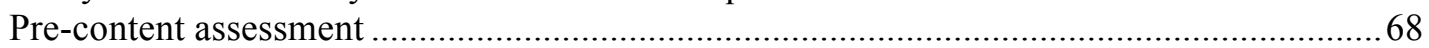

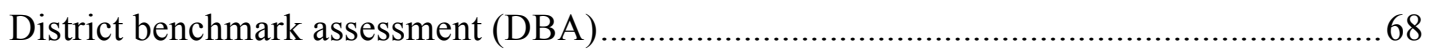

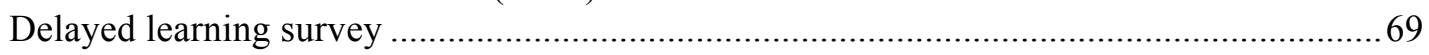

Daily formative assessments, observations and field notes.................................................69

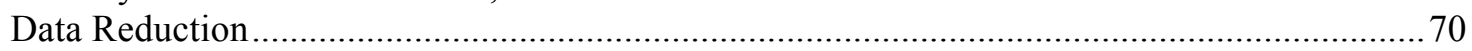

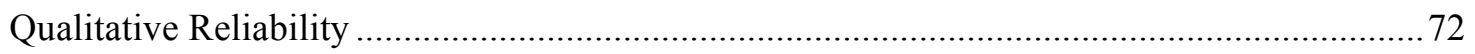

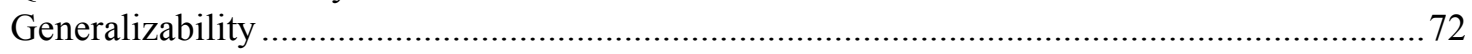

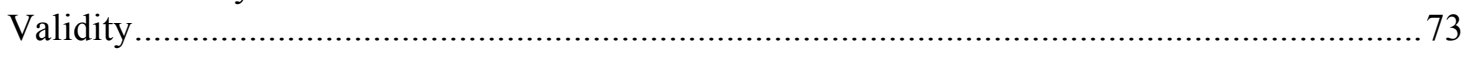

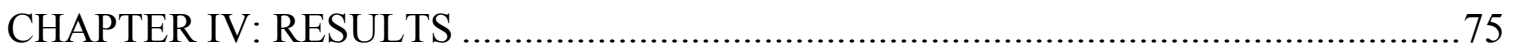

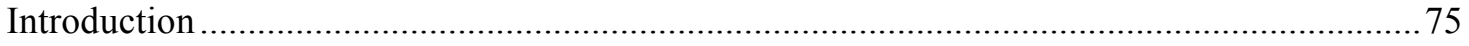

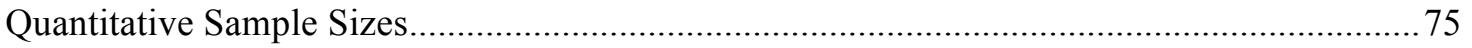

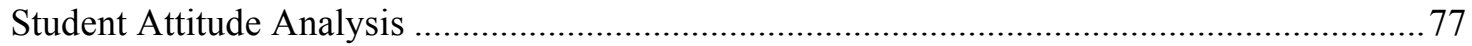

Survey of attitudes towards astronomy $(S A T A)$...............................................................

Delayed student survey ......................................................................................... 82

Teacher outlook - student attitude ……………………………………………………....83

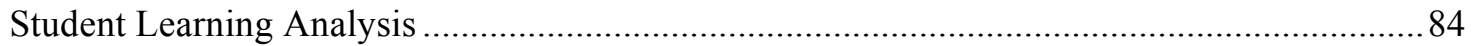

Pre-unit content assessment .......................................................................................... 84

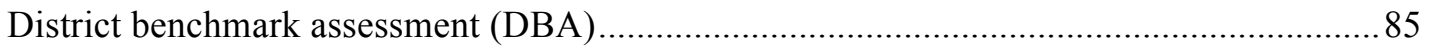

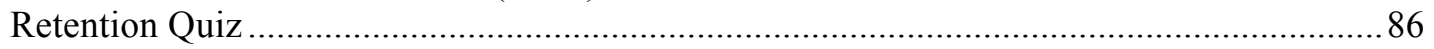

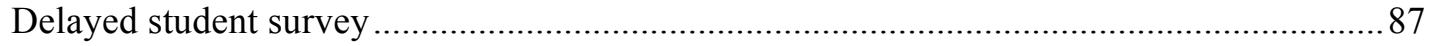

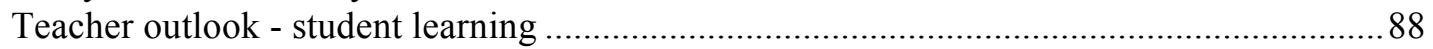

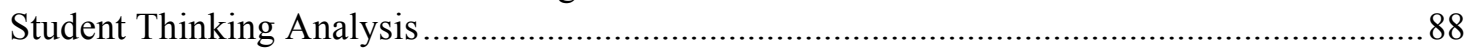

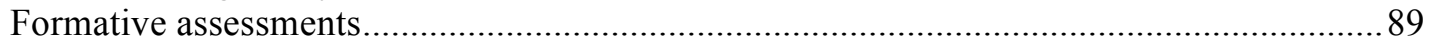

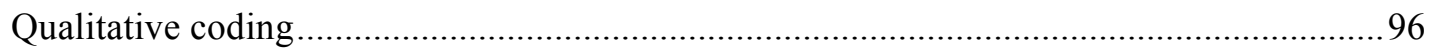

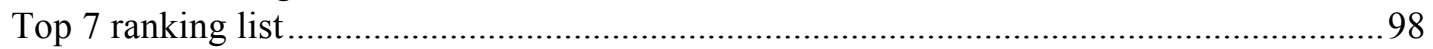

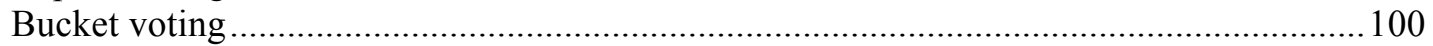




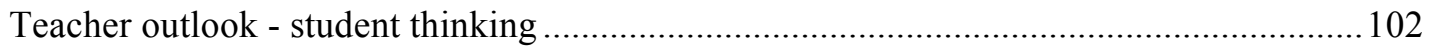

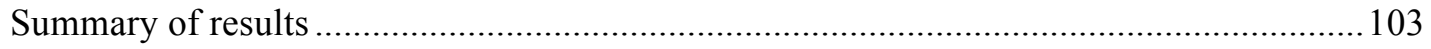

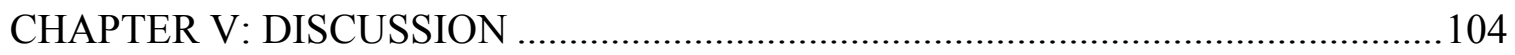

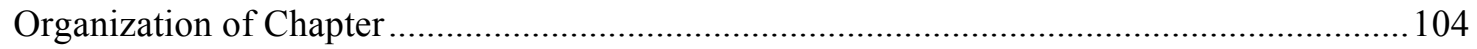

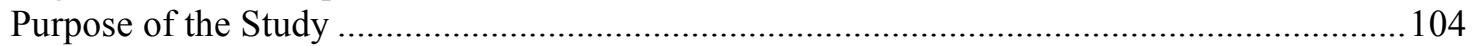

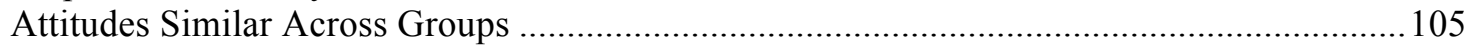

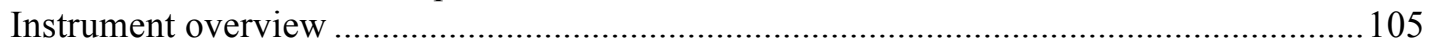

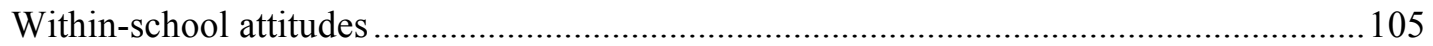

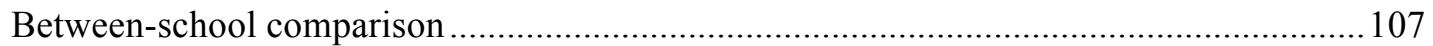

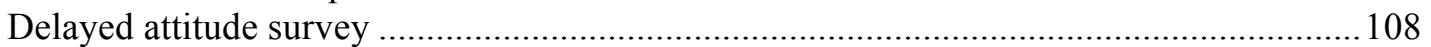

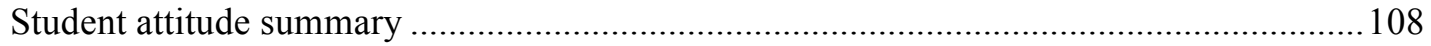

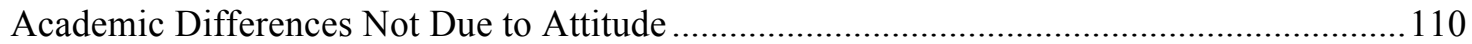

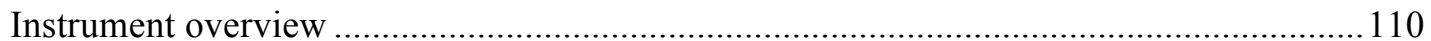

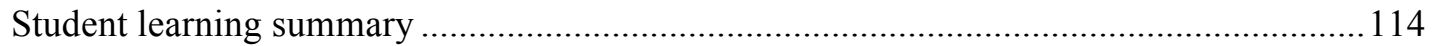

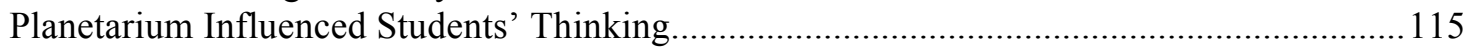

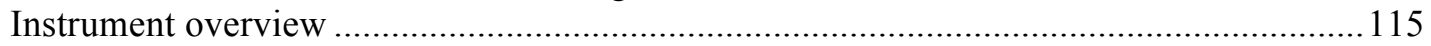

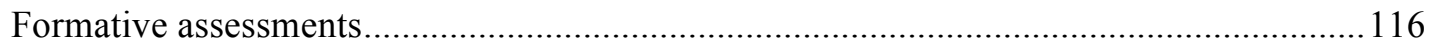

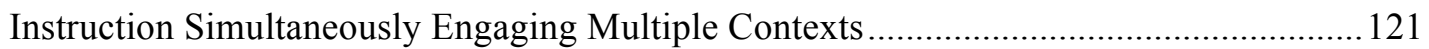

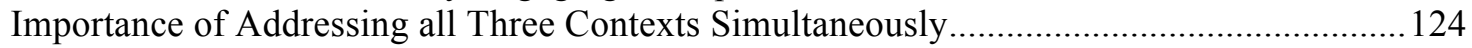

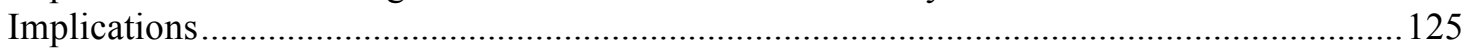

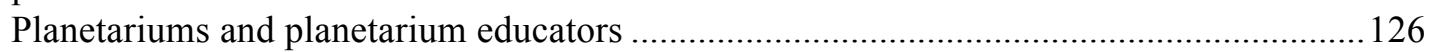

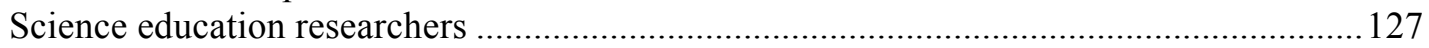

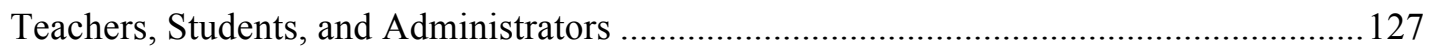

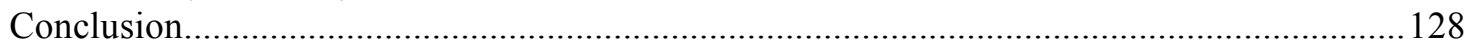

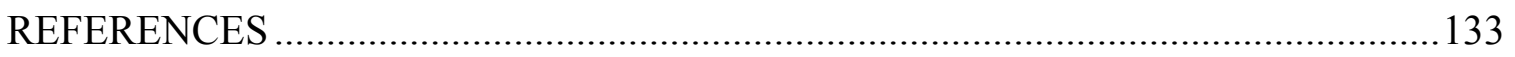

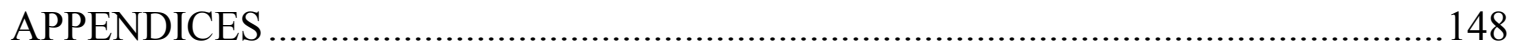

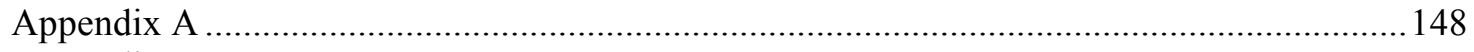

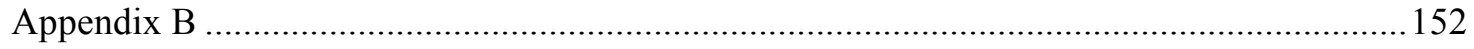

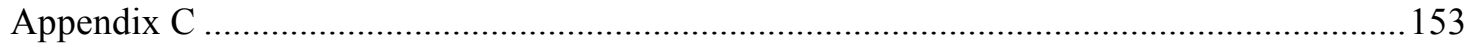

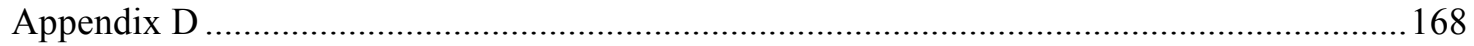

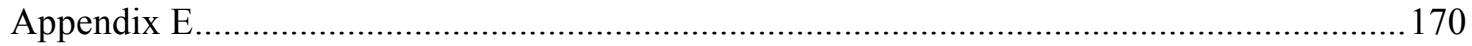

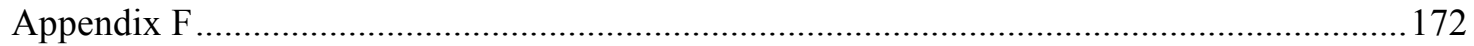

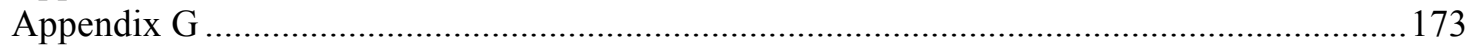

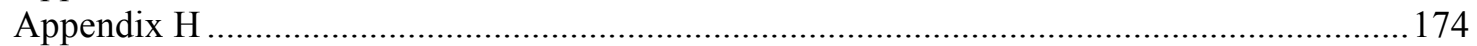

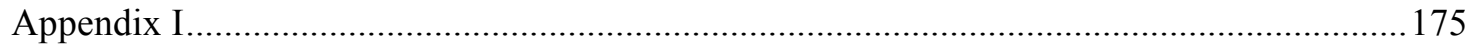

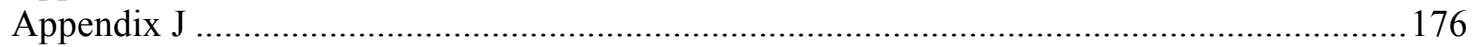

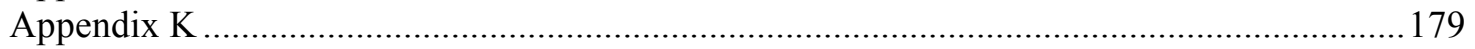

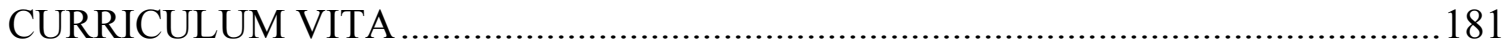




\section{LIST OF TABLES}

1. Student DBA Sample Size .............................................51

2. Overview of Data Collection....................................................

3. Quantitative Data Sample Sizes...........................................76

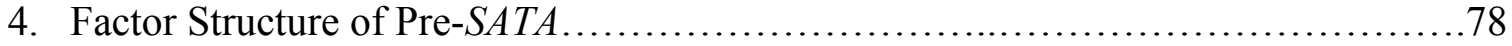

5. Pre to Post Attitude Rating Changes...................................... 80

6. Pre-Unit Content Assessment Data.............................................84

7. District Benchmark Assessment Data.........................................85

8. Inductively Developed Thematic Codes..................................90

9. Examples of the Sociocultural Context.......................................95

10. Ranking of Top 7 List.............................................. 98

11. CML Context Votes.................................................. 102

12. Attitude Summary ..................................................... 110

13. Learning Summary.................................................. 114

14. Student Outcomes Situated Within Contexts of the CML........................123 


\section{LIST OF FIGURES}

1. Contextual Model of Learning.............................................4

2. School Planetarium Starball.................................................. 9

3. School Planetarium Showing Digital Projector.................................9

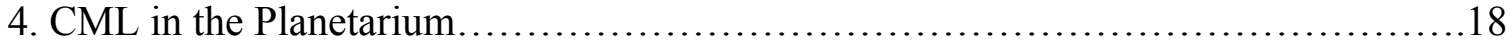

5. Mixed Methods Research Design.........................................56

6. Planetarium Enjoyment................................................. 82

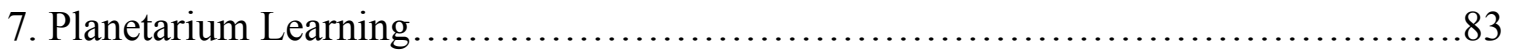




\section{CHAPTER I: INTRODUCTION}

Humans have wondered about objects in the sky and studied them since prehistoric times. Ancient Egyptians are known for the earliest drawings of the sky on tombs while Native Americans depicted celestial objects in drawings on cave walls and cliff faces. The ancient Greeks constructed globes that showed constellations and the motion of planets then, more sophisticated models of space called orreries were used to model the positions and motion of planets and moons. As technology improved and humans gained knowledge of space, the modern day planetarium began to take shape. Present day planetariums have advanced high technology projectors that use real scientific data and have the capability to fly observers throughout the universe and immerse them in a highly visual environment. The high-tech environment of the planetarium can truly enhance students' experiences in space science and provide them with models that are not possible to create or visualize in the classroom.

In 1892, the Committee of Ten (Mackenzie, 1894) decided the fate of space science in the school curriculum. Biology, chemistry, and physics were identified as the main sciences to be taught while astronomy was pushed down to an elective status. With this decision fewer teachers were majoring in areas necessary to teach astronomy and the number of qualified teachers decreased significantly. After the launch of the Soviet's Sputnik in 1957 there was a renewed interest in space science and a boom in planetarium construction swept across the United States. In 1958 NASA was formed, followed by the 
construction of approximately 1200 school and community planetariums across the United States (Sunal \& Sunal, 1977; Tomlinson, 2011), and astronomy course offerings increased in the science curriculum. At the same time that schools battled a lack of qualified astronomy educators, the planetarium became a valuable tool used for teaching students about planets, moons, stars, and how objects move and interact in space. University, high school, and community-based planetariums became popular sites for research to examine how this type of informal environment was being used in education and whether planetariums had positive effects on student learning.

Several studies have been conducted since the 1960s on the effectiveness of planetarium instruction compared to traditional classroom instruction and the results have been inconsistent. Dean and Lauck (1972), Tuttle (1966), and Wright (1968) found positive results that supported student learning from planetarium instruction while data from Reed (1970) and Rosemergy (1968) concluded that classroom instruction was more effective for students than the planetarium. Although early studies yielded conflicting results, more recent studies have shown planetariums have beneficial effects on students and should be used in space science education (e.g. Baxter \& Preece, 2000; Palmer, 2007). Sunal (1976) stated, "The planetarium experience can change student performance in most, if not all, of the goal areas of planetarium education" (p. 348). Present day researchers agree with Sunal (1976) but continue to point out that planetarium research is lacking a standardized instrument to assess student learning, which makes comparing planetarium-based studies difficult. Additionally, studies have focused on capturing student learning as a product, rather than the process of thought and 
what students are able to assimilate into their own schema. This latter point could be an important area of future research as planetariums continue to evolve.

\section{Theoretical Framework Overview}

The theoretical framework underlying this research was the contextual model of learning (CML) (Falk \& Dierking, 1992; 2000). The CML is based on the idea that "learning is a complex phenomenon that is situated in a series of contexts" (Falk \& Storksdieck, 2004, p. 745). These contexts that contribute to museum learning, which can also be applied to other informal science venues, include the sociocultural context, the personal context, and the physical context. In various settings (e.g. museums, science centers, and zoos), the interaction and overlapping of the abovementioned contexts influences what students learn and how they learn. Since learning is both a product and a process that takes time and is different for everyone, informal science education could play a key role in advancing students' knowledge and attitudes towards science in formal education. The progressive nature of learning led to a revision of the original CML to include time as a fourth dimension (Figure 1). This addition to the model was to account for learning being cumulative where individuals make meaning and find connections across various sociocultural and physical contexts over time. According to Falk and Dierking (2000):

Perhaps the best way to think of it [the CML] is to view the personal context as moving through time; as it travels, it is constantly shaped and reshaped as it experiences events within the physical context, all of which are mediated by and through the sociocultural context. (p. 11) 
Informal science education venues that provide programs drawing upon each context of the CML have a greater chance of increasing science learning and improving the learning experience for students.

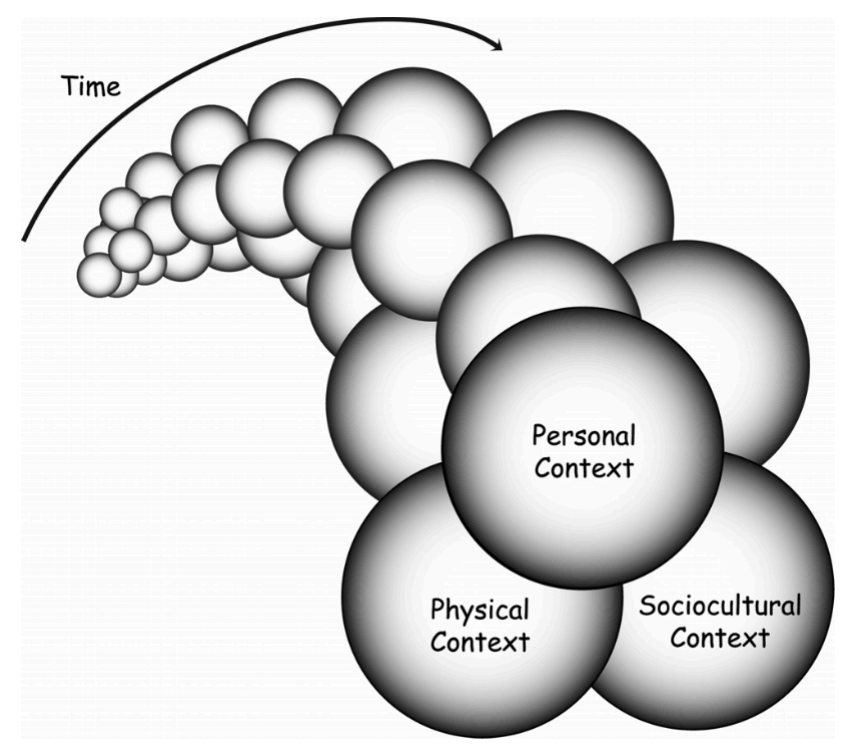

Figure 1. Contextual Model of Learning (Falk \& Dierking, 1992; revised 2000)

\section{Purpose of the Study}

The purpose of this research was to explore whether an embedded planetarium experience within a science unit influenced students' attitudes, performance on a districtwide assessment and retention quiz, and thinking about astronomical concepts. The variables being studied in this research included student attitude, student learning, and student thinking. The variables in this study were operationalized as following: attitude is part of the affective domain and is defined as, a way of thinking or feeling about something. In this case, students' attitudes toward science (astronomy) can influence how they perform in science class and whether they learn important scientific concepts. Learning is part of the cognitive domain and is defined as the acquisition of knowledge through experience, study, or by being taught. It is important to consider how 
information is presented and whether students are keeping up as they learn about space science through formal and informal science experiences. Finally, thinking is defined as, using the mind to reason about something. This research aimed to capture examples of the processes that students went through as they were presented content throughout the planetarium program; thus, the following research questions were explored:

\section{Research Questions}

1. How are students' attitudes influenced by an embedded planetarium experience while studying astronomy?

2. How does an embedded planetarium experience during an astronomy unit influence students' learning (acquiring knowledge) and retention of concepts?

3. How does the planetarium influence students' thinking (reasoning about concepts) about astronomical concepts?

\section{Hypotheses}

I hypothesized that students with exposure to a planetarium during an astronomy course would strengthen their conceptions of astronomical concepts due to the highly visual and immersive environment of the planetarium setting. These same students would then outperform students on a district-wide science assessment who did not have an embedded planetarium program during their science unit. Additionally, students who had exposure to planetarium instruction within the science unit would have greater retention of learned concepts than their counterparts due to the rich and nuanced visual learning experience they received in the multi-day planetarium program. 


\section{Limitations}

As is the case with many studies, there were limitations that existed in this research. First, the school district administration did not approve focus group interviews with students. The request for student interviews was denied because of a district policy where researchers can only have access to student data that does not directly affect students' lives with non-school related activities. Since one of the goals of this study was to explore how the planetarium shaped student thinking, interviews would have been a powerful method to capture how the four-day planetarium program influenced thinking and learning.

Secondly, student absences and other school activities during the multi-day program meant that students missed important academic content, which could have impacted students' performance on the district benchmark assessment (DBA) at the conclusion of the unit. The DBA as a whole, as well as a subset of planetarium-specific questions, may not have been completely accurate due to these unplanned circumstances. As a result, the analysis for statistically significant differences between the schools may have been affected.

Furthermore, the student sample size at each school involved in the study was not the same. In fact, the sample size varied within school for each data collection instrument used due to various pre-planned school activities (i.e. grade-level testing, charity fundraiser). The differences in sample size could have affected the statistical analysis and interpretation of the results because of the students that participated (e.g. high academic vs. low academic, high interest in science vs. low interest). 
Thirdly, potential individual teacher differences were not collected as part of this research. The same hiring committee hired the district's teachers, teachers teach the same course and content, and the teachers at the treatment school and comparison school plan the district-wide assessment together based on their students' needs. Although teacher differences do play a role in student learning, the assumption was that the overall quality of instruction and co-planning of content and pedagogy would not substantially affect the outcomes of this study, in part because the planetarium-based experience was delivered by the same planetarium educator who is not one of the regular classroom teachers; and there was a regression towards the mean in regards to participating teachers.

\section{Delimitations}

A small number of boundaries were placed on this study. First, only 13 of the 25 questions on the district benchmark were planetarium-specific and analyzed for statistically significant differences in learning within that environment. These 13 questions were selected because they were most directly related to the multi-day planetarium program and tested students' abilities to process information at a level deeper than basic memorization and recall. Secondly, of the 13 DBA questions selected for analysis, only six questions were chosen to retest students months later for measuring retention of knowledge over time. This decision reduced the testing load on students and the time borrowed from teachers to administer the test. Thirdly, to ensure consistency in the planetarium program's content and delivery, the planetarium educator was in charge of all instruction inside the planetarium and the researcher was in the role of observer. The educator and researcher carefully planned each day of the program in advance with a daily central theme in mind. A daily script was constructed, which contained a main 
theme (e.g. Earth, the solar system, size and scale of space), a general flight plan with important visuals and transitions to teach important concepts, and example questions and comments that were included for students.

\section{Data Sources and Design Controls}

This study included students from two high schools within the Melbourne County School District ${ }^{1}$, a southern county on the border of two mid-western states. It was a unique area because one school was classified as suburban while the other was classified as urban because of its close proximity to a large city in the bordering state. Being in the same district, both schools offered a tenth grade Earth and Space Science course, which was co-designed by teachers at both schools.

One of the schools worked in collaboration with a university planetarium during their astronomy unit and the other school did not. The initial collaboration between the high school and university began three years prior because a teacher at the high school also taught a college-level astronomy course and used the nearby university planetarium as a resource. Although his school had the physical dome-shaped structure of a planetarium, he lacked the ability to do anything more than show stars and planets with an optical-mechanical starball from an Earth-based perspective (Figure 2).

The teacher's interest in the subject as well as his acknowledgment of what a digital planetarium system could offer students lead to incorporating a more in-depth experience with high school students. For this reason, the digital projector (Figure 3) and software technology of the university planetarium was placed inside the high school planetarium domed-structure to provide students with enhanced learning opportunities.

\footnotetext{
${ }^{1}$ A pseudonym was used to protect the identity of the school district participating in this study.
} 


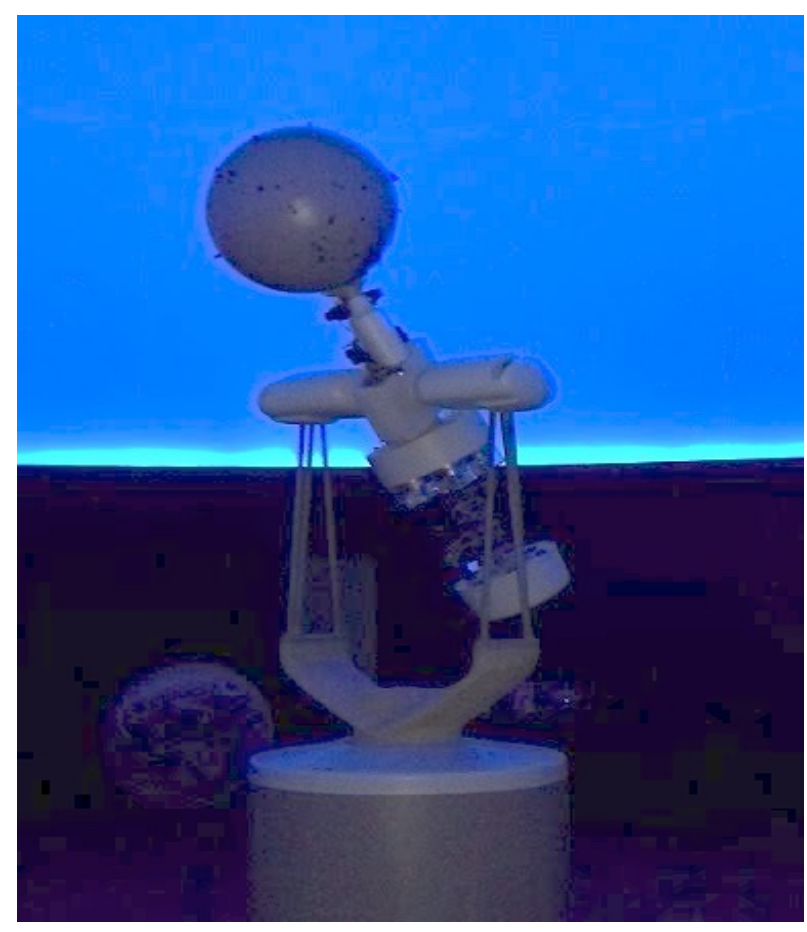

Figure 2. School Planetarium Starball - Projects the Stars from Earth-based Perspective

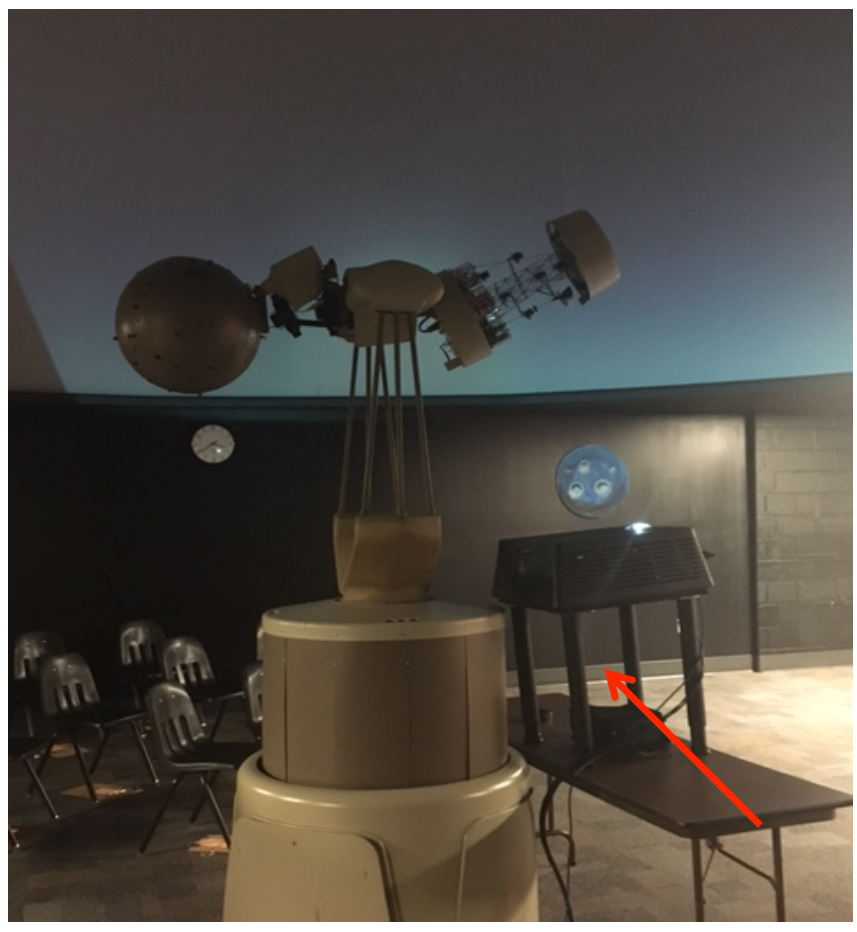

Figure 3. School Planetarium Showing Digital Projector -

Projects Science Data in 3-Dimensions and Permits Flight through Data 
At the conclusion of the nine-week unit, students at both high schools took a district- wide test, known as the district benchmark assessment (DBA), that was designed conjointly by teachers at the treatment and comparison schools (Appendix A). This assessment was part of an ongoing normal process of evaluating courses and student learning within the district. The overall DBA results and subsets of DBA questions (Appendix A) were analyzed to compare any differences in students' performance between the schools. The validity of the DBA was specifically for the schools in this study since it was a district-designed measure that teachers and administrators relied on for tracking student progress. However, other school districts may or may not choose a similar assessment as most appropriate for their schools, in which case the potential validity of this measure would need to be determined within those specific settings.

Daily formative assessments (Appendix B) gave insight into student learning and aspects of the planetarium program that may have influenced their thinking about astronomical concepts. Furthermore, the compilation of these daily assessments provided data on how the three contexts of the CML (i.e. personal, physical, sociocultural) worked together to contribute to students' experiences throughout the planetarium program. Additionally, researcher observations, field notes, and informal teacher interviews were gathered to evaluate student thinking and learning over the course of the astronomy unit.

A difficult aspect of planetarium research has been obtaining an accurate measurement of what, and how much, students actually learn from this informal science instruction. Past studies collected data immediately and did not measure students' longterm retention of astronomy concepts. A concern was that immediate assessment did not necessarily measure that learning occurred during a specific program. 
How planetariums influence student thinking and learning as well as the retention of content are missing pieces within the existing research; therefore, this study included measurement of knowledge at the conclusion of the school's astronomy unit as well as measurement months after the astronomy unit and planetarium program. A delayed measurement captured the amount of content students retained from the unit and a delayed survey allowed students to comment on whether they enjoyed the planetarium and if they felt that the multi-day experience helped them learn astronomical concepts.

\section{Definitions of Key Terms}

1. Committee of Ten - A group of educators that, in 1892, recommended the standardization of American high school curriculum.

2. Contextual Model of Learning $(\mathrm{CML})$ - A theoretical construct for investigating learning through various contexts (personal, physical, sociocultural) within an informal learning environment.

3. Digital planetarium system - A projection system that is capable of showing stars and planets as well as dynamics interactions and modeling of objects in space. Digital systems allow observers to fly through space and view things from different perspectives.

4. District benchmark assessment (DBA) - An end of unit test designed and administered by the school district for students taking the same course at different schools.

5. Embedded planetarium experience - When a school brings its students to a planetarium, or has a portable planetarium visit their school, during a science unit to provide students with learning opportunities that they cannot otherwise 
experience.

6. Formal education - Classroom-based education provided by teachers in a school.

7. Informal education - General term for education that occurs outside of a standard school setting (after-school programs, museums, science centers, or at home).

8. Informal learning - Learning that takes place outside of the classroom, including structured learning situations (e.g. museums, science centers) and unplanned learning occurring through free-choice activities (e.g. gardens, parks, zoos).

9. Informal science institution (ISI) - A location outside of school where students go to learn science. Examples of ISIs include museums, planetariums, zoos, science centers, etc.

10. Optical-mechanical starball - A projector that allows observers to view stars in the night sky, the Sun, and planets, all from an Earth-based perspective. Observers can view where they are in relation to each other and how they move across the sky.

11. Personal context - Includes student motivation and expectations, prior knowledge and experience, and prior interests and beliefs.

12. Physical context - Includes orientation to the physical space and reinforcing events and experiences in the planetarium to real-world experiences.

13. Planetarium - A building in which images of stars, planets, and constellations are projected on the inner surface of a dome for entertainment or education. 
14. Sociocultural context - Includes within-group mediation and facilitated mediation by the planetarium educator. In other words, how the interactions between students in the class and students with the planetarium educator contribute to learning.

15. Visualizations - Any image or video displayed on the domed structure of the planetarium during the planetarium program. They are dynamic and can be viewed from varying perspectives seamlessly. Examples of visualizations include: the rotation and/or revolution of a planet(s), close up views of objects (e.g. the Moon, Saturn's rings), connecting the stars with lines for students to observe the constellation image, and flying through space or around objects.

\section{Organization of Remaining Chapters}

Chapter 2 is a review of the literature related to formal versus informal education, informal science education and planetariums, and student outcomes in response to informal learning experiences. Chapter 3 will be a description of the methodology that will guide the study, including descriptions of the participants, data collection methods, and how the data will be analyzed. Chapter 4 will include results from analyses of the data collected in the study. Chapter 5 will be a discussion of the significance of this research for school administration, teachers, and planetarium directors/educators and the implications for future research and practice. 


\section{CHAPTER II: REVIEW OF THE LITERATURE}

\section{Introduction}

The goal of this study was to evaluate the impact of a collaborative experience between a local high school and university planetarium to educate students on astronomical concepts. The university typically offers two types of informal science experiences involving either a campus-based planetarium or a portable planetarium that travels to schools. In this particular case, the local high school had a permanent domed facility and what the university provided was not the actual portable planetarium, but the digital technology to project onto the dome along with an experienced planetarium educator to deliver the programming.

The capabilities of the planetarium to immerse students in a unique environment, and to project visualizations that show natural space phenomena, help students obtain a better grasp on the scale of space. These visualizations are vital to helping students learn space science in a very different way than from a textbook in a classroom. The three main research questions guiding this study were:

1. How are students' attitudes influenced by an embedded planetarium experience while studying astronomy?

2. How does an embedded planetarium experience during an astronomy unit influence students' learning (acquiring knowledge) and retention of concepts? 
3. How does the planetarium influence students' thinking (reasoning about concepts) about astronomical concepts?

This literature review focuses on providing a synthesis of our knowledge about informal education and the student outcomes that are a result of informal learning in science contexts. First, a review of the theoretical framework guiding the study and an explanation of how the planetarium lies at the intersection of the contextual model. Next, a history of how informal science education has changed over the years, along with the varying structures of informal science education that exist. Then, examples of informal science venues where students will have opportunities to further their science knowledge and how the rich visualizations of the planetarium engage students with space phenomena. Finally, a review of what it means to learn, factors that have impacts on student learning, the history of the planetarium and its role in informal science education, and outcome on students.

\section{Theoretical Framework}

The Contextual Model of Learning (CML) (Falk \& Dierking, 1992; 2000) is a framework outlining that learning is complex and involves a series of contexts (e.g. sociocultural, personal, and physical), all of which will change over time as learners are shaped by experiences, what is happening in the world around them, and where learning occurs. Although it draws on constructivist, cognitive, and sociocultural learning theories, "the key feature of this framework is the emphasis on context" (Falk \& Storksdieck, 2005, p. 745). This emphasis is based on previous research where others have also used context as a framework for thinking about learning (e.g. Ceci, 1996; Ceci \& Bronfenbrenner, 1985; Sternberg \& Wagner, 1996). The three contexts will be 
discussed further to provide more detail about how they factor into how individuals are influenced by each.

\section{Sociocultural context}

The sociocultural context is based on humans being a part of the world where social and cultural factors influence how we think and how we learn. The combination of social and cultural elements is useful in explaining the wide diversity of various learning styles among students. Hence, in formal and informal science education settings it is important for educators to consider the interactions among students, between students and guides/teachers, and how these interactions affect learning in each particular setting. In formal education settings, it is important for teachers to be encouraging toward students and create a positive classroom atmosphere to promote engagement and learning.

Also, the removal of the teacher from being the 'sage on stage' to making them the 'guide on the side' allows students to have a voice and discuss topics amongst their peer group, which can lead to organic and powerful learning. These same ideas hold true in informal settings as well. Falk and Storksdieck (2005) identify both, within-group social mediation and mediation by others outside the immediate social group, as important factors that are influential for learning. For this reason, ISIs should create an environment where individuals are provided a chance to have both types of interactions for optimal learning possibilities.

\section{Physical context}

The physical context seems straightforward in that it is the actual physical environment where learning occurs (e.g. a classroom, at the zoo, in a museum, or within a planetarium). Previous research has studied how learning is influenced by the physical 
space and the ability of visitors to orient themselves within an ISI (e.g. Evans, 1995; Falk \& Balling, 1982, Kubota \& Olstad, 1991). In addition to the overall space and architecture, the details within can affect the total experience and what is learned. Research has shown that lighting, crowding, color, sound, and space have subtle impacts on learning (e.g. Coe, 1985; Evans, 1995; Hedge, 1995; Falk \& Storksdieck, 2005).

Furthermore, other factors such as exhibits (positioning and content), labels and educational signage, and how much time visitors spend at exhibits (Bitgood, Serrell, \& Thompson, 1994; Bitgood \& Patterson, 1995; Falk, 1994; Serrell, 1996, 1998) are important influences on learning. Falk and Storksdieck (2005) identified five important factors within the physical context that are influential in optimizing what an informal institution offers visitors: "advance organizers, orientation to the physical space, architecture and large-scale environment, design and exposure to exhibits and programs, and subsequent reinforcing events and experiences outside the museum” (p. 747).

\section{Personal context}

The personal context represents the individual characteristics that a visitor/student brings into the learning environment, whether in a formal or informal setting. Prior knowledge and personal experiences on informal learning have been widely studied (e.g. Dierking \& Pollock, 1998; Falk \& Adelman, 2003; Hein, 1998) along with visitors’ personal interests (e.g. Adelman et al., 2001; Adelman, Falk \& James, 2000; Falk \& Adelman, 2003), while other studies have identified visitor's motivations for attending a museum (or other ISI) as influential to learning (e.g. Falk, 1983; Falk, Moussouri \& Coulson, 1998). 
ISIs and other informal settings have no control over the personal context, but can provide learners with control over their choices and activities while visiting. This will lead to a personal investment in learning and allow visitors to engage in activities tied to prior knowledge and interests. Allowing students to have free choice and self-control may also lead to learners experiencing and learning new things on their own volition. Falk and Storksdieck (2005) identified the following as important personal context factors that are influential for learning: "visitor motivation and expectations, prior knowledge, prior experiences, prior interests, and choice and control" (p. 747).

\section{Planetariums within the framework}

Although the planetarium venue does not fit neatly into definitions of informal science education, the CML can still be a helpful integrative framework to study how the planetarium experience lies at the intersection of these three contexts and how the overlap of contexts contributes to student learning (Figure 4).

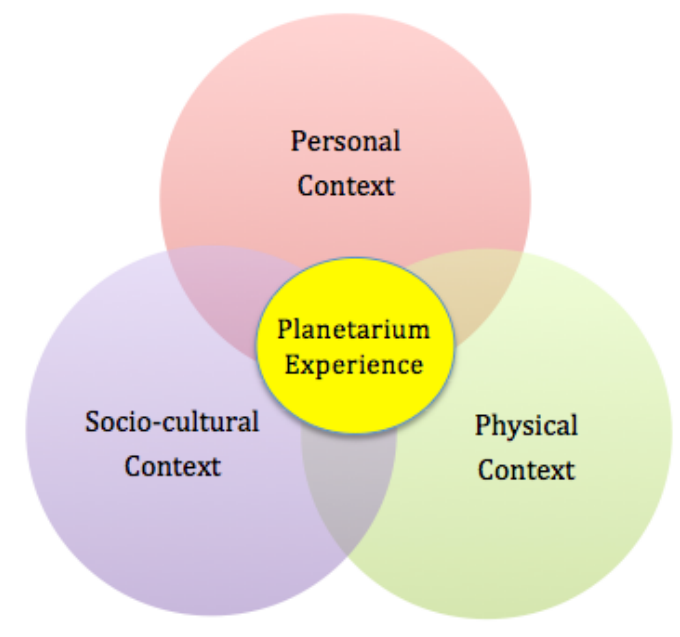

Figure 4. CML in Planetarium (modified from Falk \& Dierking, 1992)

The planetarium is a valuable tool to promote astronomy education and help visitors understand space phenomena. With a carefully planned planetarium experience 
students can observe, ask/answer questions, and interact with a planetarium educator about past, current, and future events to learn within the sociocultural context. In addition to these interactions, students are taking part in a lived experience that is shared with others. The visualizations and storyline used to teach astronomy content give students a valuable connection to the real world.

Students can visit a planetarium either through school field trips or on weekends by choice. Either way, they have their own personal expectations and bring prior knowledge and interests into their visit. Although there is rarely free choice or control in this informal science education venue, students are given ample opportunity through exhibits and shows to expand their knowledge base and gain new experiences. This learning takes place within the personal context of the CML.

Finally, the physical context of the planetarium is one that draws immediate attention as students enter. Unlike any other place they have visited, students are very aware of the unique physical context of the planetarium such as the size of the dome, the darkness and changes in lighting during a show, and the visualizations and flight they experience. With advanced planning and an introduction to the planetarium before entering, such a novel environment will not distract student learning.

The three contexts of the theoretical framework and how each fits within the planetarium setting have been introduced above. In the upcoming sections, how each context factors into informal science education will be revisited and expanded. Although easy to separate and define on paper, these contexts naturally overlap in the field and pieces of each context can be found in each section as informal science education is discussed below. 


\section{Sociocultural Context}

The sociocultural context includes social and cultural components that have contributed to how humans have perceived science and definitions of science education over time.

\section{Changing views of informal science education}

1970s-1980s: Early definitions. Informal education has been of a topic of interest for many years. Since the 1970s there have been numerous attempts to define what it is and where it occurs. One issue we face is that education is complex and having one standard definition would oversimplify the educational process. When the term is separated into its individual parts, informal includes words such as unofficial, casual, and relaxed, while education is the process of giving or receiving instruction. Coombs and Ahmed (1974) first described informal education as:

... the lifelong process by which every individual acquires and accumulates knowledge, skills, attitudes and insights from daily experiences and exposure to the environment - at home, at work, at play: from the example and attitude of families and friends; from travel, reading newspapers and books; or by listening to the radio or viewing films or television. Generally informal education is unorganized, unsystematic and even unintentional at times, yet accounts for the great bulk of any person's total lifetime learning - including that of a highly 'schooled' person. (p. 8)

Not long after, informal education was defined as a place where students go for an educational purpose, outside of school. This place would provide materials for students to observe or provide direct experiences for students to study (Krepel \& Durall, 1981). A 
common thread across both of these early definitions is that the word school was not included. In fact, both were explicit in stating that informal education occurred in locations other than within the walls of a school.

1990s: Changing definition. The absence of 'school' in early definitions from decades before was because researchers attempted to make a clear distinction between formal (school-based) and informal education. Students go to school with the intention of learning and the environment in which they acquire new knowledge is formal in nature. The entire process of education is organized, students have little to no choice in the activities and topics that are being taught, and there are expected norms for students to follow. Teachers are in charge, there is a curriculum to follow, and students engage in school as directed while they progress through each grade.

A quarter of a century later, the National Science Foundation (NSF) defined informal education similarly to that of Coombs and Ahmed (1974). This type of education is voluntary and self-directed, it is fun and adds to understanding, and the learning occurs out-of-school (NSF, 1997). There are often hands-on activities found in science centers and other similar institutions where students are driven by their motivation to learn and their own interests as they work through exhibits. These institutions are typically set up for students to explore freely. They often have collaborative and social experiences built in as well as including authentic experiences for visitors (Bitgood, Serrell \& Thompson, 1994; Falk \& Dierking, 1992; Hein, 1998). Crane, Nicholson, Chen and Bitgood (1994) supported a component from Coombs and Ahmed's (1974) definition of education and stressed that learning can occur through a variety of media such as TV, books, and community-based projects. Dierking 
(1991) argued that trying to make a clear distinction between formal and informal education is not appropriate because "learning is learning, and it is strongly influenced by setting, social interaction, and individual beliefs, knowledge, and attitudes" (p. 4). This quotation preceded the development of the CML by Falk \& Dierking (1992).

Student learning can be difficult to measure from a single day experience, or even through a program lasting longer because learning is not isolated from everything else happening to the student and around the student during the time immersed in an informal education program. As interest in the field of informal science education grew, researchers continued to point out the issue with one standard definition.

2000s: Expanding Definition. Very little has changed in how we view informal education even in more recent years. Rennie, Feher, Dierking and Falk (2003) described informal learning as "out-of-school learning that is self-motivated, voluntary, and guided by learners' needs and interests" (p. 113) and out-of-school contexts can include many venues, but within science education, a number of science institutions (e.g. planetariums, museums, zoos, aquaria, nature centers) have been identified as locations where students have opportunities to increase interest and gain knowledge in science (Guisasola, Morentin \& Zuza, 2005; Phillips, Finkelstein \& Wever-Frerichs, 2007; Zoldosova \& Prokop, 2006).

Many of the same components remain from earlier definitions and what has been added only expands our thinking about informal science education from the student perspective and what can be provided by science centers to improve learning. Since it has already been established where informal learning occurs, a focus on the goals of 
providing rich learning opportunities for students by allowing them to drive their own individual learning has come to the forefront of how we define informal learning.

\section{Goals of informal science education}

The increase in informal science camps and outreach programs as well as improvements in informal venues' programs in recent years has occurred for many reasons. These educational experiences offer further exploration and study of the sciences outside of school and there has been a desire to improve school achievement for students (Vandeboncoeur, 2006). These informal educational opportunities may also act as an important piece to lessen the gap between students of different racial groups, socioeconomic statuses, and academic abilities. As accessibility and outreach targeting at-risk and/or underrepresented student populations rises, the role of informal science education could be the key to improving connections between science in the classroom and beyond for all students.

Informal science institutions (ISI) and educational programs are structured differently depending on their primary goals. Science institutions have objectives other than improving knowledge of science concepts (Guisasola et al., 2005). They may be designed to improve scientific literacy by helping students 'learn science', 'do science', and 'learn about science' (Hodson, 1998). They could also be designed to stimulate students' interests, attitudes (Zoldosova \& Prokop, 2006), to encourage pursuit in science academic and career paths (Sacco, Falk \& Bell, 2014), or simply to entertain and encourage visitors to return and explore further in the future. Despite what the objective may be, research points to a number of program characteristics that may increase the effectiveness of what is offered and lead to positive outcomes for students. 
Within this study, the combination of the in-school planetarium dome and the university digital projection system were used to teach students about astronomy in a novel environment. The goals of the collaboration between the high school and university planetarium were to introduce students to astronomy from different perspectives and engage them with an out-of-classroom learning experience. The embedded planetarium acted as a connection piece for teachers to reference in hopes of improving student academic achievement.

\section{Informal science education aligned with formal curriculum}

Partnerships. Some ISIs may be designed purely to accomplish the goals they have in mind, while others work with schools to design their programs. Although both environments could be effective in engaging visitors and contain valuable and accurate science, one setting may have additional benefits over the other. When partnerships are created with schools, ISIs can build and/or support the 'formal' school science curriculum (Dwinal, 2014). By providing the most relevant content to students it adds further value to what an ISI offers. Since field trips can be complex to plan and expensive to carry out, teachers that reap the best educational results can justify their investment and are likely to plan return visits in the future (Orion \& Hofstein, 1994).

Forming a partnership requires effort on the part of ISIs reaching out to work with local schools and teachers being open to collaboration. One study identified that ISIs struggle to fully support students and teachers using the actual curriculum and materials that teachers have in the classroom (Phillips, Finkelstein \& Wever-Frerichs, 2007). With that in mind, teachers could help ISIs design a solid science curriculum that would be of greater value to the community. An increase in collaboration would also benefit teachers 
because ISIs could assist in developing additional resources, increasing the amount of learning experiences offered to students, and provide teachers with content knowledge and confidence to teach certain scientific topics (Adams, Gupta \& DeFelice, 2012; Dwinal, 2014; Itzek-Greulich et al., 2015).

Role of the teacher. A successful partnership is dependent on the role of the teacher, as they are instrumental in appropriate curricular planning for students. Teachers must be willing to collaborate, be proactive in unit planning, and guide students by properly preparing them beforehand and debriefing afterwards. Studies have found that teachers fail to use school visits to museums as effectively as they might (Griffin, 2004; Storksdieck, 2004). When the field trip is integrated into the curriculum and closely aligned with content learned in school, it is a more beneficial experience for students (Falk \& Storksdieck, 2005; Fallik et al., 2013; Glowinski \& Bayrhuber, 2011; Hofstein \& Rosenfeld, 1996).

Field trip planning. Field trips are more than just taking students somewhere out of school though. Teachers should familiarize students with the venue and the purpose of the trip in advance. Following the informal science experience, teachers should then debrief students upon returning to school (Anderson \& Lucas, 1997; Guisasola et al., 2005; Tran, 2007).

This combination of pre-trip and post-trip activity along with curriculum-aligned experiences during the visit to the ISI has a better chance to increase the value of the field trip and guide students in achieving the goals of the activity. Just as the teacher is there to assist in curriculum planning, the ISI educators would be available to support the teacher in any phase of the experience (pre-trip preparation, during trip education, and 
post-trip wrap up). With common goals in mind, learning can be connected across the settings of school and ISIs (Bell \& Bevan, 2015) to reach students in a deeper, more meaningful way.

Collaborations. In a large-scale study by Phillips et al. (2007), surveys were collected from a sample of ISIs $(n=475)$ concerning characteristics and programs offered. On one hand, the responses looked positive: 1$) 73 \%(n=345)$ provided programs, workshops, materials, and curricula for teachers beyond the one-day field trip and 2) $55 \%(n=259)$ provided structural and educational support (before and after activities). However, only $45 \%(n=212)$ of the sample reported having collaborative relationships with area schools. This could have been because teachers were unaware of what local informal institutions offered, teachers were unwilling to work with ISIs, or because ISIs were not properly marketing and reaching out to schools. With current research identifying the positive effects of collaborative efforts (Dwinal, 2014), more ISIs and schools should work together in an attempt to blend the best of both worlds. In support of this, multiple studies have discussed the positive impact on students when the less-structured setting of the informal institution is blended with the more-structured requirements of school (Hein, 1998; Hofstein \& Rosenfeld, 1996; Ramey-Gassert \& Walberg, 1994).

This study was guided by the literature on establishing a partnership and working collaboratively with teachers to provide a meaningful experience for students. A strong relationship between the treatment high school and university planetarium was formed through consistent communication and advanced planning. Curricular goals and key indicators were shared and a planetarium program was specifically designed to meet the 
needs of the academic course. Teachers were involved in the program and establishing schedules to best meet the needs of students' time in the classroom and in the planetarium, teachers were present and able to assist during daily planetarium shows, and teachers were able to reference visuals and content learned in the planetarium during class time to help students learn content.

\section{Informal science education program structure}

Whether ISIs collaborate with schools in the design of programs or not, there is another important aspect of informal science education. The structure of the educational program is a contributing factor in students' learning. Informal education has not been clearly defined and there are many cases where characteristics of different types of educational environments and informal learning overlap, which contributes to the lack of clarity. At the base level, ISIs can be set up to be adult-led, adult-guided, or student-led experiences.

Adult-led experiences are as they sound, an adult is in charge of what students are learning. This could be implemented in a number of different ways, with the ISI educator, docent, or the classroom teacher teaching a lesson to students. A possible pitfall in adult-led informal settings may occur when formal teaching approaches are applied in informal contexts. This can cause confusion for students because formal learning is different than the learning that normally takes place in an informal science center (Guisasola et al., 2005). This would especially be true if the classroom teacher takes control of teaching the students.

The additional factor of student choice can play a role in an adult-led structure as well. Students could be attending a science center because of interest and on their own 
time, or they could be attending as part of a school field trip in which the activity is mandatory and at least partly structured by adults (teacher or science center staff). Based on commonly used definitions of informal science education, voluntary participation is included and students may experience greater gains in learning (Guisasola, et al., 2005; Hodson, 1998; Phillips et al., 2007; Zoldosova \& Prokop, 2006) from the informal science program than students who are forced to attend.

ISIs may also offer programs that are adult-guided. Many ISIs employ educators or use docents that have a certain expertise in the field. Although these adults are likely taking the lead in what students are doing, they would consider the service they provide as adult-guided rather than adult-led due to the 'informal' nature of the program. Plummer (2014a) reported on the important role that adults play in helping children by directing their attention, regulating the complexity of information, and providing opportunities for experiential learning (NRC, 2007; NSTA, 2014). Other studies also identified instructors' roles to guide and ask students questions (Guisasola et al., 2005) and to motivate students to learn more about natural phenomena (Zoldosova \& Prokop, 2006). Specifically within planetarium settings, multiple early studies pointed to the dialogue between students and the instructor as being essential to the informal learning experience (Reed, 1971, 1973; Thompson, 1968; Tuttle, 1966). The adult-guided format uses the unique informal setting and a non-classroom teacher perspective to strengthen students' science interest and knowledge.

The final program structure option places the student at the center of attention and allows them to be responsible for their own learning and progression through exhibits and activities. ISIs can provide students free choice throughout the visit or field trip, allowing 
them to spend time and participate willingly. Within a museum or science center not all visitors react the same way to an exhibit or participate in an interactive activity and the decision to engage remains with the individual (Rennie et al., 2003). On top of interest and knowledge levels of visitors, the personal context, social context, and the physical setting (Falk \& Dierking, 1992; Yu, 1999) are all factors as to whether students will actively participate and be engaged. Knowing that visitors can vary tremendously is why a variety of activities throughout will reach more visitors in a free-choice environment. The value in this free-choice setting is that it promotes and nurtures learning because it is non-evaluative (Falk \& Dierking, 1992, 2000; Falk, Koran \& Dierking, 1986) and students are not forced to participate $(\mathrm{Yu}, 1999)$. In fact, some believe that the studentcentered approach could be easily transferred into the classroom and could link school science and informal science education (Phillips et al., 2007).

In most programs the educational structure is likely a combination of multiple structures (e.g. adult-led, adult-guided, and student-led) to optimize what the ISI can offer and the educational experience for visitors. This 'semi-formal' structure would occur when a child participates in a structured after-school camp (Sacco et al. 2014). Even though it is voluntary participation for the student, the experience itself is not one of freechoice because an adult educator would be directing the camp activities. Another semiformal example would take place when families visit museums on their own time, yet take a guided tour with a museum educator. The lines can easily be blurred between adult-led, adult-guided, student-led, and the hybrid structures of ISIs. For this reason, ISIs need clear goals for the programs they offer and should establish various designs and structures to reach a wide array of visitors. 
During this study, a concerted effort was made to increase student involvement in comparison to other planetarium programs, which are typically adult-centered and lack interaction with students. A planetarium educator-led program was important in teaching students difficult scientific concepts by asking guiding questions and encouraging dialogue throughout. This approach allowed students to inquire about topics of interest, to express knowledge, and to encourage thinking more than had they not been guided.

\section{Physical Context}

Students are immediately engaged with the physical environment of an informal science education setting. The physical context includes everything from the size and shape of the building, to the lighting and coloration of the surroundings, and down to the details of signs and exhibits.

\section{Informal science education venues}

The physical context of the informal science program has been identified as a factor that improves learning (Falk \& Dierking, 1992, 1997; Rennie et al., 2003). On the contrary, other research has claimed a link between ineffective student learning and the novel physical and social environments of museums and informal science centers that are highly stimulating (Kubota \& Olstad, 1991). Often the novelty of the physical setting is highlighted as a potential distractor to student learning. One way to combat this potential issue may be to familiarize students with the field trip to an ISI setting before the day of the visit. If students are prepared for the novelty factor they will experience in the ISI, they will be better prepared for cognitive tasks during the program (Hofstein \& Rosenfeld, 1996). The physical space as well as the appeal of the exhibits and signage 
will increase the chances of learning science content while enjoying the informal experience.

The process of education can occur in any environment and students are surrounded by educational opportunities and science everywhere. These opportunities can present themselves in museums, zoos, aquaria, nature centers, and botanical gardens (Anderson et al., 2003; Bell \& Bevan, 2015; Guisasola et al., 2005; Phillips et al., 2007; Rennie et al., 2003; Zoldosova \& Prokop, 2006). In the early 1990s, science museums, zoos, and botanical gardens were among the first places outside of schools where the impacts (e.g. cognitive and affective) on students were examined (Anderson et al., 2003; Rennie et al., 2003). By the mid-1990s, there was acceptance of the cognitive, affective, and social impacts on visitors to these environments (Rennie \& McClafferty, 1996). As noted by Tran (2007), teachers need these venues to help teach subject matter that cannot be covered effectively in the classroom, for complementing and/or supplementing classroom instruction, as well as introducing students to resources in their community (Anderson \& Zhang, 2003; Kisiel, 2003). Knowledge of the resources and exposure to those resources is an important aspect of ISIs because piqued interest could inspire students to pursue careers in a science, technology, engineering, or math (STEM) field (Sacco et al., 2014).

The number and variety of ISIs have increased over the years, leading to more opportunities for students to learn science. Venues such as zoos, aquaria, nature centers, planetariums, and botanical gardens have improved their facilities and offerings to engage and excite students. As stated by Phillips et al. (2007), ISIs give free choice to explore, they provide authentic opportunities, and they allow for a collaborative and 
social learning experience for participants (Bitgood, Serrell \& Thompson 1994; Falk \& Dierking 1992; Hein, 1998). In addition to ISIs, television, books, other media sources, and family and community-based projects contribute to the education of our students (Crane, Nicholson, Chen \& Bitgood, 1994). With the reforms in science education and new science standards (Next Generation Science Standards, NGSS Lead States, 2013), ISIs could play a key role in improving science education (Itzek-Greulich et al., 2015; Phillips et al., 2007).

\section{Planetarium capabilities}

During the 1970s as the planetarium became a focal point for astronomy education in schools, more students visited planetariums throughout the school year. The Sun, Moon, Earth, other planets, stars/constellations, and the relationships between them could be modeled accurately in a planetarium setting. Any educator having access to a planetarium could immerse students into a rich visual environment and teach these concepts that would be difficult to model in a classroom. One of the difficulties of space science is the enormous spatial scale of the universe and how to teach students such distances between objects and sizes of objects in space. The ability to visualize is important in attempts to make sense of scientific processes, yet not all students have the ability to visualize equally. A planetarium can help students with concepts by placing them on the Earth or, with newer planetarium technology, having them observe the Earth while hovering in space. It can also take students on a virtual trip through space to observe objects beyond our view.

The planetarium is a powerful tool to help students understand why we experience what we do on our planet. Full-dome displays have dramatic impacts on audience 
members because they are highly immersed in the visual simulations offered by the planetarium environment (Yu, 2009). In this environment, students are surrounded by the screen and are able to observe images and videos in every direction. This construction and shape of the structure leads to a feeling of being in the middle of the show. This feeling is not easily obtained in a classroom on small computer or television screens. A benefit of the planetarium is its shape and size. Research has shown that larger screens and wider fields of view, lead to greater excitement, intensity, and enjoyment for viewers (Lombard, Reich, Grabe, Bracken \& Ditton, 2000). For this reason, both permanent and portable planetariums continue to be an important tool in education for engaging students.

When all beneficial aspects of the planetarium are considered - the immersive dome structure, the digital projection equipment, computer software - the venue would seem to be a helpful tool for teaching students the large-scale astronomical phenomena they would not otherwise be able to experience in a classroom. The immersive experience with highly rich visualizations and flight capability take students to a completely new experience, which can truly benefit their comprehension of astronomical concepts.

\section{Personal Context}

The personal context is an integral component for all students and how they learn, whether in school or out of school. Individuals vary due to different life experiences, which have shaped their motivation, interest, and knowledge. This context could be influenced in a variety of ways depending on the informal learning experience. 


\section{Informal science education: education vs. learning}

Science education does not just happen within the walls of a school. It happens everywhere, from schools to ISIs to watching television. We must first answer the question, what is education? A new way to describe education as defined by Smith (2015) is, "The wise, hopeful and respectful cultivation of learning undertaken in the belief that all should have the chance to share in life." Smith separates 'education' from 'schooling', saying that, "teachers and schools have been pushed into 'schooling' - trying to drill learning into people according to some plan often drawn up by others." This idealistic definition of education is unfortunately not common in schools across the country. Schools have been overtaken by policies and are driven by standardized testing, which has resulted in the 'schooling' of our youth, rather than the 'education' of our future leaders.

Often times, education is seen as a process, while learning is the product or outcome. However, learning can really be considered as both a process and a product (Falk \& Dierking, 1997; Smith, 2003). There are difficulties when attempting to pinpoint: a) Where and when learning begins and ends; b) how people learn and why they learn in a certain way; c) the environment and characteristics of those different environments that lead to increased learning; and d) how to measure learning accurately. Although many obstacles may stand in the way, research in measuring student learning through achievement tests or tasks, and understanding the process involved in how students learn are important to advancing education and improving schools. 


\section{Formal and informal science learning}

Features characterizing. While learning can take on many definitions, from memorization and acquisition of new knowledge or skills, to making sense or understanding not only the individual parts, but how the individual parts come together to make the system work (Saljo, 1979), it is important to study how students learn science. Since the process of education begins as infants (learning how to use utensils and how to behave) and continues until our last days of 'formal' education (highest grade level completed), most of our lives we are taking part in learning. Learning is a cumulative process that involves connections and reinforcement between a variety of learning experiences encountered in life: at home, in school, and out in the community and workplace (Rennie et al., 2003). When we refer to school, we associate this with students sitting in classrooms, learning specific subjects from teachers, and progressing from one grade to the next. However, this association ignores that learning is cumulative and occurs in places outside of school too.

It is estimated that Americans spend $95 \%$ of their average life outside the classroom, so it would be safe to say that individuals learn knowledge and science skills outside of school (Sacco et al., 2014). The interest in informal science education and learning stems from this fact that much more time is spent outside the four walls of the classroom, yet learning continues. If the educational system could harness this learning of science in venues outside of school, then students' experiences in school-based science may also improve. Although the definition of informal education has gone through iterations, one thing has remained constant... people learn something from these 
experiences. Although many questions remain, it is imperative to identify the differences between formal and informal learning and how students learn in each environment. Informal learning occurs on field trips and formal learning occurs within schools (Anderson et al., 2003; Wellington, 1991). Based on this definition, characteristics to differentiate informal and formal learning environments were developed by Wellington (1991) and reported by Hofstein and Rosenfeld (1996). The characteristics contain important features that could contribute to learning and could be instrumental in describing the differences experienced by students. A subset of informal characteristics includes activities that are: voluntary, unstructured, unevaluated, learner-centered and led by students, occurring out-of-school, they are non-curriculum based, there are unintended outcomes, and social intercourse is present. On the contrary, characteristics of formal activities are: required, structured, assessed and evaluated, teacher-led and teachercentered, occurring within a classroom, based on a curriculum, have empirically measured outcomes, and include more solitary work. These characteristics are on opposite ends of the spectrum and seem to be dissociated from each other, as if there is no link between them.

The National Association for Research in Science Teaching (NARST) published a report on informal science learning in 1999. The report included six important components for learning science in out-of-school settings, most of which were similar to characteristics identified by Wellington (1991). Informal learning is voluntary and selfmotivated. Additionally, students' needs and interests drive learning, and the physical setting and social interactions are extremely important to their learning. Students also learn over time and make connections between the learning experiences they encounter in 
all environments (formal and informal). Finally, the report identified learning as both a process and a product and that there should not be one standard way to assess student learning (Dierking, Falk, Rennie, Anderson \& Ellenbogen, 2003).

Others have also made comparisons between formal and informal science learning that are in the same vein. Informal science learning is different because it is indirect, exploratory, voluntary, and personal learning springs from students' curiosity, observations, and activity (Guisasola et al., 2005). Also, informal science is interestdriven and connects to community activities, while on the other hand classroom experiences are carefully designed, extended investigations (Bell \& Bevan, 2015). Informal learning has been identified as occurring naturally and being student-driven, which is different than activities carried out under the supervision of a teacher and completed because a grade is attached.

There are strong similarities between definitions and characteristics of informal education and learning over the past twenty-plus years. Sefton-Green (2003) stated something halfway through this journey to define informal learning, which may now be apparent, "There is no consensus about what informal learning might be" (p. 40). Minor changes exist within definitions, researchers self-report what they consider important characteristics, and a search continues for an accurate way to measure the cognitive effects on students through ISIs' programs. For this reason, further research is needed to gather as much information as possible with the goal of improving how we educate students in settings outside schools. Furthermore, it is necessary to develop out-of-school programs, exhibits, and science experiences to reach students in a meaningful way and increase their learning of science concepts. In fact, a future trend could be to combine 
formal and informal science (co-formal science education) by sharing learning goals and providing students with a more hands-on and authentic view of science.

Learning in informal settings. In attempts to better understand the learning that occurs at an ISI, researchers continue to struggle with identifying what students learn from the actual experience itself. Many informal activities are one-time occurrences and it is difficult to measure the effects of these activities on student learning, which could take time to develop (Rennie et al., 2003). Besides the newly gained information they obtain, students have pre-existing knowledge, conceptions before they participate, and are exposed to events after that could play a role in their knowledge. It is difficult to account for true learning from the experience when measuring learning through postvisit, or achievement tests because learning continues after the visit to an informal institution (Anderson et al., 2000; Falk \& Dierking, 1997). Another difficulty in measuring learning from an informal experience is that learners may not be able to make connections between knowledge gained during the informal visit and what happens after (Rennie \& McClafferty, 1995).

Understanding how students learn is complex. As Anderson et al. (2003) stated, "learning is multifaceted and unbounded by time, institution, or social context" (p. 178). This makes it difficult to make a distinction between the learning that occurs in different environments. Anderson's thinking about learning in this way should push science educators and researchers to consider further exploration into the effects of not only informal learning, but into classrooms that blend formal and informal learning experiences on student attitude and achievement in science (Hofstein \& Rosenfeld, 1996). This blending of education could have significant positive impacts on our current 
educational system, how students perceive science, and the number of students that enter into STEM careers.

Important factors for informal learning. Informal science institutions (ISIs = museums, zoos, planetariums, nature centers, etc...), out-of-school science centers, and science outreach programs are often different in their design and offerings to participants. Even as one evaluates what different zoos or planetariums offer, they will witness various atmospheres and methods of presentation. ISIs must consider many things when setting up exhibits and offering science programs in order to create a positive experience for visitors. Unfortunately, most of these things are not under their control. A few concerns would include: individual versus family visitors, age of participants, prior knowledge or experience of the environment and content, and the amount of time visitors will spend at each location.

On top of these concerns, ISIs aim to promote science, educate the public about science, and entertain. Entertainment is an important aspect of museums and science centers because those institutions want visitors to not only be engaged with the experience they offer, but they want return visits. Guisasola et al. (2005) stated, "although science centers are very popular with the public, they are often accused of trivializing science learning by prioritizing visitor fun" (p. 544). There should be a balance between education and entertainment to meet both the goals of the science center as well as visitors. Realizing the importance of combining education and entertainment, a number of planetariums redesigned their space and programs to create a better environment for visitors during the 2000s (Lantz, 2009). Since that time, many planetariums have been identified as hybrid institutions because they have transitioned to 
an educational space that also strives to entertain (Croft, 2008). Other ISIs and museums should make it a priority to stimulate peoples' interest in science by creating interactive exhibits and establishing an ideal flow to guide visitors through the experience.

In addition to entertainment, other factors have been identified as important to improving informal science learning. Students (and other visitors) of all ages will come into museums and science centers. For this reason, their science knowledge, interests, and life experiences will vary tremendously. Research has shown that the best chance of learning occurs when science centers contain exhibits relevant to visitors' interests and prior knowledge (Rennie \& Johnston, 2004; Sacco et al., 2014; Sindorf, 2014). According to Lelliot and Pendlebury, 2009 and Zoldosova and Prokop, 2006, the most natural learning is realized through personal experience. Furthermore, other research has reported that prior experiences as well as the level of science understanding, expectations, and attitudes of visitors will increase learning in informal science settings (Guisasola et al., 2005).

By working with schools, teachers, universities, and faculty, ISIs could improve their programs. A sound curriculum with good materials, hands-on activities, interactive exhibits, and the design of developmentally appropriate experiences would all improve what informal institutions provide to students.

Outcomes on students from ISIs. With the increased interest in informal science education since the early 1990s, a number of studies have been conducted to discover the impacts on visitors' learning after visiting science museums and other informal science institutions. Although early research relied on traditional experiment-based designs and focused on the products of the ISI experience, the findings were narrow and had limited 
generalizability. They were limited by the statistical methods used at that time and did not measure any unexpected outcomes on the students (Rennie et al., 2003). As statistical methods have improved, researchers have learned from previous studies that ISI science learning experiences can be conceptual, cognitive, epistemic, affective, or aim to improve students' skills (NRC, 1996; Simon, Erduran \& Osborne, 2006). Whatever those goals may be, a number of studies have reported that the outcomes on students and visitors to ISIs were positive.

ISIs have programs lasting anywhere from hours to weeks, therefore they are limited by the amount of information and activities based on what they offer to students. Science centers have had a positive impact on the acquisition of knowledge and competences according to studies by Luehmann and Markowitz (2007) and ItzekGreulich et al. (2015), while other studies saw increases in students' intrinsic motivation (Salmi, 1993; Salmi, 2003; Zoldosova \& Prokop, 2006). Additionally, participation in a summer science program showed significant influence not only on knowledge gains, but on students' attitudes as well (Fernandez-Manzanal et al., 1999; Knox, Moynihan \& Markowitz, 2003; Markowitz, 2004; Orion \& Hofstein, 1994). Whether one day visits or multi-week programs, students are learning science from these out-of-school experiences. Studies have indicated that students may actually learn more when they participate in out-of-school learning compared with what they are being taught in school (Seybold, Braunbeck \& Randler, 2014; Sturm \& Bogner, 2010). If this is true, then more participation in out-of-school experiences should be encouraged and more programs should be designed and offered to students of all socioeconomic statuses to help students of all abilities and backgrounds. Hofstein and Rosenfeld (1996) stated, "Informal science 
learning experiences can make significant contributions in providing appropriate learning opportunities to diverse learners and in motivating them to learn science, both within and outside of schools" (p. 88). These contributions could have lasting positive effects on students by improving attitudes and keeping up better with school-based work. Informal science education programs have increased in popularity and have been recognized as mechanisms for reaching at-risk and unengaged youth. It is important to provide authentic programs that are aligned with goals and to track the impact of these programs on our students (Wulf et al., 2010).

By providing a welcoming and engaging physical environment, interactive and interesting activities, and working more closely with schools and teachers, informal science institutions will flourish and become an integral part of improving students' views of science. In addition to museums and science centers (e.g. planetariums, zoos, aquaria, parks, gardens), students' exposure to digital learning (websites, apps, online media), and media (TV, radio, movies) will collectively and cumulatively contribute to an individual's lifelong science learning (Sacco et al., 2014). Others refer to lifelong learning as life-wide learning, but the two are similar and include the important fact that we learn new information from all aspects of our lives, not just from school or informal venues. As reported in Bell and Bevan (2015), the National Research Council informal science report defined life-wide learning as:

"The learning that takes place as people routinely circulate across a range of social settings and activities - classrooms, after-school programs, informal educational institutions, online venues, homes, and other community locales. Learning derives, in both opportunistic and patterned ways, from this breadth of 
human experience and the related supports and occasions for learning that are available to an individual or group." (p. 28)

Revisiting earlier research, Dierking (1997) stated, "learning is learning..." (p. 4) and Anderson et al. (2003) stated, "learning is multifaceted and not bounded by time..." (p. 178). It is difficult to pinpoint when learning specifically occurs because humans are constantly obtaining new information, re-evaluating current thinking, and assimilating newly learned information into prior conceptions. Any activities and/or experiences providing students with opportunities to participate will benefit their overall knowledge and ability to do science.

Role of the teacher. When it comes to school-aged students and school-based field trips, there is an additional factor beyond the control of the ISI (physical setting and content) or characteristics of the student (age, prior knowledge, interests, attitude, personal experiences) that plays a large role in the learning that occurs. Teachers are important to what and how students learn science. Teachers can and should explicitly state the purpose of the field trip and identify connections between what is being learned in the classroom with what they will learn at the ISI (Guisasola et al., 2005, ItzekGreulich, 2015). If a field trip is unrelated to what students are learning in school, then the trip itself will not be as effective (Orion \& Hofstein, 1994; Falk \& Storksdieck, 2005; Fallik, Rosenfeld \& Eylon, 2013). These field trips that are not linked to the curriculum or are severely mistimed within a science unit are less likely to result in learning as the teacher would have liked or intended for students. Also, research indicates that more effective learning of science from an ISI may depend on good preparation before the field trip and debriefing afterwards with students (Anderson \& Lucas, 1997; Tal, Bamberger \& 
Morag, 2005; Guisasola et al., 2005; Itzek-Greulich, 2015). Teachers that prepare give an overview of the ISI, explaining the purpose of the trip, and that have specifically stated objectives prepare students to learn. Furthermore, the post-visit debrief is vital to wrap-up the experience, answer questions, and help students reflect on the information

obtained. Overall, the effectiveness of science field trips to ISIs and the level of science knowledge that students may walk away with at the conclusion of the field trip are dependent on the teacher.

\section{The Planetarium}

\section{History of planetariums}

Planetarium-like devices date back to the famous Greek scientist, Archimedes (Chartrand, 1973). These ancient devices, which were similar to present-day orreries, were constructed to model the movement of the Sun, the Moon, and the planets. These early devices were quite small and simplistic but represented the desire that humans have always had to understand the heavens. The desire to construct bigger devices for larger scale simulations of our solar system led to advancements in the planetarium over the years. Finally, in the late 1700s new machines and planetariums appeared with the intent to educate and inspire people.

The first example of the modern day planetarium was displayed in the Deutsches Museum in 1923 where images were projected onto a domed hemisphere (Chartrand, 1973; Lantz, 2009; Menke, 1987). Over the next decade, the United States’ first planetariums appeared in Chicago (1930), Philadelphia (1933), Los Angeles (1935), and New York (1935). Meanwhile, planetarium numbers were also increasing worldwide until production slowed at the beginning of World War II. In the United States, it was 
not until the launch of the Soviet's Sputnik (1957) that a nation's interest was piqued, astronomy in the curriculum was revitalized, and planetarium production increased. Space exploration thrust space science into the forefront and through the late 1950s and 1960s over 1200 school-associated planetariums were built across the United States (Tomlinson, 2011). In fact, the planetarium was one of the six outstanding innovative educational projects named by President Eisenhower's Advisory Council (Lantz, 2009). Planetariums were a valuable addition to science education and what schools could offer to students.

The early goals of planetariums were aesthetics, creating an engaging environment, and piquing the curiosity of visitors. Due to the large increase in the number of planetariums post-Sputnik, researchers' interest was to go beyond the affective outcomes and evaluate the cognitive impacts on students (Lantz, 2009). In addition to the cognitive gains researchers were looking for, the post-Sputnik era brought about the need for factual educational programming. Early information displayed by an orrery or planetarium may not have been completely accurate due to the size and scale of our universe. There were obvious limitations with size, space, knowledge, and the technology used to construct early models of our universe.

Planetariums have continued to improve through advances in technology. In 1923, Carl Zeiss introduced the first projection-based system for planetariums with the goal of providing scientific accuracy (Chartrand, 1973; Lantz, 2009). Since that time, advances continue to be made and the planetarium has become a high-tech environment for learning science. Current day projection systems allow for the delivery of experiences that show and share growing databases, natural phenomena, and near- 
photorealistic rendering capability (Lantz, 2009). As was started by Zeiss in the 1920s, today's planetarium educators and researchers agree that up-to-date and accurate scientific information is vital to a planetarium presentation (Croft, 2008).

\section{Planetariums in astronomy education}

A planetarium can be beneficial for students' understanding because it provides opportunities for explorations of spatial scale not available to the classroom teacher in a school (Lelliott, 2010; Sadler, 1998; Yu, 2009). The planetarium is a unique environment that is invaluable for providing observational opportunities because it can accurately represent the daily, monthly, and annual patterns occurring in the sky (Tomlinson, 2011). This is important for students because they can experience/observe scientific processes in a matter of moments as opposed to having to make observations over long periods of time. Dr. Philip Fox, the first director of the Adler planetarium in Chicago said it best, 'People think that astronomy is a 'useless science,' but a planetarium is just as valuable to mankind as the art institute or the civic opera" (Menke, 1987).

Teachers could use the planetarium as an additional tool of instruction to have students think differently about the same concepts they teach in school. In addition to patterns in the sky, planetariums help students to better understand our (the Earth's) place in space and how it relates to the larger universe (Tomlinson, 2011). Students would have the ability to observe interactions in space, which explain why we experience certain consequences on the Earth (e.g. the seasons). This is something that is not possible without the help of a planetarium or planetarium software. 


\section{Summary}

Humans are surrounded by learning experiences throughout their lives. If formal schooling and teachers could integrate what students 'do' and 'know' outside of school, the face of education could change for the positive. Due to the exposure students have with informal science learning experiences, this field has been of interest for many years. Researchers have defined and modified what constitutes informal education and informal learning in various settings. Within the field of science, there are many example of informal education: zoos, aquaria, planetariums, nature centers, and more. What remains in question for some about informal learning is: Is it the location where learning occurs? The process of how learning occurs? Or, is learning the product achieved from visiting an ISI?

These venues and their programs exist to not only educate, but to entertain the public. In order to stay relevant and attract visitors, these museums and science centers must offer engaging, interactive exhibits that will encourage thought and exploration. Research has identified a number of characteristics that occur in ISIs and characteristics that may contribute to the success of informal science offerings to schools and students. Informal science institutions can exist as stand-alone settings where visitors will attend by their own choice. Exhibits and activities may be scientifically accurate and engaging to visitors, visitors choose to participate or not, and there is no explicit connection with school science.

On the other hand, ISIs can collaborate and create meaningful relationships with teachers to provide an experience connected to what students are learning in school. These partnerships help to promote ISIs and increase their value and use by teachers if 
what they offer is curriculum-based. Of course, these partnerships shift the voluntary and free-choice decisions away from the student because the program is educator-led, it is mandatory, and it is structured. Even though the design and structure of informal science settings can vary tremendously, students are still provided with valuable learning opportunities. With the proper planning (before, during, and after the visit) all individual's goals of educating students, increasing their interest in science, and linking science inside and outside of school can be accomplished.

\section{Current Study}

This study deeply explored the role a planetarium played on students in a high school astronomy course. Although planetariums are seen as informal science institutions, this study took place within the formal setting of an area high school, creating what I have coined as 'co-formal' education (a combination of informal and formal science education characteristics). In addition, this blending of environments was coupled with other factors that blur the idea of informal education and learning: a) The program being offered was not voluntary for students, as it was part of their course; b) the local teacher and planetarium educator collaborated in advance to align the program content with the science curriculum; and c) the structure of the program was adultguided, with the planetarium educator guiding lessons. 


\section{CHAPTER III: METHODOLOGY}

\section{Researcher's Role in Study}

I was a planetarium educator for three years working mostly with K-12 students engaged in a field trip to a campus planetarium venue. These field trips lasted 90 minutes and included a pre-produced show, an interactive teaching segment, and concluded with a tour of the night sky. During the three years, I was also involved in delivering portable planetarium field experiences to students within area schools too. Portable planetariums are effective in reaching many students throughout the day because new groups can cycle through every 20-45 minutes. In the role of informal science educator I observed students' reactions to the physical space of the planetariums and I developed a deeper understanding of the many alternative conceptions students have about space science concepts. I also observed the excitement and enjoyment of students of all ages who bring their unique personal contexts to these informal science programs.

Students in grades K-12 can learn astronomical concepts, processes, patterns, and cause and effect relationships during field trips to planetariums. Whether students are visiting at the beginning, in the middle, or at the end of their unit of study, I noticed that not all student groups ask the same questions, nor do they all have the same reactions upon entering the dome for a produced show or observing the live-flight visualizations projected during the program. Although I entered into this research with a favorable view of planetarium inclusion while teaching space science, I wanted to explore how 
students' thinking and learning were influenced, as well as find out what aspects of the planetarium students enjoyed most.

\section{Research Questions}

The three research questions that guided this study were:

1. How are students' attitudes influenced by an embedded planetarium experience while studying astronomy?

2. How does an embedded planetarium experience during an astronomy unit influence students' learning (acquiring knowledge) and retention of concepts?

3. How does the planetarium influence students' thinking (reasoning about concepts) about astronomical concepts?

\section{Participants}

This research was conducted in two large high schools, which are the only high schools in this particular district, Hickory H.S. ${ }^{2}$ (treatment school) and Bayside H.S. (comparison school), both classified as suburban by the state department of education. Science teachers between Hickory and Bayside high schools work collaboratively to develop district-level curriculum targets and assessments for similar courses that are offered at each school for comparing the course and student achievement. In this study, the course of interest was Earth and Space Science and the unit of focus was astronomy, which occurred in the first nine weeks of the school year.

The treatment group had a four-day planetarium program embedded within their normal astronomy unit without lengthening the time spent on this unit, while the comparison group did not have a planetarium program while learning astronomy. The

\footnotetext{
2 Pseudonyms were used to protect the identities of the high schools in this study.
} 
students that participated in this study were mostly high school sophomores enrolled in this particular science course, but there was a very small percentage of upperclassmen taking the course for the first time due to previous scheduling conflicts or because they did not pass the course prior.

Students in the treatment school included a broad range of academic abilities and were distributed in classes taught by three different teachers, and included all students in the treatment school taking this required class. In the comparison school, those students were enrolled in multiple sections of the class taught by the science department chair. In the comparison school, the students in the science department chair's class are generally academically stronger students than the general population of students in that school. This group of students will later be compared to the treatment group, which represents the full spectrum of the student body in the treatment school.

There were greater than 200 students from Hickory and over 130 students from Bayside H.S. that participated in this study throughout its duration. During the four-day planetarium program built into their normal astronomy instruction, more than 230 students from Hickory H.S. were in attendance, but the total sample size varied from day to day because of conflicts, absences, and lack of participation with certain parts of the study. Additionally, student participants from Bayside H.S. were not identical for each data source. As the results are reported for specific measures, specific sample sizes will be reported as well. As for the district-wide assessment (the district benchmark assessment - DBA), which was a key piece of data to compare students between the two schools, 343 students completed the unit DBA (Table 1). 


\section{Table 1}

$\underline{\text { Student District Benchmark Assessment (DBA) Sample Size }}$

\begin{tabular}{lcc}
\hline & $\begin{array}{c}\text { Hickory } \\
\text { (treatment) }\end{array}$ & $\begin{array}{c}\text { Bayside } \\
\text { (comparison) }\end{array}$ \\
\cline { 2 - 3 } Females & 91 & 57 \\
Males & 118 & 77 \\
Total & 209 & 134 \\
\hline
\end{tabular}

\section{Obtaining permissions}

The first step in obtaining permission from school district personnel was to perform a pilot study while the planetarium visited one of the high schools over a threeday period in Fall 2015. As noted earlier, at the teachers' request we had been embedding our planetarium experience in the astronomy unit of this high school for the prior three years, and this pilot study was simply an extension of our ongoing relationship with the school. The pilot study was set up through a teacher of the course, who acted as a gatekeeper (Creswell, 2009) for other teachers of the course and to the appropriate personnel at the district level. Direct observations and field notes were taken, as well as recording students' responses upon entering the planetarium, interactions between students, and interactions between students and the planetarium educator. The high school teachers were interested in the research topic and agreed to be participants in this research if approved.

The second step involved taking the research proposal idea to the school district's administration and requesting their approval. Although they had no issues with collecting anonymous student data (e.g. gender, GPA, test scores), they were not comfortable granting approval for direct interaction with students (e.g. small focus group 
interviews). The district asked for confirmation of research approval by the University of Louisville before moving forward with data collection.

Once the research proposal was unofficially approved by the school district, an official proposal was submitted under expedited review to the Institutional Review Board (IRB) at the University of Louisville. After approval for the study by the IRB, the district was notified, parent and student informed consent letters were constructed, and letters were sent to teachers to distribute to students and families. All students enrolled in the course were notified that they would be completing a number of activities during the unit and that the planetarium program was being recorded. If there were concerns from parents or students, they had the opportunity to speak to their teacher, the researcher, or contact a member of the IRB with further questions. With no foreseeable harm for students, there were no questions and no opt-outs from the study.

\section{Description of planetarium program}

A four-day planetarium program design was a collaborative effort between the researcher and a planetarium educator (hereafter referred to as 'design team') at the University of Louisville. Once teachers between the two high schools identified course goals, what they called 'key indicators' for students to learn, and wrote the DBA, the design team collaboration began. Initial stages of planning used the DBA to identify what visuals were possible with the existing software technology and important discussion points to include.

The design team carefully planned the program to include 'key indicator' concepts (curriculum goals) without explicitly stating what would appear on the DBA. They chose visuals to depict each scientific concept and example questions to ask 
students during the daily program. Since both members of the design team were teachers, it was assumed that deviation from the script could occur based on students' interests and questions, but all students would receive similar experiences each day because the same university planetarium educator would be delivering all planetarium instruction. A coherent story line (or script) was created to engage students without inundating them with unnecessary, or overly complicated, information. The idea was to build on basic concepts that were associated with everyday experiences, then add more complex concepts requiring advanced thinking each day.

The design team's script included pre-planned visuals, pre-planned flights through space (the viewer has the perspective of being in a spaceship and flying), specific questions, and certain concepts to accomplish the pre-determined theme established for each day. Similar to what the districts' science teachers had been typically doing for the rest of their curriculum in terms of aligning instruction with predetermined instructional goals, the four days were developed with the DBA in mind, as well as spatial scale, beginning small and personally relevant and then leading farther out into space until reaching the edge of the observable universe. On day one, the emphasis was on Earth and nearby objects (e.g. the Moon and the Sun), the second day included other planets and moons in our solar system, day three took students out into the Milky Way and introduced them to other galaxies, and on day four students experienced space at the largest scale. The details of daily scripts can be found in the appendices (Appendix C).

\section{Limitations of the study}

In addition to answering the research questions stated, all attempts were made to not create extra work for participating teachers and to not negatively impact students' 
time. Both high schools in this study use Google (e.g. Google docs, forms, etc.) to collect information, share data, and communicate with students. This allowed the researcher to construct data collection instruments in a familiar format and make them easily accessible to students. The use of online data collection for attitude surveys and content assessment eliminated the impact of lost classroom time for teachers and students could complete them at a convenient time within their schedule.

Furthermore, upon completion of the DBA the researcher had access to all the benchmark data to evaluate students' scores in ways unique to this research (e.g. separating questions into those addressed by the planetarium programming and those not). This took any additional workload off of high school teachers and allowed the researcher to record, compare, and analyze results without negatively impacting teachers' time or keeping students from receiving their scores.

The qualitative formative assessment questions evaluating how the planetarium influenced students' thinking in a new, more interesting, or deeper way was administered within the school planetarium at the conclusion of each lesson. By having students complete this task within the dome and during class time, it lessened the impact of the study on participants because they were already in this location and did not have to travel, miss any additional class time, or lose personal time.

\section{Research design}

This study collected both qualitative and quantitative data to capture how a planetarium shaped students' experiences during an astronomy unit. A concurrent transformative mixed methods design (Figure 5) was used to concurrently collect qualitative and quantitative data in order to inform the study's research questions. An 
important aspect of the transformative design was that a theoretical lens guided the data collection, which in this study was the Contextual Model of Learning (Falk \& Dierking, 1992; 2000). Creswell (2009) stated, "This [concurrent transformative] model has the added advantage of positioning mixed methods research within a transformative framework, which may make it especially appealing to quantitative or qualitative researchers...” (p. 216).

\begin{tabular}{|c|}
\hline Concurrent Transformative Design \\
QUALITATIVE $+\quad$ QUANTITATIVE \\
Social science theory, qualitative theory, advocacy worldview
\end{tabular}

Figure 5. Mixed Methods Research Design

This was an appropriate research design to use within this study because the fourday planetarium program was framed as a single experience that occurred over a short period of time. The quantitative and qualitative data were both collected within this span of time in a concurrent fashion. These two types of data collection and interpretation were not separated by discrete events and time, as would be the case in a sequential transformative research design.

The various data were collected independently and were not initially used to inform each other. First, quantitative data was collected to uncover students' attitudes and knowledge when entering into the course. Secondly, qualitative data were collected daily to gather examples of students' thinking about specific content and processes within the planetarium. Finally, more quantitative data were collected at the end of the multiday experience for evidence of students' learning and triangulation of the qualitative responses and delayed surveys from students. 
The combination of data allowed for the evaluation of the apparent effect of a planetarium on students' thinking about astronomy concepts, which aspects of the planetarium were most impactful on their learning, their performance on a district assessment, and whether students attributed their learning and interest in astronomy to their planetarium experience at a later date.

\section{Overview of data sources}

The data collected and the methods used were appropriate for exploring this research topic for a variety of reasons. In previous planetarium studies dating back to the 1960's, findings have been inconsistent and there has been no standardized test developed and used to measure student learning. In fact, isolating learning that does take place in a planetarium is difficult because of students' pre-existing knowledge and at what point a planetarium program test is administered in relation to the field trip (e.g. immediately when the program is over before exiting planetarium; when students return to school on same day; or days after the planetarium visit). There may be short-term knowledge gained by students but they may not retain that knowledge over time and it is difficult to attribute knowledge to the actual planetarium experience compared to what students learned elsewhere.

Three pieces of data were collected to measure students' knowledge over time. The first was a pre-unit content assessment that paralleled course and DBA concepts. This was collected at the beginning of the science unit and used to analyze students' entry knowledge of the subject. The second data source came from DBA scores at the conclusion of the unit, while the third content assessment (retention quiz) was obtained through a delayed administration of six specific questions taken from the original DBA. 
These data were used in combination to determine growth in students' knowledge, retention of astronomy concepts in relation to original scores, and retention of knowledge in comparison to students at the comparison high school.

There have been many studies that have looked at the affective outcomes on students from a visit to the planetarium. This study collected pre and post-attitude survey data, and months later asked students about the planetarium, to link students' selfassessment of performance on the DBA and subsets of questions with their planetarium experience while studying astronomy. The data determined if students had positive attitudes about astronomy, if the planetarium was interesting to them, and whether the planetarium helped them learn astronomy. Moreover, on the final day students ranked planetarium characteristics they felt were most effective for learning and chose which context (i.e. physical, personal, or sociocultural) had the greatest impact on their learning. Finally, observations, field notes, and informal teacher interviews helped to confirm students' views of the planetarium experience.

Daily formative assessments were key to understanding the role of the planetarium in thinking about and learning astronomy. Previous studies attempting to measure students' learning have looked at learning as a product. This study aimed to evaluate learning as a process. These data captured students' thinking and identified areas where the planetarium helped students understand or think about scientific phenomena in a new, more interesting, or deeper way. The daily formative assessments captured the educational benefits of the planetarium directly from the students rather than from the researcher's perspective. Despite students' scores on the pre-unit content quiz 
or on the DBA, they still might have learned much due to the planetarium and this would not be captured without hearing the voices of the students themselves.

The variety of the data sources used throughout this study, how the data were collected, when data were collected, and the research questions addressed through the collection of each piece of data are presented below (Table 2). Additionally, where data were collected is included to reiterate an important piece of this study - that high school teachers' and students' time were respected.

\section{Table 2}

Overview of Data Collection

\begin{tabular}{|c|c|c|c|c|}
\hline $\begin{array}{l}\text { Data } \\
\text { Source }\end{array}$ & $\begin{array}{l}\text { Data Collection } \\
\text { Method }\end{array}$ & Timeframe & $\begin{array}{l}\text { Data Collection } \\
\text { Location }\end{array}$ & $\begin{array}{l}\text { Research } \\
\text { Question }\end{array}$ \\
\hline $\begin{array}{l}\text { Student pre- } \\
\text { attitude survey }\end{array}$ & Google Form & $\begin{array}{l}\text { September as unit } \\
\text { of study begins }\end{array}$ & $\begin{array}{c}\text { In class or at } \\
\text { home }\end{array}$ & $\# 1$ \\
\hline $\begin{array}{l}\text { Student pre- } \\
\text { content } \\
\text { assessment }\end{array}$ & Google Form & $\begin{array}{l}\text { September as unit } \\
\text { of study begins }\end{array}$ & $\begin{array}{l}\text { In class or at } \\
\text { home }\end{array}$ & $\# 2$ \\
\hline $\begin{array}{l}\text { Observations } \\
\text { and field notes }\end{array}$ & $\begin{array}{l}\text { In person within } \\
\text { planetarium }\end{array}$ & $\begin{array}{l}\text { Late September } \\
\text { during instruction }\end{array}$ & Planetarium & $\begin{array}{l}\# 1 \\
\# 3\end{array}$ \\
\hline $\begin{array}{l}\text { Daily student } \\
\text { formative } \\
\text { assessments }\end{array}$ & $\begin{array}{l}\text { In person within } \\
\text { planetarium }\end{array}$ & $\begin{array}{l}\text { At the conclusion } \\
\text { of each day. Late } \\
\text { September }\end{array}$ & Planetarium & $\begin{array}{l}\# 1 \\
\# 2 \\
\# 3\end{array}$ \\
\hline $\begin{array}{l}\text { Student DBA } \\
\text { scores }(2 \\
\text { subscales - one } \\
\text { measuring } \\
\text { planetarium } \\
\text { topics, second } \\
\text { measuring } \\
\text { unrelated Earth } \\
\text { science topics) }\end{array}$ & Paper/Scantron & $\begin{array}{l}\text { Early October } \\
\text { shortly after } \\
\text { concluding } \\
\text { planetarium } \\
\text { instruction }\end{array}$ & In class & $\# 2$ \\
\hline $\begin{array}{l}\text { Student post- } \\
\text { attitude survey }\end{array}$ & Google Form & $\begin{array}{l}\text { Mid to Late } \\
\text { October }\end{array}$ & $\begin{array}{l}\text { In class or at } \\
\text { home }\end{array}$ & $\# 1$ \\
\hline
\end{tabular}




\begin{tabular}{|c|c|c|c|c|}
\hline $\begin{array}{l}\text { Student delayed } \\
\text { DBA }\end{array}$ & Paper & January & In class & $\# 2$ \\
\hline $\begin{array}{l}\text { Student delayed } \\
\text { survey }\end{array}$ & Google Form & January & $\begin{array}{c}\text { In class or at } \\
\text { home }\end{array}$ & $\begin{array}{l}\# 1 \\
\# 2\end{array}$ \\
\hline $\begin{array}{l}\text { Teacher } \\
\text { interview } \\
\text { questions }\end{array}$ & Email & $\begin{array}{c}\text { September and } \\
\text { January }\end{array}$ & At home & $\begin{array}{l}\# 1 \\
\# 2 \\
\# 3\end{array}$ \\
\hline
\end{tabular}

\section{Quantitative Data Collection}

An overview of each quantitative data source will be discussed in greater detail in the following sections along with the origin of the instrument and what it measured.

\section{Survey of attitudes towards astronomy}

Using Table 2 as a guide, each data collection instrument is discussed here in more detail. First, the Survey of Attitudes Towards Astronomy (SATA) was used to measure students' pre-attitude and post-attitudes toward astronomy and science (Appendix D). The SATA was reported to have four subscales: affective, cognitive competence, value, and difficult. The survey was designed to measure astronomy and science attitudes and has a reported Cronbach alpha $=0.76$ and Spearman-Brown reliability coefficient $=0.84($ Zeilik, 2012). The original set of 34 questions was used to gather information about students' attitudes in this study.

\section{Pre-unit content assessment}

The design team created a short content quiz that was given to students at the beginning of the unit to establish a baseline of students' knowledge entering into the course (Appendix E). Quiz content was taken from the schools' course curriculum and DBA examination to create 10 questions that paralleled important concepts. The validity of these questions for measuring the district-defined course goals parallel to the district assessment was strengthened by having them written and approved by two planetarium 
educators, and then sharing and editing as suggested with the planetarium director at the University of Louisville and high school teachers participating in the study.

\section{District Benchmark Assessment}

The district's teachers of this 10th grade Earth and Space science course constructed the district benchmark assessment (DBA) and it acted as the district's summative assessment of the nine-week science unit. The district's teachers constructed this DBA based on district curriculum goals and use the results to make instructional decisions for future revisions. This was not a standardized instrument for use outside of that context. The DBA included 25 questions covering many aspects of space science (e.g. Hubble's Law, solar systems, galaxies, and gravity). The overall score of the DBA was an important piece of data to evaluate what students learned during the unit, but to gather more accurate information about the planetarium's impact, the DBA was divided into 2 subsets (13 planetarium and 12 non-planetarium questions) to measure treatment effects in this study.

\section{Retention Quiz}

After evaluating the subset of 13 questions relevant to the planetarium programming, six questions were chosen from the DBA and given to students three months later to measure students' retention of important space science concepts. Students' initial performance was evaluated and questions were placed into one of three categories based on the percentage correct by students in each high school - high, medium, and low. This classification led to four questions each being placed in the high (87.3\% average) and medium (75.5\% average) categories; and five questions were placed in the low category $(60.6 \%$ average $)$. 
The six-question retention quiz was constructed by selecting two questions from each category, which included specific astronomy concepts taught during the planetarium program (Appendix A). In order to keep the test short and avoid increased testing load on students, only questions that had relatively high cognitive demand were selected after balancing across the high, medium, and low categories.

\section{Student voting instruments}

Other quantitative data were collected on the final day of the planetarium program. Students were provided a list of things that planetariums do well (Appendix F) and asked to rank them in the order that helped them learn about astronomy (i.e. $1=$ most important, 7 = least important). Additionally, as the program was concluding students were given a bingo chip, asked to read labels on three buckets located at the back of the planetarium, and then place their chip into a bucket as a vote. Each bucket's label corresponded to one of the three contexts of the CML and students' votes represented which was most impactful on their learning over the four-day embedded planetarium program (Appendix G).

\section{Delayed student survey}

Students at Hickory H.S. were asked to answer two survey questions upon completion of the retention quiz (Appendix H). Students' direct opinions were collected to evaluate the role of the planetarium in their enjoyment of the astronomy unit and whether they thought the planetarium helped them learn astronomy content. These questions helped to inform the researcher whether this informal science learning experience played a direct role in their learning as measured by their DBA scores and 
retention scores in comparison to their counterparts at Bayside H.S. who did not have an embedded planetarium experience while learning astronomy.

\section{Qualitative Data Collection}

The qualitative data collected from students, teachers, and the researcher are described in more detail in the following sections, including what the goals were of each data source.

\section{Formative assessments}

Daily formative assessments were handed out to students at the conclusion of each day of the planetarium experience. These assessments provided students with an opportunity to answer a specific question related to the daily theme (e.g. Earth, solar system, universe, scale) and provide an example to explain thinking or learning. The researcher and planetarium director co-created a question outline that would enable students to provide their own example(s) and describe how the planetarium helped them think in a new, different, or more interesting way about astronomy concepts without telling them what to write about. Each day, the basic framework of the question and presentation of the assessment to students remained the same. After the initial introduction on day one, students needed little guidance on the following days since the only change in the question dealt with the daily theme.

The physical space of the planetarium was used to gather assessments immediately following each day of the program. The benefit of data collection inside the planetarium was a higher return rate of daily questions from participants. While completing these assessments, in a modification of standard stimulated recall approaches (DeWitt \& Osborne, 2010; Morgan, 2007), a dynamic visual from that day’s planetarium 
instruction was projected onto the dome at the end of each day. The visualizations could have helped students revisit prior concepts and elicited more thorough descriptions and explanations of space phenomena. Each day's visual was pre-determined by the design team, and approved by the Director of the planetarium, to optimize the capabilities of the planetarium's technology and to use thought provoking dynamic scenes (e.g. objects in motion or interactions in space). For example, on the second day the planets were enlarged for students to observe appearance and rotation, planets were revolving around the Sun, the asteroid and Kuiper belts were visible, and everything was in motion on the planetarium dome. The visuals acted as a guide to assist students in thinking about the daily content without telling them what to think about and were meant to help students if needed, but students were not expected or asked to comment on the specific scene projected onto the dome.

In addition to informing the researcher of what and how students were thinking and learning from the planetarium, this data collection design attempted to link the formal and informal science education learning experiences for students. Allowing students time to observe and experience astronomy concepts from different perspectives in a unique environment may have contributed to an increase in learning opportunities. These data helped shed light on students' thinking and were used to paint a more accurate representation of what students learned as opposed to only evaluating their DBA score, which can be influenced by to outside factors (e.g. test anxiety, lack of sleep).

\section{Observations and teacher interviews}

The final sources of data collected were observations, field notes, and informal teacher questioning. The researcher was present in the planetarium during each 
presentation and notes were taken beginning with student entry and any noticeable reaction to the physical space or dome images, continuing through the program, and as students exited the planetarium. Observations were conducted on every group in the planetarium over the four days to gather as much information as possible and every group presentation was audio-recorded to have record of interactions between student-student and student-instructor (the sociocultural context). Field notes were recorded in a notebook to monitor consistency in topics/concepts covered during each presentation by the planetarium educator, to capture specific student comments, questions, and answers, and researcher thoughts in the moment. These observations and field notes were used to triangulate with other data sources (e.g. formative assessments, attitude surveys).

Teachers were surveyed informally onsite during the program, and through a number of questions in email about the planetarium experience. The goals were to triangulate student's opinions of the program and to evaluate if expectations of the connections between classroom teaching and planetarium content were being met. Additionally, when students completed a retention quiz and survey, the same group of teachers was asked to reflect and comment on specific questions (Appendix I) about students during that unit. Teachers' direct contact with students and observations also acted as support for all three aspects of this research - student attitudes, learning, and thinking.

\section{Data Collection Summary}

The data collection overview (Table 2) indicated how each data source was used to answer the research questions guiding this study. The main highlight to note was that multiple data sources provided insight into each research question. Every data source 
was identified to collect the appropriate information for data triangulation, which would strengthen validation of the findings and make findings more robust (Creswell, 2009; Yin, 2006). In studies where qualitative data collection and analytic methods are used it is important to establish credibility and trustworthiness through using appropriate procedures and explicitly stating the methods used.

Moreover, the data collected in this study was tied to the theoretical framework guiding this study. The Contextual Model of Learning (Falk \& Dierking, 1992; 2000) includes three contexts and the collected data fit into each context: data for the physical context will come from observations, field notes, and student responses on the daily formative assessment; data for the personal context will come attitude surveys, pre-unit content assessment, observations, field notes, and daily formative assessments; and data for the sociocultural context will arise from observations and field notes of the interactions between student-student and student-teacher.

\section{Data Analysis}

The analytic strategies for each data source presented here will occur in the order that they were collected during this research, and when necessary, data sources that contributed to answering a research question will be grouped together.

\section{Survey of attitudes towards astronomy $(S A T A)$}

The SATA was administered to students to measure attitudes toward astronomy and science before and after the unit in question. For each of the 34 questions, means and standard deviations were calculated to identify how students' attitudes may have changed and from pre to post-unit. An exploratory factor analysis (FA) was conducted to create subscales and then dependent t-tests were conducted on the six identified subscales to 
check for statistically significant shifts between the pre and post-survey within both schools. Any positive shift in attitude within either school may indicate that students had a good experience in the course. A negative shift in attitude may indicate that students did not enjoy the course or learning about space science topics.

A two-sample independent $t$-test was performed to check for statistical significance between schools on the pre-unit survey and the post-unit survey. The independent $t$-test was used to compare whether attitude differences existed between students at Hickory H.S. and Bayside H.S. before they began learning astronomy. Then, survey results were compared afterwards to evaluate attitude shifts and which group had more positive attitudes, the treatment group or the comparison group.

\section{Delayed student survey and teacher interview questions}

In addition to the $S A T A$, which did not directly ask students at Hickory H.S. about the role of the planetarium and how it may have shaped their attitudes, a short survey was given three months after the planetarium program. This short survey was intended to gather students' voices to determine if they learned because of the planetarium and whether they enjoyed astronomy because of the planetarium experience. These direct, planetarium-specific questions were used to explain changes in students' attitudes that may not have been measured by the SATA. The analysis of these questions was based on the percentage of students that agreed or strongly agreed that the planetarium was a beneficial tool within their class compared to the amount of students that disagreed or strongly disagreed that that was true. Furthermore, teachers were questioned about students' attitudes and whether ideas from the planetarium experience were taken back into the classroom during this program as a form of triangulation. 


\section{Pre-content assessment}

The 10-question pre-content assessment was given at both schools to evaluate students' astronomy knowledge at the beginning of the unit (their first unit of the school

year). The percentage correct of each question was calculated and scores were compared between Hickory and Bayside H.S. students. This assessment acted as the foundation from which growth in content knowledge was measured over time for all participants in both schools and a statistical test was conducted to determine if participating students were similar or not in their pre-content knowledge.

\section{District benchmark assessment (DBA)}

Analysis of the DBA occurred on three different levels. First, the DBA was collected and graded by classroom teachers because students' grades depended on their scores, which is a normal district practice that precedes this study. These results were shared with the researcher and the overall scores (25 questions) were evaluated. The mean scores and standard deviations on the DBA were calculated and compared across schools through an independent t-test to look for statistically significant differences in performance between students in the two schools.

Secondly, the 13 questions that were direct learning targets taught in the planetarium (because the DBA included earth science concepts in addition to the space science targeted by the planetarium) were analyzed by conducting a separate independent samples t-test of this sub-score. Furthermore, the remaining 12 questions that were not planetarium-specific were analyzed across schools as another way to capture potential group differences that could be controlled for when looking at planetarium outcomes. Thirdly, the six-questions taken from the DBA and used as the retention quiz were 
compared across schools to evaluate students' knowledge and whether a statistical difference existed after three months. A comparison between schools' DBA scores, a closer analysis of the subset, and the retention quiz provided insight into the possible association between the planetarium and student learning.

\section{Delayed learning survey}

The use of the DBA and evaluation of the subsets of questions, alongside the measurement of retention over time, may not have fully captured the planetarium's direct role in student learning. For this reason, students were asked to complete a delayed survey, which directly asked them if they felt that the planetarium helped them learn astronomy. The results of this survey provided a triangulation for more confidence in interpreting results of how the planetarium, specifically, may have affected students.

\section{Daily formative assessments, observations and field notes}

The qualitative data analysis came from observations and recording of the daily planetarium experiences and formative assessments. An observation protocol was established for daily observations (Appendix J), field notes were taken each day, and the program was audio-recorded. A combination of what was said, how it was said, interactions, and how students answered their daily assessment questions provided insight into the effect of the experience on students, in their attitudes, learning, and thinking about astronomy.

Once observations, field notes, and assessments were transcribed, the researcher performed coding on the major a priori themes of this study: the three contexts of the guiding theoretical framework (i.e. personal, physical, and sociocultural) and specific mention of daily topics. Student responses were also analyzed for statements that could 
lead to emerging codes that pointed towards shifts in students' attitudes, the process of students' thinking (reasoning with) about astronomy, and students' learning (acquisition of knowledge) of content from the planetarium experience.

After initial coding by the primary researcher, a second science education doctoral student not associated with the planetarium was recruited as an independent coder for these qualitative data. There are multiple benefits of a doctoral student acting as the secondary coder: they are a knowledgeable source, they are unbiased toward the research, and it allowed inter-rater reliability (IRR) to be calculated.

A random sample of student work, representing approximately $10 \%$ of the total responses, was selected and coded by the second doctoral student using the set of a priori themes from the Contextual Model of Learning. Once completed, the accuracy of coding between the independent coders was compared with the goal of achieving an acceptable IRR of at least $80 \%$. After the first round of coding responses there was only $54 \%$ agreement, which was well below the desired IRR. A second round of coding took place with the coders working in collaboration. After discussion of the differences amongst the original sample $(n=106)$, approximately $20 \%$ of those responses $(n=22)$ were recoded and a $91 \%$ IRR was obtained. The final piece of establishing good IRR was crosschecking another sample of student responses at a later date to avoid rater drift. During this final comparison of coding responses $(n=25)$, an IRR of $87 \%$ was obtained.

\section{Data Reduction}

Reductions in data were needed on two different data collection methods in this study. The SATA had four subscales: affective, cognitive competence, value, and difficult, which originated from the factor loading of the 34 question survey. Within this 
study, students at two schools completed the attitude survey two times (pre and postunit). The 34 questions were reduced into six subscales through factor analysis, which were similar to original subscales. Next, the results were compared from pre to post within each school and the surveys were also compared on the pre and post between schools.

Secondly, daily formative assessments (observations and student end-of-day quick responses to a daily prompt) made up a large portion of the overall data and needed to be reduced significantly. In total, there were approximately 18 hours of audio recordings, transcription of daily planetarium shows, and transcription of students' answers. Daily, there were between 230-270 students that participated in this study and completed an assessment each day of the program $(n=1007)$. The main method of recording important happenings, while reducing the data while inside the planetarium, occurred through transcription of specific actions of students that informed the physical context and interactions between student-student and student-teacher, which informed the sociocultural context.

Amongst this amount of student data the main goals were to identify specific examples, within the three contexts of the CML, of students' attitudes, students' thinking, and students' learning. The starting point for deciding what data to keep for further analyses was based on certain key words and phrases that pointed toward evidence for each of these goals (Appendix J). Beyond the mere mention of key words and phrases, the researcher coded the data, worked with an independent coder to assist in the process and establish a strong set of codes/themes (Creswell, 2009), and used member checking for increased accuracy in the interpretation of findings from the qualitative data 
(Creswell, 2009). Once emerging themes for each goal were identified, condensed, and further revised over time, the sheer amount of transcribed data was reduced considerably.

\section{Qualitative Reliability}

Smagorinsky (2008) proposed two options for the coding of data: independent coding and collaborative coding. The independent coder method was chosen with a researcher and an independent coder separately coding the data. Independent coding occurs when the researcher establishes codes, trains a second coder on the process, and then allows the second coder to independently work with a percentage of the data. This coding scheme is often used in qualitative data analysis and an accepted value of agreement within the research community is $80 \%$ (e.g. Heppner, Wampold, \& Kivlighan Jr., 2007; Miles \& Huberman, 1994; Smagorinsky, 2008).

By having an unbiased, non-planetarium doctoral student contribute to the coding of qualitative student responses, it increased the inter-rater reliability of the results. Creswell (2009) supports and recommends the use of crosschecking codes by a second coder to improve the qualitative reliability within a study. The independent coder was not aware of visualizations used within the planetarium and did not experience firsthand what was observed by the researcher. This meant that coding was based only on what the students wrote, as opposed to reading into students' comments based on what was observed or through knowing what they were referring too by experiencing the daily program.

\section{Generalizability}

Generalizability is not normally the goal of qualitative research because these research studies aim to describe a particular event(s) or individual(s) in context within the 
study (Creswell, 2013). In the mixed methods design used for this study, there was a unique setting where students learned science. In a sense, the students at Hickory H.S. were a collective case study to find out how the novel environment of a planetarium helped shape students' thinking and learning. Yin (2003) "feels that qualitative case study results can be generalized to some broader theory" (p. 193). The results of the research could be generalized because high school students across the world are studying science, visiting planetariums, and informal science education is important in improving students' science experiences.

\section{Validity}

In entering into this study, I considered my role as a planetarium educator and what I have observed with school groups over the prior three years. I have experienced the excitement as students of all ages visit the planetarium for field trips. As an educator in this type of informal science institution, I have witnessed changes in knowledge over the course of a 90-minute field experience. To manage any potential researcher bias in this study, the data collection and analytic techniques used in this study were designed to reduce researcher bias and improve data interpretation through the triangulation of data sources and the use a secondary coder for consistent coding of student responses.

The findings of this study were trustworthy because (a) appropriate data collection methods were reported in detail; (b) reliability procedures were followed through inter-rater reliability of qualitative student responses; and (c) validity strategies were used: triangulation (e.g. confirming positive student attitudes through delayed survey, teacher input, and researcher observations), member checking (e.g. mention of learning on daily assessments and later asked about learning on delayed survey), and 
clarifying my biases (Creswell, 2009). Since the qualitative data composed a large part of the data analysis, audio recordings and daily assessments required attention to detail to arrive at the most accurate interpretations. Data were reduced through selective transcription and illustrative examples of students' responses to the planetarium and answers provided on daily assessments were presented. Although reduced, data were not used only for arriving at preferred conclusions and disconfirming data were not ignored, as seen by negative student comments and disagreement on the delayed survey in regards to the role of the planetarium for them.

In the spirit of conducting fair research and without consideration for my own expectations, disconfirming data of the planetarium experience will be considered in the analysis of the role of the planetarium on students studying astronomy. Disconfirming, or discrepant data, was defined by Smagorinsky (2008) as, "unrepresentative of the corpus as a whole and that raise questions about available generalizations" (p. 397). Any discrepant data will be included through graphical representations of students' responses in upcoming chapters for readers to see that the experience may not have been beneficial for all students. I would find it interesting if the planetarium did not have a positive impact on students' affective and cognitive domains, but would be inclined to evaluate my research methods, conduct the study with other groups of students (e.g. racial diversity, different ages), follow up with students through in-depth interviews, and devise another way to study how planetariums may influence students' understanding of or thinking about astronomy. 


\section{CHAPTER IV: RESULTS}

\section{Introduction}

This chapter begins with an overview of the sample sizes for each quantitative data source since sample sizes varied throughout the study. Next, a review of the data collected during the study and an analysis of the data are included for each research question of the study. These analyses correspond to the research questions that guided this study:

1. How are students' attitudes influenced by an embedded planetarium experience while studying astronomy?

2. How does an embedded planetarium experience during an astronomy unit influence students' learning (acquiring knowledge) and retention of concepts?

3. How does the planetarium influence students' thinking (reasoning about concepts) about astronomical concepts?

\section{Quantitative Sample Sizes}

Over the course of this study, participant sample sizes varied by day and by school. In addition to varying sample sizes, not all data sources were used at both schools to collect necessary data. Data were collected from Hickory H.S. (treatment group) and Bayside H.S. (comparison group) to compare students' attitudes and learning of content knowledge, while other data sources were unique to the planetarium context and thus not available to use with the comparison school. Student thinking and the 
process of learning were only measured with Hickory students because the planetarium was a key component of their astronomy unit. The amount of data collected from each school (Table 3) and more detailed information about the qualitative data collected from students at Hickory H.S. are presented below.

\section{Table 3}

Quantitative Data Sample Sizes

\begin{tabular}{ccc}
\hline & Hickory H.S. & \multicolumn{2}{c}{ Bayside H.S. } \\
\cline { 2 - 3 } \cline { 3 - 3 } Instrument & \multicolumn{2}{c}{ Sample size $(n)$} \\
\hline Pre-unit attitude survey & 215 & 145 \\
Post-unit attitude survey & 138 & 124 \\
Pre-unit content assessment & 211 & 139 \\
District benchmark assessment & 209 & 134 \\
Context bucket voting & 201 & -- \\
Top 7 Ranking List & 172 & -- \\
Retention Quiz & 209 & 109 \\
Delayed planetarium survey & 162 & -- \\
\hline
\end{tabular}

The reason for greater participation within Hickory H.S. was due to the in-school planetarium, the previous collaborative relationship, and teacher-driven interest in better understanding how the planetarium impacts their students. The students from Hickory H.S. were distributed across seven periods and three science teachers, while Bayside H.S. students were distributed across four periods and only one teacher. Data sources were collected at both schools with the exception of the bucket voting, the top 7 ranking list, and the delayed planetarium survey since students at Bayside did not receive any planetarium instruction while learning astronomy. 


\section{Student Attitude Analysis}

In the context of this study, attitude is defined as a way of thinking or feeling about something. A goal of this research was to measure if students would experience a shift in attitude after learning astronomy. Students at both schools were surveyed to measure attitudes towards science and astronomy (the primary focus) at the beginning of the science unit and then surveyed at the conclusion of the unit to determine if any shifts occurred. Significant attitude shifts between schools from pre to post was of particular interest to examine the role of the planetarium on students who had the embedded planetarium experience.

\section{Survey of attitudes towards astronomy $(S A T A)$}

SPSS Statistics Version 24 was used to conduct an exploratory factor analysis (FA) using principal axis factoring (PAF). The FA acted as a data reduction technique and identified the underlying dimensions of students' responses on the SATA. The PAF used oblique rotation (Promax) on 34 items on the pre-attitude survey $(n=360)$, which allowed factors to be correlated. A Cronbach alpha equal to 0.691 was obtained for the pre-survey overall, which indicated that questions grouped similarly with this sample of students as it did with others who have completed the $S A T A$; the reported Cronbach alpha for an earlier study was 0.760 (Zeilik, 2012). Prior to analyzing the data with SPSS, the data were screened and the majority of assumptions were met, with the exception of a small amount of questions not being normally distributed. Also, the recommended sample size of at least 300 , or 10 cases per item was met for the pre-survey FA, but was slightly under on the post-survey FA. 
After the initial FA of the entire pre-SATA, the decision was made to remove four items due to not loading into any of the six components retained (\#7, \#30, \#31, and \#32). A Cronbach alpha of .701 was obtained for the smaller subset of 30 questions. The Kaiser-Meyer-Olkin measure of sampling adequacy equaled 0.891 , which indicated that the data were suitable for PAF. Bartlett's Test of Sphericity was statistically significant, with a chi-square value $=4284.4, p<.0001$. In considering the number of factors to retain, the Kaiser-Guttman rule (eigenvalues > 1.0) for factor extraction (Kaiser, 1991) and evaluation of the Scree plot (Thompson, 2004) were used.

The pattern matrix was examined and items with loadings greater than 0.3 were retained as recommended by Stevens (1996). The six factors in the FA accounted for approximately $46.5 \%$ of the total variance and communalities on the 30 items ranged from 0.23 to 0.73 . Table 4 reports the details of the factor structure, including the researcher-designated name for the factors, which questions loaded in each factor, communalities of items, the Cronbach alpha for each factor, and the percentage of variance accounted for by each factor.

\section{Table 4}

Factor Structure of pre-SATA

\begin{tabular}{lcccc}
\hline Factor & $\begin{array}{c}\text { Questions } \\
\text { loaded }\end{array}$ & $\begin{array}{c}\text { Communalities } \\
\left(h^{2}\right)\end{array}$ & $\begin{array}{c}\text { Cronbach } \\
\alpha\end{array}$ & $\begin{array}{c}\% \\
\text { Variance } \\
\text { explained }\end{array}$ \\
\hline Personal_Negative & 15 & .610 & .89 & $25.73 \%$ \\
2 & .522 & & \\
6 & .508 & & \\
& 17 & .408 & & \\
5 & .525 & & \\
14 & .523 & & \\
9 & .546 & & \\
28 & .479 & & \\
& .569 & & \\
& &
\end{tabular}




\begin{tabular}{|c|c|c|c|c|}
\hline & 26 & .599 & & \\
\hline \multirow[t]{6}{*}{ Science_Negative } & 25 & .439 & .74 & $7.62 \%$ \\
\hline & 33 & .384 & & \\
\hline & 11 & .309 & & \\
\hline & 4 & .390 & & \\
\hline & 21 & .543 & & \\
\hline & 23 & .336 & & \\
\hline \multirow[t]{2}{*}{ Personal_Positive } & 20 & .703 & .82 & $4.92 \%$ \\
\hline & 29 & .638 & & \\
\hline \multirow[t]{5}{*}{ Astronomy_Easy } & 3 & .380 & .63 & $3.98 \%$ \\
\hline & 34 & .320 & & \\
\hline & 1 & .274 & & \\
\hline & 24 & .309 & & \\
\hline & 27 & .481 & & \\
\hline \multirow[t]{5}{*}{ Astronomy_Difficult } & 13 & .494 & .68 & $2.17 \%$ \\
\hline & 8 & .333 & & \\
\hline & 12 & .329 & & \\
\hline & 18 & .233 & & \\
\hline & 19 & .358 & & \\
\hline \multirow[t]{2}{*}{ Personal_Enjoyment } & 10 & .729 & .85 & $2.04 \%$ \\
\hline & 16 & .665 & & \\
\hline
\end{tabular}

Using the factor structure above, the six factors were forced into a FA of the postsurvey to compare question grouping and shifts in students' attitudes at the conclusion of the science unit. All retained factors $(n=30)$ remained the same, but they did not load in the same positions (e.g. Personal_Positive loaded $3^{\text {rd }}$ on the pre-survey and $5^{\text {th }}$ on the post-survey). However, the initial factor structure determined for the pre-survey was also a reasonable fit for the post-survey.

Table 5 includes data from both high schools and whether any statistically significant attitude changes occurred from pre to post within each school using dependent $t$-tests. Also, statistically significant differences comparing pre-pre and post-post between schools were calculated using independent samples $t$-tests. A decrease in rating from pre to post-survey on Personal_Negative, Science_Negative, and Astronomy_Difficult indicated a positive shift, while an increase in rating on 
Personal_Positive, Astronomy_Easy, and Personal_Enjoyment indicated a positive shift for students over the course of the astronomy unit.

Table 5

Pre to Post Attitude Rating Changes

\begin{tabular}{|c|c|c|c|c|c|c|c|c|}
\hline \multirow[b]{2}{*}{ Factor } & \multicolumn{2}{|c|}{$\begin{array}{l}\text { Hickory }(\mathrm{H}) \\
\text { Mean rating } \\
(\mathrm{SD})\end{array}$} & \multirow[b]{2}{*}{$p$} & \multicolumn{2}{|c|}{$\begin{array}{c}\text { Bayside (B) } \\
\text { Mean rating } \\
(\mathrm{SD})\end{array}$} & \multirow[b]{2}{*}{$p$} & \multicolumn{2}{|c|}{ H-B comparison } \\
\hline & Pre & Post & & Pre & Post & & Pre- $p$ & Post- $p$ \\
\hline $\begin{array}{l}\text { Personal_ } \\
\text { Negative }\end{array}$ & $\begin{array}{l}2.45 \\
(.80)\end{array}$ & $\begin{array}{l}2.45 \\
(.86)\end{array}$ & .67 & $\begin{array}{l}2.62 \\
(.77)\end{array}$ & $\begin{array}{l}2.38 \\
(.89)\end{array}$ & $.04^{*}$ & $.05^{*}$ & .53 \\
\hline $\begin{array}{l}\text { Science_- } \\
\text { Negative }\end{array}$ & $\begin{array}{l}2.42 \\
(.74)\end{array}$ & $\begin{array}{l}2.65 \\
(.68)\end{array}$ & $<.01^{*}$ & $\begin{array}{l}2.70 \\
(.68)\end{array}$ & $\begin{array}{l}2.63 \\
(.82)\end{array}$ & .31 & $<.001^{*}$ & .82 \\
\hline $\begin{array}{l}\text { Personal_- } \\
\text { Positive }\end{array}$ & $\begin{array}{l}3.39 \\
(.64)\end{array}$ & $\begin{array}{l}3.98 \\
(.88)\end{array}$ & $<.001^{*}$ & $\begin{array}{l}3.16 \\
(.63)\end{array}$ & $\begin{array}{l}3.98 \\
(.96)\end{array}$ & $<.001^{*}$ & $<.01^{*}$ & .94 \\
\hline $\begin{array}{l}\text { Astronomy } \\
\text { _Easy }\end{array}$ & $\begin{array}{l}2.89 \\
(.59)\end{array}$ & $\begin{array}{l}3.08 \\
(.71)\end{array}$ & .07 & $\begin{array}{l}2.91 \\
(.69)\end{array}$ & $\begin{array}{l}3.14 \\
(.73)\end{array}$ & $.02^{*}$ & .79 & .51 \\
\hline $\begin{array}{l}\text { Astronomy } \\
\text { _Difficult }\end{array}$ & $\begin{array}{l}3.39 \\
(.64)\end{array}$ & $\begin{array}{l}3.12 \\
(.67)\end{array}$ & $<.01^{*}$ & $\begin{array}{l}3.16 \\
(.63)\end{array}$ & $\begin{array}{l}3.10 \\
(.76)\end{array}$ & .38 & $<.01^{*}$ & .77 \\
\hline $\begin{array}{l}\text { Personal_} \\
\text { Enjoyment }\end{array}$ & $\begin{array}{l}3.73 \\
(.96)\end{array}$ & $\begin{array}{c}3.42 \\
(1.08)\end{array}$ & $<.01^{*}$ & $\begin{array}{c}3.19 \\
(1.03)\end{array}$ & $\begin{array}{c}3.37 \\
(1.13)\end{array}$ & .28 & $<.001^{*}$ & .70 \\
\hline
\end{tabular}

Note: * Indicates a statistically significant difference in means within or between schools, $p<.05$, two-tailed, unequal variances. Higher numbers on the post-survey indicated stronger agreement with the factor, either positive or negative.

Hickory H.S. (treatment school) survey results. These students showed statistically significant shifts on 4 out of 6 factors: Science_Negative, $t(137)=2.89$, attitudes indicated that students felt science/astronomy were not as useful or relevant as they thought before the unit; Personal_Positive, $t(137)=5.99$, shifted and students felt that they learned astronomy/science; Astronomy__ifficult, $t(137)=3.61$, indicated that students did not think astronomy was as complicated, technical, or required memorization 
as they originally thought; and Personal_Enjoyment, $t(137)=2.99$, resulted in students not enjoying astronomy as much at the conclusion of the unit.

Bayside H.S. (comparison school) survey results. Bayside H.S. students' scored significantly different on 3 out of 6 factors: Personal_Negative, $t(123)=2.11$, indicated that they did not find science/astronomy as difficult as they initially thought they would; Personal_Positive, $t(123)=7.70$, results showed that students learned science/astronomy during the unit; and Astronomy_Easy, $t(123)=2.40$, pointed towards students feeling that science/astronomy concepts were easier to understand than they thought before the unit.

Hickory - Bayside survey comparisons. When comparing students from each school, there were five factors where statistically significant differences existed on the pre-survey: Personal_Negative, $t(315.94)=-2.02$; Science_Negative, $t(326.15)=-3.81$; Personal_Positive, $t(314.31)=3.37$; Astronomy_Difficult, $t(314.31)=3.37$; and Personal_Enjoyment, $t(295.27)=5.00$. These differences indicated that Hickory students were more comfortable entering into the science unit and they felt more confident in their ability to learn astronomy/science. Although astronomy may require discipline and new ways of thinking, they thought they would enjoy the course more than students at Bayside.

After analysis of the six components on the post-survey, no statistically significant differences existed in students' attitudes. These results indicated that students at both schools had similar attitudes about science and astronomy at the conclusion of their science unit. 


\section{Delayed student survey}

In order to gather specific student attitudes dealing with the planetarium and its role in enjoyment and learning of astronomy, rather than astronomy in general, which is likely strongly influenced by course experiences external to the planetarium, students were given a time-delayed two-question survey using Google Forms. This delayed survey allowed time to pass, new science content to be studied, and students needed to reflect back to their astronomy unit and the four-day planetarium experience. These responses yielded direct insight about the planetarium rather than science and astronomy in general, which may have been the primary thinking when students completed the original SATA. Figure 6 represents students' perceptions about enjoyment (attitude) and Figure 7 represents students' perceptions about learning in the planetarium.

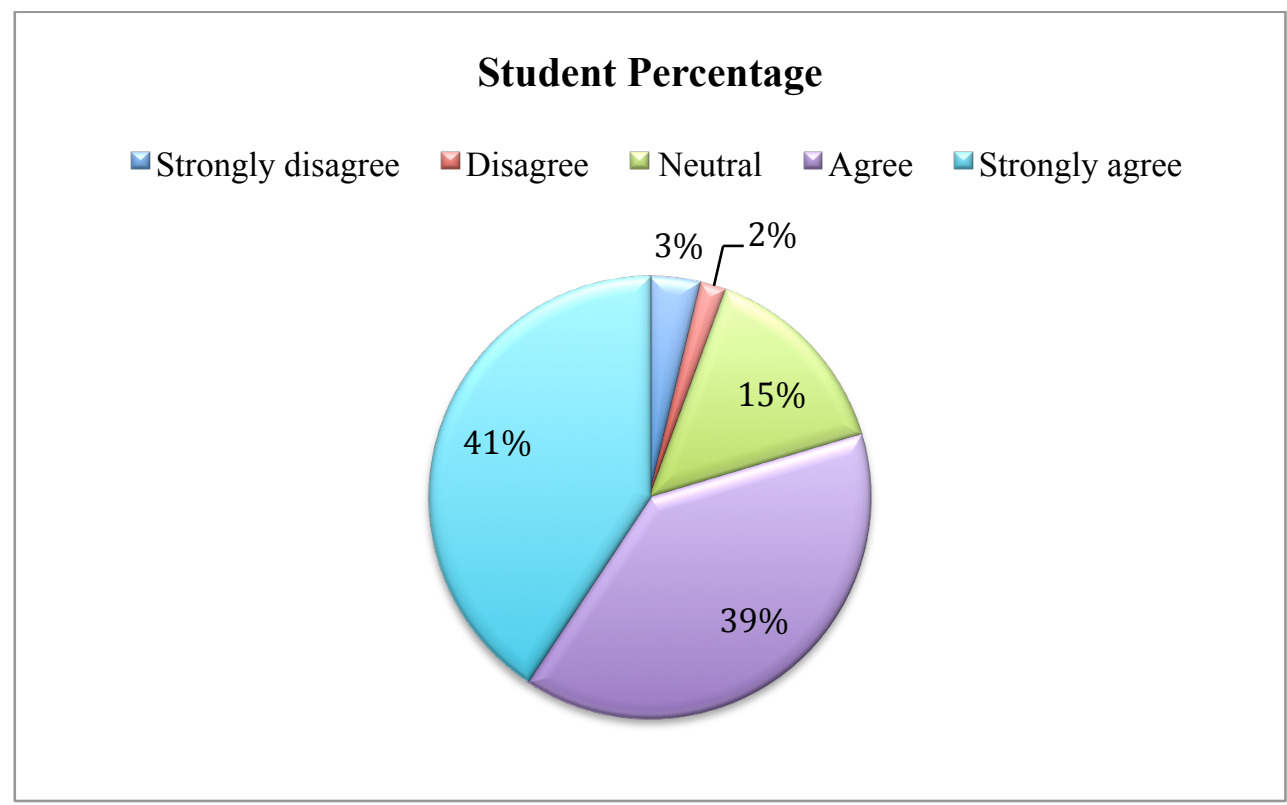

Figure 6. Planetarium Enjoyment

(I enjoyed astronomy because of our time in the planetarium.) 


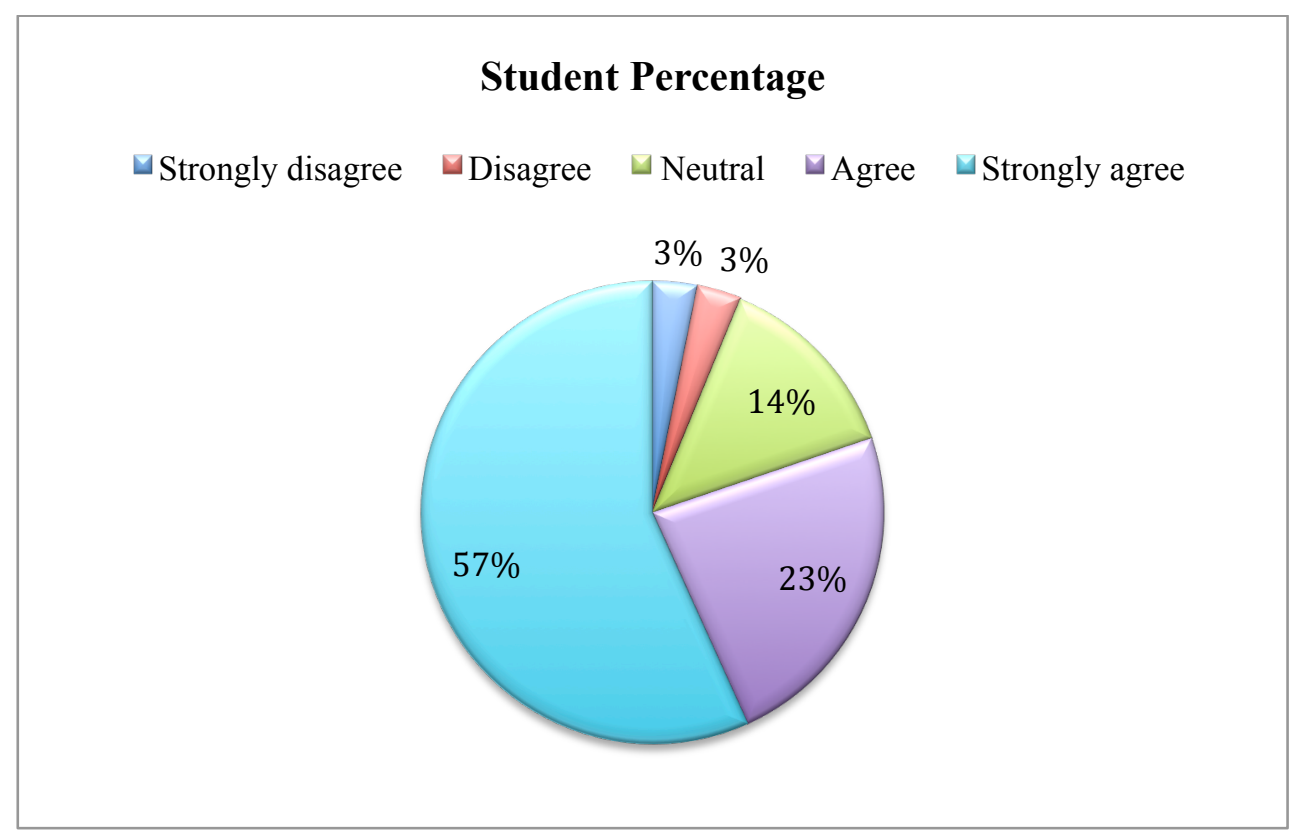

Figure 7. Planetarium Learning

(The planetarium helped me learn astronomy.)

As seen in the figures above, it was evident that the planetarium played a powerful role for students in Hickory H.S. Approximately $80 \%$ agreed or strongly agreed that they enjoyed astronomy because of the planetarium that they learned due to the planetarium. Only nine students out of the entire sample disagreed or strongly disagreed with the enjoyment statement and 10 disagreed or strongly disagreed with the learning statement, which meant that the planetarium did not play an important part in their enjoyment or learning during the course. These perceptions of students' own enjoyment and learning are promising for the positive role that the planetarium played during this study with the treatment group.

\section{Teacher outlook - student attitude}

Teachers reported positive feedback about the planetarium program and said that students were more excited about astronomy upon returning to the classroom. Teachers 
observed an increase in students' interest because of the planetarium program and their students voiced that they wanted to return to the planetarium to learn more.

\section{Student Learning Analysis}

In this study, learning is defined as the acquisition of knowledge through experience, study, or by being taught. Learning from the planetarium was measured by evaluating students' performance on a number of assessments.

\section{Pre-unit content assessment}

The pre-unit content assessment included 10 questions that paralleled concepts studied within the science course and were selected based off of questions on the DBA (Table 6). The assessment was written by planetarium educators, approved by high school teachers, and administered to students through Google Forms.

\section{Table 6}

\section{$\underline{\text { Pre-Unit Content Assessment Data }}$}

\begin{tabular}{lcc}
\hline & Hickory H.S. & Bayside H.S. \\
\cline { 2 - 3 } Question & \% correct & \% correct \\
\hline 1 & 75.4 & 58.3 \\
2 & 74.4 & 58.3 \\
3 & 5.20 & 21.6 \\
4 & 18.5 & 23.7 \\
5 & 52.1 & 39.6 \\
6 & 30.3 & 23.0 \\
7 & 25.6 & 28.1 \\
8 & 34.6 & 40.3 \\
9 & 18.5 & 24.5 \\
10 & 35.5 & 21.6 \\
Avg. \% correct (SD) & $37.0(23.5)$ & $33.9(14.6)$ \\
\hline
\end{tabular}


As was mentioned in the description of participants in the school district, students at Hickory H.S. have outperformed Bayside H.S. students on a statewide, standardized science test (Biology End of Course Assessment) by an average of approximately $20 \%$ over the past six years. On this assessment measuring entry science knowledge of participants in this sample, Hickory H.S. students scored higher on 5 of the 10 questions. A two-sample means $t$-test resulted in $t(346.3)=1.53, p=0.94$, indicating that this group of Hickory students were statistically similar in science achievement with Bayside students.

\section{District benchmark assessment (DBA)}

Table 7 includes multiple statistical tests that were conducted on questions from the DBA, which included 25 questions covering Earth and Space Science. This test was used to measure students' knowledge learned from the science unit and to provide students with grades. DBA planetarium-specific questions were separated out to evaluate any differences that may have existed between schools and a subset of those questions were administered as a time-delayed retention quiz to measure retention of knowledge.

\section{Table 7}

\section{District Benchmark Assessment Data}

\begin{tabular}{lcccccc}
\hline & \multicolumn{2}{c}{ Hickory H.S. } & & \multicolumn{2}{c}{ Bayside H.S. } & \\
\cline { 2 - 3 } Test & Mean (SD) & $95 \% \mathrm{CI}$ & & Mean (SD) & $95 \% \mathrm{CI}$ & $p$ \\
\hline $\begin{array}{l}\text { DBA total } \\
(25 \text { Q) }\end{array}$ & $18.75(4.20)$ & \pm 0.58 & & $17.54(5.69)$ & \pm 0.98 & $.036^{*}$ \\
$\begin{array}{l}\text { DBA } \\
\text { planetarium } \\
(13 \text { Q) }\end{array}$ & $9.87(2.28)$ & \pm 0.31 & & $9.21(3.12)$ & \pm 0.54 & $.035^{*}$ \\
\hline
\end{tabular}




\begin{tabular}{lccccc}
\hline $\begin{array}{l}\text { DBA non- } \\
\text { planetarium } \\
(12 \text { Q) }\end{array}$ & $8.88(2.30)$ & \pm 0.32 & $8.34(2.91)$ & \pm 0.50 & .068 \\
$\begin{array}{l}\text { DBA } \\
\text { original }\end{array}$ & $4.75(1.35)$ & \pm 0.19 & $4.16(1.76)$ & \pm 0.30 & $<.01^{*}$ \\
$\begin{array}{l}\text { subset (6 Q) } \\
\text { Retention }\end{array}$ & $4.29(1.18)$ & \pm 0.16 & $3.61(1.41)$ & \pm 0.27 & $<.001^{*}$ \\
$\begin{array}{l}\text { Quiz } \\
\text { subset (6 Q) }\end{array}$ & & & & & \\
\hline $\begin{array}{l}\text { Note: CI = confidence interval, }{ }^{*} p<.05, \text { two-tailed, unequal variances } \\
\end{array}$
\end{tabular}

All $t$-tests were calculated using SPSS Statistics Version 24. Independent samples $t$-tests were used to evaluate differences between Hickory and Bayside students. Students at Hickory scored significantly higher on the overall DBA: $t(225.54)=2.11 p=.036$, on the subset of 13 planetarium-specific questions: $t(223.31)=2.12, p=.035$, on the original DBA 6 questions: $t(230.81)=3.33, p=<.01$, and on the delayed retention quiz: $t(187.58)=4.31, p=<.001$. After evaluation of the other questions on the DBA that were non-planetarium specific, there was no statistical difference in students' scores between the two schools: $t(236.77)=1.83, p=.068$.

\section{Retention Quiz}

Furthermore, paired samples $t$-tests were conducted to evaluate how students' scores within schools changed from the original DBA (6 questions) to the delayed retention quiz (same 6 questions) three months later. Hickory students decreased from 4.75 to 4.29 (a $9.7 \%$ decrease) and the $t$-test resulted in the following, $t(208)=3.92, p=$ $<.0001$. In order to conduct a paired samples $t$-test, the sample size must be equal from pre to post and therefore, an adjustment in sample size had to be made for Bayside since a small number of delayed tests were not returned. 
Due to comparing only students completing both the original and delayed retention quiz, Bayside students had an original mean and standard deviation of 4.16 (1.76), which decreased to 3.61 (1.41) on the delayed assessment. This difference equal to 0.55 points (a $13.2 \%$ decrease) equated to $t(108)=4.82, p=<.0001$. Unsurprisingly, both groups of students forgot information and performed statistically worse than before.

In order to analyze whether the retention score drop was statistically significant between groups, a $t$-test of the difference score was calculated, $t(223.9)=1.54, p=.12$. Even though the drop in scores between immediate testing and delayed testing showed no statistically significant difference, the data do show that the gap in scores between schools grew from a difference of 0.59 points higher on the original to 0.68 points higher on the retention quiz. This difference in loss of knowledge was equal to $3.5 \%$ and showed a trend towards treatment group students retaining astronomy concepts better.

In summary, treatment group students (Hickory) outperformed comparison group students (Bayside) on the planetarium-related portion for both the original and delayed retention quiz by a statistically significant margin. Also, the percentage difference in scores went from $12.4 \%$ on the original to $15.9 \%$ on the delayed assessment, which indicated that the planetarium experience may have mitigated loss of academic knowledge over time for the treatment group. Since the one major difference in instruction between students in these two schools was planetarium-enriched instruction, this provided evidence that the planetarium played a positive role in retention.

\section{Delayed student survey}

The second question included in the delayed student survey asked students to comment on whether the planetarium helped them learn astronomy (Figure 7 above). 
This direct, planetarium-specific question was important to ask and was a form of member checking and triangulation of data sources. Other data pointed towards the planetarium having a positive influence on students and helping them learn astronomical concepts. Additionally, students at Hickory who had the embedded planetarium program were able to retain knowledge at a higher rate than those not receiving planetarium instruction at Bayside.

The survey results for this question were helpful in understanding that the planetarium, specifically, did help students learn. Over $80 \%$ of student respondents agreed or strongly agreed that the planetarium helped them learn astronomy, while only 10 students $(6.2 \%)$ out of the entire sample disagreed or strongly disagreed that this was a true statement.

\section{Teacher outlook - student learning}

Teachers agreed that students liked to learn in the planetarium. They felt that students asked more questions after visits to the planetarium and also noticed that DBA scores had increased. The department head at Hickory H.S. reported that the difference in students' scores from pre-planetarium instruction during the course to scores over the past four years since the planetarium program has been in place had increased approximately $13 \%$ during that time.

\section{Student Thinking Analysis}

Thinking was defined as the process of using the mind to consider or reason about something in this study. Another major research question was to measure how the planetarium helped students think about astronomy. This goal could only be achieved by gathering data directly from the student - what was influencing or shaping their thought 
process while learning astronomy. Thinking is difficult to measure through testing, so students were given an opportunity to express what was happening on the inside (in their heads) while learning astronomy during an embedded planetarium program.

\section{Formative assessments}

Students completed daily formative assessments at the end of each planetariumbased instructional period to capture thinking in the moment based on the question: “How did today's planetarium experience give you a deeper, more interesting, or new way of thinking about...?". The qualitative statistical software program Quirkos was used to code students' responses into codes that were established by the researcher. Student responses could be categorized into a single code or into multiple codes based on the answer they provided.

The following main themes, sub-themes that emerged from the coding, and student exemplars best representing the sub-themes are provided in Table 8 . 


\section{Table 8}

\section{Inductively Developed Thematic Codes from Student Responses}

\begin{tabular}{lll}
\hline Theme & Sub-themes & Student Exemplars \\
Personal & Increased & I could see it more clearly. I got really into it. I like how I could see the constellations. I just loved how I could see
\end{tabular}

Context interest

$(n=374)$

Being in the planetarium made astronomy a lot more interesting than in class. I am a visual learner so this was great for me!

It made me realize how big and detailed the solar system is. It also got me more interested than in the classroom.

Increased It's hard to sit in class and hear our teacher talk. But being able to visually see it move REALLY helped. It gave me knowledge a way better understanding.

It helped me understand the way things work and made a better picture in my head of the Moon and Earth's tilt and rotation.

I was able to visually experience something I might never see in my life, helping me (a visual learner) understand the material better.

Revelation Today, something that connected for me was the Earth and its tilt that causes seasons. Seeing how it was always pointing at the North Star really helped me connect it.

It gave me a deeper way of thinking about human exploration of space that we do not know as much as I thought. There is tons of things that we don't even know exist and we knew very little.

It honestly hurts my head. This made me feel like not even a speck of dust to the universe. I honestly am very shocked because I didn't realize this.

Awareness I got to see things such as size comparisons and what space actually looks like. It made me think a little harder than beyond self

or beyond Earth before about what's out there and makes me want to have real life experiences with stars and planets.

I feel really small having a visual like being able to go out of the solar system helps me understand how small I really am. It gives me deeper understanding of how big everything actually is.

Seeing how vast our universe is and how undiscovered it is, is very scary. It makes me rethink everything. 


\begin{tabular}{|c|c|c|}
\hline \multirow{11}{*}{$\begin{array}{l}\text { Physical } \\
\text { Context } \\
(n=233)\end{array}$} & \multirow[t]{3}{*}{ Visualizations } & $\begin{array}{l}\text { It shows more in depth of Earth and how things happen around it. Instead of just learning about it in a classroom you } \\
\text { can see it. }\end{array}$ \\
\hline & & $\begin{array}{l}\text { I was able to get a more visual representation of what we have been talking about in class. For example, when he } \\
\text { showed us the Earth's tilt it showed me pretty much what it looks like when it rotates. }\end{array}$ \\
\hline & & It was much easier to visualize things like time zones and seasons when I can see a $3 D$ model. \\
\hline & \multirow[t]{2}{*}{$\begin{array}{l}\text { Different } \\
\text { perspectives }\end{array}$} & $\begin{array}{l}\text { The planetarium put the size of the Earth into better perspective with the use of the flying in and out and the } \\
\text { representation of the Earth in both its actual size and enlarged form. }\end{array}$ \\
\hline & & $\begin{array}{l}\text { I think showing the different phases of the Moon from different perspectives helped me visualize how I see it from } \\
\text { Earth. }\end{array}$ \\
\hline & \multirow{3}{*}{$\begin{array}{l}\text { Dynamic } \\
\text { modeling }\end{array}$} & The solar system made more sense seeing it in action and being able to see it, not just hear about it. \\
\hline & & Rotations and shadows of celestial bodies are hard to grasp without visual representations, so this helped with that. \\
\hline & & It lets you see everything work together, like when you see the Earth rotation and you see the Sun 'chase' the Moon. \\
\hline & \multirow{3}{*}{$\begin{array}{l}\text { Beyond the } \\
\text { classroom }\end{array}$} & It provided a visual integrative learning environment to allow students to visualize what they're learning. \\
\hline & & By going to the planetarium I was able to visually experience something I might never see in my life. \\
\hline & & It made the material seem more real. It's hard to make a real life connection from book material. \\
\hline \multirow[t]{7}{*}{$\begin{array}{l}\text { Scale } \\
(n=208)\end{array}$} & \multirow[t]{4}{*}{$\begin{array}{l}\text { Internal } \\
\text { perspective }\end{array}$} & $\begin{array}{l}\text { It showed the enormous size of the solar system. It made me think that we are just one small speck of dust in the } \\
\text { universe. }\end{array}$ \\
\hline & & $\begin{array}{l}\text { It provided me with a new way of thinking when we zoomed out and actually saw how small the Earth actually is } \\
\text { and how big space is. Since he kept enlarging the Earth so we knew what we were looking at. }\end{array}$ \\
\hline & & $\begin{array}{l}\text { When we were shown the distance of the Moon to the Earth, the Earth to the Sun, and so on to the observable } \\
\text { universe, it put how small we are in the grand scheme of things. It made me realize how big outer space is. }\end{array}$ \\
\hline & & $\begin{array}{l}\text { Today's experience helped me understand that not only are small things, like atoms are hard to understand, but so } \\
\text { are large things like galaxies and the universe stuff. }\end{array}$ \\
\hline & \multirow{3}{*}{$\begin{array}{l}\text { External } \\
\text { perspective }\end{array}$} & It's nearly impossible to explore the entire universe. It is incomprehensible as to how large space is. \\
\hline & & It showed the scale of the Moon and Earth. \\
\hline & & The size of space is unbelievably massive, especially since the furthest humans have traveled is to the Moon. \\
\hline
\end{tabular}




\begin{tabular}{|c|c|c|}
\hline \multirow[t]{9}{*}{$\begin{array}{l}\text { Positive } \\
\text { comments } \\
(n=101)\end{array}$} & \multirow[t]{4}{*}{$\begin{array}{l}\text { Classroom } \\
\text { comparison }\end{array}$} & $\begin{array}{l}\text { This really helped me visually see everything better. I feel like I understand everything a lot better now that I } \\
\text { actually got to see everything. I feel like I have learned a lot more today than the two weeks of classwork that we } \\
\text { have done. }\end{array}$ \\
\hline & & This brings the lesson alive and allows you to see more than just pictures. It's a live presentation. \\
\hline & & $\begin{array}{l}\text { It showed me a good perspective and view of space information. It showed me that planetariums give me a better } \\
\text { view and an overall deeper understanding. }\end{array}$ \\
\hline & & $\begin{array}{l}\text { It's hard to sit in class and hear our teacher talk. But being able to visually see it move REALLY helped. It gave } \\
\text { me a better understanding. }\end{array}$ \\
\hline & \multirow{3}{*}{$\begin{array}{l}\text { Helped thinking } \\
\text { or } \\
\text { learning }\end{array}$} & $\begin{array}{l}\text { This is probably the peak of my enjoyment of this class. Space is really interesting to me. By seeing the sizes and } \\
\text { distances, I can really imagine it in my head more easily. }\end{array}$ \\
\hline & & $\begin{array}{l}\text { Having a visual really helps me understand what my teacher talks about. A visual model that moves and can depict } \\
\text { many experiences that normally I wouldn't be able to understand. The Earth's poles are a big and good example. I } \\
\text { really didn't grasp before this presentation how the Earth was tilted. }\end{array}$ \\
\hline & & Seeing it visually makes me have a deeper understanding towards size, distance, and composition. \\
\hline & \multirow{7}{*}{$\begin{array}{l}\text { Interest in } \\
\text { science }\end{array}$} & I liked the way the presentation showed different views, not just from Earth. It kept me very interested. \\
\hline & & $\begin{array}{l}\text { Seeing what we learned is helpful and interesting. I can learn more information when I am intrigued. It's a lot } \\
\text { easier to learn when you can clearly see what you're talking about. }\end{array}$ \\
\hline \multirow{5}{*}{$\begin{array}{l}\text { Negative } \\
\text { comments } \\
(n=5)\end{array}$} & & $\begin{array}{l}\text { The idea that we should sit around and not interact is very odd. The interaction of the student is one of the most } \\
\text { important for the educational process. }\end{array}$ \\
\hline & & No, I knew all of it already. \\
\hline & & ... but couldn't focus because my neck hurts. This is cool but my neck hurts. \\
\hline & & Well, the longer I sit in the planetarium the longer I can sleep for. \\
\hline & & No, today I didn't learn anything new and it did not change my perspective. \\
\hline
\end{tabular}

Note. Many of the examples cited were coded into multiple categories. The examples included here are shown only with one of those categories. Bold and italicized sections highlight key words/phrases in student responses, which contributed to categorization into specific codes. 
A priori codes for qualitative data analysis included specific daily topics and the three contexts of the Contextual Model of Learning (Falk \& Dierking, 1992; 2000). A detailed list of key words and phrases used to categorize students' responses is included in Appendix J. The 1,007 student responses collected yielded 1,454 codes because of the possibility of responses falling into multiple categories. In fact, only 162 student responses $(11.1 \%)$ were only coded into a single category.

The following examples are provided to give insight into the decision-making for placing responses into specific categories.

Student response: "It helped me understand the way things work and made a better picture in my head of the Moon and Earth's tilt and rotation."

Researcher categorization: Response included 'it helped me understand' (personal); 'made a better picture in my head of the Moon (personal and Moon); and 'Earth's tilt and rotation" (Earth).

Researcher interpretation: The planetarium was able to show the Moon's size relative to the Earth; enlarge the Moon for easier observation and for viewing Moon phases from both an Earth-based and space perspective; and position students in space so they could view the Earth on it's tilt and observe its rotation. The combination of flying students off of the Earth's surface and taking them into space to observe objects, showing different perspectives, and dynamic modeling of objects in space contributed to this student's thinking about what they had previously learned about space and through their daily experiences, which helped them understand better (Personal - increased knowledge). 
Student response: "When we were shown the distance of the Moon to the Earth, the Earth to the Sun, and so on to the observable universe, it put how small we are in the grand scheme of things. It made me realize how big outer space is."

Researcher categorization: Response included 'shown the distance of the Moon to the Earth, the Earth to the Sun, and so on...' (flight and physical); 'it put how small we are in the grand scheme of things and how big outer space is' (scale); and 'it made me realize' (personal)

Researcher interpretation: Although this student did not specifically mention flight, an inference was made about the flight simulation due to the student's linguistic construction of "to the Earth, to the Sun, and to the observable universe.” The immersive planetarium environment and ability to fly helped put the scale of distance in space into better perspective for this student and impacted them personally to influence their thinking about humans and our planet in comparison to what else is out there (Scale - internal perspective).

Table 9 includes specific examples of various interactions between studentstudent, student-teacher, and student responses to the environment and what they experienced that took place during the planetarium program. These interactions and reactions represent the social component of the sociocultural context. Additionally, examples of visualizations students observed and discussed within the planetarium and how they connected to real-world experiences are included. These represent the cultural component of the sociocultural context. This overview provides insight into the presence of the sociocultural context and how it may have influenced students. 


\title{
Table 9
}

\section{Examples of the Sociocultural Context $(n=104)$}

\author{
Student (S) - $\quad$ T - "What will happen to our Sun in the future?" \\ teacher (T) S - "It will become a red giant." \\ interactions \\ T - "Why is there an aurora at the North Pole?" \\ $\mathrm{S}-$ "The magnetic field is stronger at the ends." \\ $\mathrm{S}$ - "Why is the Moon visible during the day sometimes?" \\ $\mathrm{T}$ - "It is visible at different times (day or night) based on where the Moon is in \\ relation to the Earth and Sun."
}

\section{Interpretation}

Interactions representing the presence of questions and answers between students and teacher, which are typically absent in traditional planetarium settings. Students were actively involved each day of the program through questioning and discussions allowing them to have a more personal investment in learning.

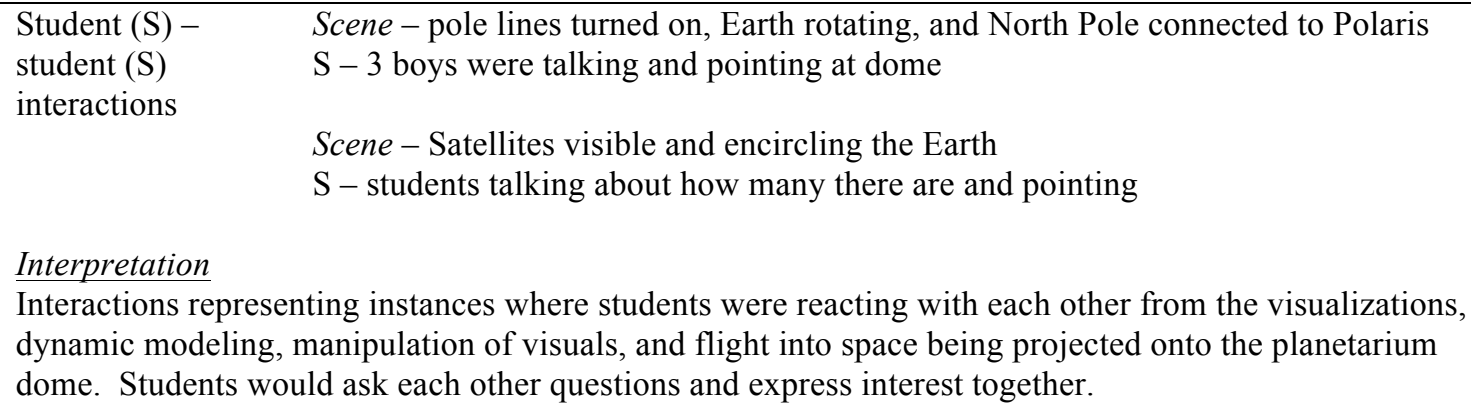

\section{Interpretation}

Interactions representing instances where students were reacting with each other from the visualizations, dynamic modeling, manipulation of visuals, and flight into space being projected onto the planetarium dome. Students would ask each other questions and express interest together.

$\begin{array}{ll}\begin{array}{l}\text { Student (S) } \\ \text { responses to } \\ \text { planetarium }\end{array} & \begin{array}{l}\text { Scene - night sky in motion with constellation lines turned on } \\ \text { S - pointing and saying "cool' }\end{array} \\ & \begin{array}{l}\text { Scene - flight to the Oort Cloud } \\ \text { S - "That's crazy" in response to visual }\end{array} \\ & \begin{array}{l}\text { Scene - Flight off of Earth's surface } \\ \text { S - "That's really cool" }\end{array} \\ & \text { Scene - flight through space and mentioning distances in space } \\ \text { S - "Dang" }\end{array}$

\section{Interpretation}

Verbal reactions and whistles by students were common over the four days and represented the engagement with the instructional space and interest in what was being projected onto the planetarium dome.

\begin{tabular}{|c|c|}
\hline \multirow[t]{2}{*}{$\begin{array}{l}\text { Real-world } \\
\text { connection }\end{array}$} & $\begin{array}{l}\text { Students have observed the Moon often over time and they know the Moon's phases } \\
\text { change. Students were shown the Moon from Earth and space perspective, the } \\
\text { Moon's orbital pathway around the Earth, and video simulations of the Moon's } \\
\text { creation (post-Theia collision with Earth). }\end{array}$ \\
\hline & $\begin{array}{l}\text { The planetarium visualizations revisited prior knowledge of the Moon, provided } \\
\text { different perspectives to strengthen students' understanding of every day phenomena, }\end{array}$ \\
\hline
\end{tabular}


and introduced them to the origin of the Moon and what is projected to happen in the future.

In combination, the planetarium was able to help students take something that they already knew about (the Moon), expand their knowledge (why things happen), and gave them new things to think about (what if we did not have the Moon)

\section{Qualitative coding}

Although gender was not a focal point of this study, the breakdown of male and female compared in their responses is included as well (Appendix K). These responses were collected from the daily formative assessments given over the four-day embedded planetarium program. The distribution of comments across gender was virtually identical within the 21 categories used for coding student responses.

The two categories to note where males and females differed were scale and positive/negative. Scale was mentioned by males 27 more times than females, or by $16.2 \%$ of males and $13.7 \%$ of females. The positive category included student comments that captured positive aspects and feelings about the planetarium. Any student comment that did not support use of the planetarium or implied dislike was placed in the negative category. In combination, female students had a greater number of positive comments $(50$ total $=9.5 \%)$ and zero negative feelings toward the experience. In comparison, male students had only 40 positive comments $(6.5 \%)$ and five negative comments $(0.8 \%)$.

A future direction of research could look more closely at the role of the planetarium on males and females and how they may differ in their processing of the experience and their ability to assimilate new knowledge.

The three contexts of the Contextual Model of Learning (CML) (Falk \& Dierking, $1992 ; 2000)$ were evident in a large percentage of the total number of responses personal context $(25.4 \%)$, physical context $(15.8 \%)$, and sociocultural context $(7.1 \%)$. 
Another major theme that garnered over 200 comments $(14.1 \%)$ from students and was mentioned on all four days of the planetarium program was scale. Although scale was an underlying concept embedded throughout the program, it was not a target concept and not explicitly stated until the third day.

Within each theme that emerged from the analysis of all 1,454 comments, the use of similar verbiage and ideas led to the creation of sub-themes. The sub-themes captured students' inner thinking and reactions to the planetarium environment and visualizations. The student exemplars chosen for inclusion in Table 8 were representative of the subthemes and provided evidence for the role of the planetarium in supporting student thinking. From observational data and the shear number of positive comments collected from students, the embedded planetarium program seemed to have a positive effect on students. An additional avenue of future research could study the connection between students' experiences within the planetarium and how they perform on an examination of course content, allowing to measure learning outside of the traditional testing format.

The number of comments where students mentioned interest, understanding, thinking or re-thinking, making connections, and 'seeing it happen' were coded in the positive theme and were support of the embedded experience being positive for students. The overwhelming number of positive responses included comments about the personal impact on them, the physical space of the planetarium, and the capabilities within that space that are not possible within the traditional classroom. Moreover, out of 1,454 comments only five comments included something negative $(<0.4 \%)$. Considering that students were able to speak freely about their experience, the lack of negative responses suggests that students were pleased with the planetarium. The lack of negativity also acts 
as triangulation for the role of the planetarium on students' attitudes and helping them think and learn astronomy.

\section{Top 7 ranking list}

On the final day of the 4-day planetarium program, students were given a list of 7 planetarium instructional features and asked to rank in order from most important (1) to least important (7), "What about the planetarium has helped you in thinking about or understanding astronomical concepts?" The top seven list was compiled by the researcher, the planetarium director, and were items mentioned in planetarium research as being important aspects of this type of informal science institution (ISI) - immersive environment, dynamic modeling, and scale (Littmann, 2009); immersive environment (Yu, Sahami, Sahami \& Sessions, 2015); offering different perspectives (Chastenay, 2015); and motion (dynamic modeling) and scale (Plummer, 2014b, 2014c).

The top seven also included flight through space, manipulation of time, and separated scale into two distinct categories - size and distance. Table 10 includes the frequency count and weighted average of each item, which showed what students thought were most important in helping them think about astronomy (lower number $=$ more impactful on thinking and understanding). Additionally, the delta weighted average column represents the difference in ranking between planetarium characteristics.

\section{Table 10}

\section{Ranking of Top 7 List}

\begin{tabular}{ccccccccccc}
\hline \multicolumn{10}{c}{ Student Ranking } \\
\cline { 2 - 8 } & 1 & 2 & 3 & 4 & 5 & 6 & 7 & $\begin{array}{c}\text { Weighted } \\
\text { Average }\end{array}$ & $\begin{array}{c}\Delta \\
\text { Weighted } \\
\text { Avg. }\end{array}$ \\
\hline
\end{tabular}




\begin{tabular}{lccccccccc}
\hline Flight & 46 & 26 & 17 & 31 & 15 & 12 & 25 & 3.46 & -- \\
Scale - size & 22 & 42 & 29 & 28 & 12 & 21 & 18 & 3.59 & 0.13 \\
$\begin{array}{l}\text { Scale }- \\
\text { distance }\end{array}$ & 26 & 26 & 30 & 33 & 30 & 18 & 9 & 3.61 & 0.02 \\
$\begin{array}{l}\text { Immersive } \\
\text { environment }\end{array}$ & 28 & 20 & 38 & 21 & 25 & 24 & 16 & 3.76 & 0.15 \\
$\begin{array}{l}\text { Dynamic } \\
\text { modeling }\end{array}$ & 21 & 27 & 26 & 17 & 24 & 33 & 24 & 4.11 & 0.35 \\
$\begin{array}{l}\text { Different } \\
\text { perspectives }\end{array}$ & 15 & 19 & 21 & 23 & 40 & 33 & 21 & 4.38 & 0.27 \\
$\begin{array}{l}\text { Manipulation } \\
\text { of time }\end{array}$ & 14 & 12 & 11 & 19 & 26 & 31 & 59 & 5.09 & 0.71 \\
\hline
\end{tabular}

Note. A lower weighted average indicated more importance for students

The results showed that students felt more strongly about 4 of the 7 planetarium characteristics. The planetarium's ability to fly through space was ranked in the top two by $41.9 \%$ of students. Students got to experience flight to and landing on objects in space, flight around objects for more detailed observations, and flight between objects from the Earth, all the way out to the edge of the observable universe. The two types of scale were highly ranked in the top two as well. Size (37.2\%) and distance (30.2\%) indicated that students' thinking was influenced by the planetarium's ability to represent scale more accurately and provide them with more insight into the size of objects in comparison to others and how far apart objects were in space. The immersive environment of the planetarium was also ranked in the top three by $50 \%$ of students. The unique environment made students feel as if they were in space, which was important for their thinking about and understanding of astronomy.

On the contrary, students ranked three aspects of the planetarium lower than the others in helping them think about astronomy. Different perspectives was ranked in the top two by only $19.8 \%$, compared to $31.4 \%$ of students ranking it in the bottom two. 
Although the planetarium is capable of showing students the same phenomena from multiple perspectives (e.g. sunrise from Earth and sunrise from space), this was less of a factor for helping them think about and understand astronomy. Manipulation of time was even less of a factor for students' thinking; only gathering $15.1 \%$ of votes in the top two and $52.3 \%$ at the bottom. The control of time to speed up naturally occurring processes (e.g. the length of a day, month, or year) to make observations easier did not have as strong of an impression on students as other factors during this embedded planetarium program.

Individual rankings were combined to form the overall weighted average for the group and the delta-weighted average showed the differences between items. According to Tretter, Jones, Andre, Negishi, and Minogue (2006), the differences between average rankings can be interpreted as a conceptual boundary (or distinction) between items across a group. The results showed that the first four characteristics were conceptually close to each other (range 0.02 - 0.15). Much larger differences appeared between the last three items (range $0.27-0.71$ ), creating a clear distinction between items. Grouplevel responses on this ranking list resulted in two categories and conceptual boundaries of spatial scale.

\section{Bucket voting}

The CML includes three contexts (as well as a time dimension) and purports that the interaction and overlapping of contexts shapes students' learning experiences in informal science institutions (ISIs). In this embedded planetarium program, the personal context included students' pre-unit knowledge, their interest in astronomy content, and how they processed and assimilated new information that was presented to them on a 
daily basis. The physical context included being in the unique planetarium space, which included different lighting, background music, a domed-structure that enabled 3D dynamic modeling, and a very different learning environment than the traditional classroom. The sociocultural context, which is normally absent in a traditional planetarium setting, included within-group (students) and between-group (studentteacher) interactions, which was encouraged by intentional questions embedded during each day's storyline. Furthermore, the coherent storyline was created to connect the shared planetarium experience with students' real-world lived experiences.

Students received a bingo chip on the final day and were asked to vote for which aspect of the planetarium experience was most impactful on them. Three buckets were placed in the rear of the planetarium at the exit and each included a short student-friendly narrative that represented a context of the Contextual Model of Learning (CML) (Falk \& Dierking, 1992; 2000). With the CML being the guiding framework of this study, it was important to gather students' opinions on which context was most important for them over the four-day embedded planetarium program. Table 11 includes the context and total number of student votes in each.

The physical context narrative stated, "The immersive environment and the dome shape making you feel like you are in space." The unique planetarium space is unlike anything students have experienced in a classroom. Next, the personal context said, "Understanding daily Earth observations (e.g. day/night, seasonal changes) better through flight into space." The capabilities of the planetarium affect how students are able to process and assimilate knowledge into their own mental model. Lastly, the sociocultural context was represented by, "Important astronomy concepts woven within a 
storyline." The storyline was created to build from simple to complex concepts, encourage interactions to promote learning, and provide continuous flight for students to tap into mentally for greater understanding of the world around them.

\section{Table 11}

$\underline{\text { CML Context Votes }}$

\section{Context}

\begin{tabular}{lccc}
$\begin{array}{l}\text { Sample } \\
(n=201)\end{array}$ & Physical & Personal & Sociocultural \\
\hline $\begin{array}{l}\text { Number of student } \\
\text { votes }\end{array}$ & 122 & 45 & 34 \\
$\begin{array}{l}\% \text { of total sample } \\
\text { n }\end{array}$ & $60.7 \%$ & $22.4 \%$ & $16.9 \%$ \\
\hline
\end{tabular}

The results of the bucket voting made it clear that students were influenced differently over the four-day planetarium program, but each context played an important role for students. As posited by the CML, given that all contexts received substantial votes from the student sample, the combination, or overlap, across all of these contexts is likely to be the most impactful than any one context in isolation. This overlap of contexts and how they affect students differently should not be overlooked by ISIs if they are to reach students and teach most effectively.

\section{Teacher outlook - student thinking}

Teachers identified that one of the greatest benefits of the planetarium was teaching students about large-scale processes (e.g. galaxies, inflation, distance scale, and size scale). They reported that these were traditionally the most challenging topics for students to synthesize. The planetarium allowed teachers to reference certain visualizations or simulations to help students think about these concepts and make 
connections. Teachers reported that these references to the planetarium program helped make topics from the textbook and classroom discussions more understandable for their students.

\section{Summary of results}

The planetarium-enriched instruction within the treatment school had a positive influence on students. First, evidence from surveys and interviews provided evidence that students enjoyed the experience and had positive attitudes about their time learning within the planetarium. Secondly, the data from various quantitative assessments, teacher interviews, a delayed survey, and student responses on daily formative assessments suggested that students learned from the planetarium program. Thirdly, daily formative assessments suggested that students were able to think about astronomy in new and different ways due to the visualizations within the planetarium. Improvement in students' ability to think about astronomical concepts was supported by classroom teacher comments. These results and the implications of results will be discussed further in the next chapter. 


\section{CHAPTER V: DISCUSSION}

\section{Organization of Chapter}

The discussion section will continue in the same order of the research questions that guided this study and how data were presented throughout chapter 4: students' attitudes, students' learning, and students' thinking about astronomy. Following discussion of the results, implications on planetariums, science education researchers, and teachers and schools will be presented. The final pieces of chapter 5 will include recommendations for future research and a conclusion of the study.

\section{Purpose of the Study}

This study aimed to answer the following questions about the role of an embedded planetarium experience on students during an astronomy unit.

1. How are students' attitudes influenced by an embedded planetarium experience while studying astronomy?

2. How does an embedded planetarium experience during an astronomy unit influence students' learning (acquiring knowledge) and retention of concepts?

3. How does the planetarium influence students' thinking (reasoning about concepts) about astronomical concepts? 


\section{Attitudes Similar Across Groups \\ Instrument overview}

Students' attitudes about science and astronomy were initially measured using the Survey of Attitudes Towards Astronomy (SATA) (Zeilik, 2012). The survey was intended to establish a baseline of students' attitudes towards science/astronomy, gauge interest and ability in science/astronomy, and identify their beliefs about the value and difficulty of science/astronomy. The $S A T A$ had a reported Cronbach alpha reliability coefficient equal to 0.76 , which indicated the 34 questions had acceptable internal consistency (Tavakol \& Dennick, 2011).

In this study, a factor analysis (FA) was conducted to identify the underlying components of the SATA for this group of participants. The results of the FA led to the removal of four items and yielded six factors that were retained and thus named: Personal_Negative, Science_Negative, Personal_Positive, Astronomy_Easy, Astronomy_Difficult, and Personal_Enjoyment. The Cronbach alpha values of the survey as well as the individual factors were previously presented in chapter 4 and were similar to the reported reliability of the instrument.

\section{Within-school attitudes}

Hickory H.S. (treatment) students. At the conclusion of the unit and completion of the post-SATA, students' attitudes showed statistically significant changes in 4 out of 6 factors. These shifts equated to the following: students had more negative views of the role of science and astronomy in their lives than before; students did not think astronomy was as technical, complicated, or involved memorization as much as they originally had thought; the group did not enjoy the class as much as they thought they were going to at 
the beginning; and students felt even more strongly compared to the pre-SATA that they learned science and astronomy concepts, which was the greatest shift in attitude amongst all factors.

When looking at the attitude shifts that did and did not occur over the course of the nine-week unit, multiple factors may have contributed to the results. First, the number of attitude surveys completed was different $($ pre $=215$, post $=138)$, which could have impacted the direction of attitude shifts. If a group of students that were more positive or negative about science and astronomy, or if students were high or low in academic ability completed the post-survey, results would have been skewed one way or the other. Secondly, students participating in this study were enrolled in a course taught by one of three teachers. Although teachers were similar in qualifications and used the same curriculum design, personal differences and varying pedagogical decisions could have altered students' experiences in the course, thus influencing the direction of the attitude shifts observed for each factor of the survey. Lastly, the survey measured attitudes about science and astronomy overall, not attitudes specifically about the planetarium and the role it played in students' experiences.

Bayside H.S. (comparison) students. Students experienced statistically significant attitude changes in 3 out of 6 factors. These shifts in attitude meant that students were more positive about their abilities to take this course, astronomy was not as difficult as they originally perceived it to be, and that they were able to learn and understand science and astronomy over the course of the unit.

Since students at Bayside did not receive any planetarium instruction, this survey may have accurately measured their attitudes and shifts in attitude due to their direct 
experience in the course. The students that participated in this study could also have provided a more accurate pre to post-comparison of attitudes due to having the same teacher, experiencing the same teaching methods, and knowing the instructor and expectations on a similar level. Additionally, the number of attitude surveys completed $($ pre $=145$, post $=124)$ was similar and the responses came from the same group of students. This likely resulted in a more accurate representation of attitudes by measuring the same students' attitudes, regardless of their original feelings about their personal ability, opinions about the difficulty of the discipline, or enjoyment of science.

\section{Between-school comparison}

Pre-SATA. Overall, this indicated that students at Hickory H.S. were more confident about their ability to manage the course and learn, they had more positive views of science and astronomy, they thought they would enjoy the unit more, but those students also felt that astronomy would be difficult to learn entering into the unit.

Based on school achievement and state standardized science testing in biology, it was a reasonable assumption for students at Hickory H.S. to be more confident in their ability to succeed academically and be more capable of conquering an astronomy unit without as much stress or fear. These schools also varied in socioeconomic status, which may have contributed to students' views of school, the amount of time spent on studying and completing schoolwork, and resources available for students at each school.

Post-SATA. The post-SATA $p$-values indicated that there were no significant differences in attitudes on any factors between students at Hickory and Bayside at the conclusion of the science unit. These results of the attitude survey lend support that participating students in this study were more similar than the district's population of 
students in the two schools. With students being substantially similar on these affective measures, it was helpful for parsing out whether the planetarium had a meaningful impact on students at Hickory H.S. when comparing learning and thinking between groups.

\section{Delayed attitude survey}

After analysis of students' responses and evaluation of the underlying dimensions identified in the $S A T A$, it was determined that the survey may not have measured the desired outcome, specifically for students at Hickory H.S., who experienced the planetarium. This group likely completed the survey while thinking about astronomy overall and most likely in the context of the typical, classroom-based instruction about astronomy rather than the planetarium-enhanced portion during the unit.

In order to obtain a more direct measure for how the planetarium influenced students' attitudes, a delayed survey was given and students commented on the following prompt that explicitly asked them to consider the planetarium portion of the astronomy instructional experience: I enjoyed astronomy because of our time in the planetarium. Over $80 \%$ of responses by more than 160 students agreed or strongly agreed that they enjoyed the unit because of the four-day embedded program. By this measure, the students clearly indicated that the planetarium experience contributed to positive student attitudes.

\section{Student attitude summary}

While attitudinal outcomes could be attributed to various things, such as different teaching styles or to the type of student completing the post-attitude survey, it was important to note that the similar post-unit attitudes towards science and astronomy were an outcome supporting a claim that these two student populations were similar in affect 
towards astronomy. Students at these two schools take the same Earth and Space Science class, learn the same astronomy content, and take the same assessment based on an intradistrict collaboration of science teachers.

The primary goal of teachers was to provide a similar learning experience by teaching the same content and testing key indicators (important concepts). Because attitudes are often an important covariate in how students perform academically (Ames \& Archer, 1988; Freedman, 1997), the outcome that the two groups of students in this study have similar attitudes about the course strengthens any interpretations about academic outcomes that are due to non-attitude factors, such as a planetarium-embedded instructional experience.

Although results of the $S A T A$ revealed attitude similarities between groups, it was not able to parse out the role of the planetarium in influencing students' attitudes during the astronomy unit. In order to obtain specific thoughts about the planetarium, Hickory students completed a short survey asking them to specifically comment on the role of the planetarium for them. The results of that survey were extremely positive and students reported that they did enjoy and learn from the embedded planetarium experience.

Classroom teachers and researcher observations provided further support for the planetarium having a positive effect on students' attitudes. Teachers reported that students seemed more excited, interested in the content, they asked more questions, and wanted to go back to the planetarium to learn astronomy. Researcher observations captured positive responses as students entered the planetarium each day. Also, during the program students were engaged (e.g. looking up at the dome, getting comfortable in preparation for the program) and comments were those of excitement (e.g. wow, cool, 
awesome, whistles). Table 12 provides a summary of treatment and comparison student attitudes at various times during this study.

\section{Table 12}

\section{Attitude Summary}

\begin{tabular}{ll}
\hline Instrument & \multicolumn{1}{c}{ Results } \\
\hline Pre-SATA & $\begin{array}{l}\text { Analysis of the survey dimensions yielded mixed results } \\
\text { across the two groups of students. }\end{array}$ \\
Post-SATA & $\begin{array}{l}\text { The survey resulted in treatment and comparison group } \\
\text { students having similar attitudes about astronomy. This } \\
\text { minimizes the possibility that any academic differences might } \\
\text { be due to attitudinal differences between students. }\end{array}$ \\
Delayed student & $\begin{array}{l}\text { More than 80\% of students had a positive view of astronomy } \\
\text { because of the planetarium experience. }\end{array}$ \\
Rurvey & $\begin{array}{l}\text { Researcher observations supported that students' attitudinal } \\
\text { behavior over the 4-day planetarium program was positive. }\end{array}$ \\
Teacher interviews & $\begin{array}{l}\text { Teacher responses about student attitudes toward the } \\
\text { planetarium were positive and students looked forward to } \\
\text { more time in the planetarium. }\end{array}$ \\
\hline
\end{tabular}

\section{Academic Differences Not Due to Attitude}

\section{Instrument overview}

Student learning was measured through a variety of assessments covering topics generated from the school curriculum. A pre-content assessment was developed to identify a baseline of astronomy knowledge of students at both schools before studying astronomy, which allowed for comparison of students' scores. This assessment included curriculum-based concepts in which students would be tested on at the conclusion of the unit.

A district benchmark assessment (DBA) developed by science teachers at both high schools was used to measure student learning. The DBA was an important 
summative assessment for schools, as well as an important district tool for co-planning and aligning course curricula. The overall score (25), a subset of planetarium-specific questions (13), a subset of non-planetarium questions (12) and a further subset of DBA questions (6) were evaluated for statistically significant differences between schools. Furthermore, students were given the subset of six questions months later to examine how well students at both schools retained the astronomy content they had learned.

Other planetariums and schools would want to consider their circumstances and design tests appropriate for their unique situations. In regards to validity within this study though, the pre-content assessment arose from the co-planning of the planetarium program, course curriculum, and was constructed by planetarium experts. These factors added face (or consequential) validity to the pre-content assessment. Secondly, high school teachers constructed the DBA and it was used to measure students' progress based on key indicators of the curriculum. This ensured that the content of the questions was aligned with course objectives, which added curricular validity (specific to these high schools) to the instrument.

Pre-content assessment. The results of the 10-question pre-content assessment showed that the treatment students (Hickory) and comparison students (Bayside) scored similarly on astronomy content prior to the instructional unit. This offered evidence that comparisons of post-unit academic content performance across these two groups would be appropriate for interpreting if the planetarium experience (the primary instructional difference) may have had a different academic impact. 
District benchmark assessment (DBA). The DBA scores on the overall post-unit assessment showed that Hickory students scored statistically higher than Bayside students on the planetarium-related half of the unit assessment, but that on the non-planetarium half the two groups scored similarly, which strengthened the case that students were academically the same.

These data suggested that the planetarium played a positive role in student learning, interpreting the difference in planetarium-related DBA performance between students was a result of one group receiving planetarium instruction. This interpretation is strengthened by two other results reported in chapter 4: the two student groups scored similarly on the pre-unit assessment, and the post-unit measure of non-planetarium content showed that the two groups were statistically similar in performance on that portion of the post-unit assessment. Thus, a reasonable interpretation is that the planetarium-based instruction was responsible for the documented stronger academic performance by the treatment group on the planetarium-related portion of the districtdesigned post-unit assessment.

Additional support for the positive role of the planetarium on student learning came from the comparison of students' scores on six questions from the original post-unit assessment to their scores on the same six questions three months later. These six questions had been classified into one of three difficulty categories - high, medium, or low - based on the original percentage correct by all students who took the DBA. Then, they were selected for analysis because they had a higher cognitive demand than the remaining seven questions. 
Students who had an embedded planetarium experience during the astronomy unit scored statistically better than the comparison students on this subset of questions on the original post-unit assessment by a margin of 0.59 points. When students completed the 3-month delayed 6-question retention quiz, the difference in scores remained statistically significant and the gap in achievement increased from 0.59 to 0.68 points in favor of treatment students. The percentage increase in scores from original to retention by the treatment students suggests a trend that the planetarium experience may bolster long-term retention of astronomy concepts. More research on this possibility is needed in order to establish if this in fact is an outcome from instruction with a planetarium-embedded astronomy experience.

Student delayed survey. In order to gather more insight into the relationship between the planetarium and how it may have influenced students' academic learning, a 3-month delayed survey was given and students were asked to directly comment on the question of academic learning from the planetarium experience by responding to: The planetarium helped me learn astronomy. Over $79 \%$ of students that experienced the four-day planetarium program agreed or strongly agreed that the planetarium did help them learn astronomy, which supports the interpretation of the positive planetarium impact that was drawn from both the immediate post-unit academic measure as well as the positive trend of better long-term retention.

Classroom teachers agreed that through a well-coordinated program customized to specific core curriculum, students craved more planetarium time and learned more as a result of the multi-day program. The co-planning resulted in teachers being able to provide specific references from the planetarium when teaching difficult topics, which 
helped students learn material better than reading from a textbook or through classroom discussions. The next section identifies impactful features and affordances of the planetarium for how the instruction-embedded planetarium experience may have been responsible for the stronger academic learning.

\section{Student learning summary}

Table 13 includes a review of each instrument used to measure student learning in this study, the differences in student learning that existed between treatment and comparison group students, and the overall results of how students performed on various assessments.

\section{Table 13}

Learning Summary

\begin{tabular}{|c|c|c|c|}
\hline Instrument & $\begin{array}{l}\text { Diff } \\
\text { in } S \\
\text { Ler }\end{array}$ & $\begin{array}{l}\text { ences } \\
\text { ident } \\
\text { ing }\end{array}$ & Results \\
\hline & Yes & No & \\
\hline $\begin{array}{l}\text { Content pre- } \\
\text { assessment }\end{array}$ & & $\mathrm{X}$ & $\begin{array}{l}\text { Scores showed participants from treatment and } \\
\text { comparison groups were similar in entry astronomy } \\
\text { knowledge. }\end{array}$ \\
\hline $\begin{array}{l}\text { Post-unit scores on } \\
\text { non-planetarium } \\
\text { DBA questions }\end{array}$ & & $\mathrm{X}$ & $\begin{array}{l}\text { Test results showed that treatment and comparison } \\
\text { groups performed similarly on non-planetarium } \\
\text { related questions. }\end{array}$ \\
\hline $\begin{array}{l}\text { Post-unit scores on } \\
\text { planetarium DBA } \\
\text { questions }\end{array}$ & $\mathrm{X}$ & & $\begin{array}{l}\text { Test results showed that students in the treatment } \\
\text { group scored significantly higher on planetarium- } \\
\text { specific questions. }\end{array}$ \\
\hline Retention quiz & $\mathrm{X}$ & & $\begin{array}{l}\text { The results tended toward greater retention of } \\
\text { astronomical concepts for treatment group students } \\
\text { over students in the comparison group. }\end{array}$ \\
\hline $\begin{array}{l}\text { Student delayed } \\
\text { survey }\end{array}$ & $\mathrm{X}$ & & $\begin{array}{l}\text { More than } 79 \% \text { of students in the treatment group } \\
\text { attributed academic learning to the planetarium } \\
\text { experience. }\end{array}$ \\
\hline
\end{tabular}




\section{Planetarium Influenced Students' Thinking}

\section{Instrument overview}

During this science unit, students were learning astronomy concepts including: the names, order, and characteristics of planets; types of stars; the location of objects in space and how scientists study interactions. Students can learn space science concepts such as these through memorization techniques and then regurgitate that information on a test; however, students can struggle with larger-scale processes (e.g. the formation of our solar system, galaxies, scale) and their ability to think about such topics can be stretched. Space science can capture imagination, interest, and students can develop a deeper comprehension by being placed in an environment that immerses them in space and accurately models what they read about in textbooks.

The final research question of this study was to go beyond learning (as a product) through the evaluation of test scores and to gain insight into the minds of students as they participated in an embedded planetarium experience. In attempts to understand learning (as a process) and how students were thinking about these concepts each day, students were asked to answer daily questions about the role of the planetarium. Students' comments led to the identification of themes and sub-themes that began to paint a picture of what within the planetarium was important for them.

In addition to daily formative assessments, students also completed two other tasks at the conclusion of the embedded planetarium program. Each task provided further insight into the role of the planetarium in helping students think about and learn astronomy. First, a list of planetarium characteristics was constructed by the researcher (a planetarium educator) and the director of the planetarium; and was supported by other 
planetarium experts from a review of the literature. Students were asked to review a list of seven characteristics of the planetarium and rank them according to how each helped them think about or understand astronomical concepts $(1=$ most important, $7=$ least important).

Lastly, after the final day in the planetarium, students were asked to vote for which aspect of the planetarium program design was most important for them. Three buckets were placed in the rear of the planetarium and as students exited, they placed a bingo chip into the bucket that was most helpful for their thinking or learning. The bucket labels represented each context of the Contextual Model of Learning (Falk \& Dierking, 1992; 2000) - personal context, physical context, and the sociocultural context (Appendix G). These data helped inform the study how the planetarium and the program influenced students from the student perspective and added value in the interpretation of the results.

\section{Formative assessments}

The interpretation of students' responses to daily post-instruction formative assessments was informed by the Contextual Model of Learning (Falk \& Dierking, 1992; 2000), which guided this study.

Personal context. Based on over 1000 student responses to daily post-instruction prompts, the planetarium experience helped students think about space from the human and Earth perspectives and helped them realize the vastness and scale of space. The findings showed that the planetarium affected students in a personal way, which was coded 374 times. Despite any initial differences in prior experiences, knowledge, and interests, "one should expect new learning to be scaled to the realities of an individual's 
motivations and expectations" (Falk \& Storksdieck, 2005, p. 746). Regardless of the program structure, material studied, or the level of choice and control students have while learning, their personal context will be influenced differently.

Sub-themes were identified and included the different ways the planetarium had a positive impact on students' views and understanding of astronomy. Students had more positive attitudes, more interest than when learning in the classroom, and they were able to make valuable connections. The shared planetarium experience helped students think about space from various perspectives and promoted thinking about astronomy differently than in the classroom.

The interpretations of the personal context sub-themes can be attributed to the uniqueness of the planetarium environment. It captures students' interest and engages them in learning experiences that are difficult (or not possible) to replicate in a traditional classroom. The visualizations shown on the dome captivate students' imaginations and make them feel like they are flying through space. Immersing them in virtual space has a positive effect on attitudes toward learning the material, which leads to greater understanding of concepts in astronomy.

The live presentation, visuals, and storyline brought many students to personal revelations on how small they were, as many mentioned feeling like a speck, or they commented on things they did not know beyond our planet. The planetarium depicted the scale of size and distance beyond what students had ever experienced, leading to an appreciation for the amount of knowledge scientists have about space. The realization that humans are very small in the grand scheme of things and that Earth is not very big in 
comparison to other objects in space is support that the planetarium gave students something that the traditional classroom had not.

Physical context. Comments about the planetarium being a different learning experience, one that enhanced their understanding of concepts by being able to visualize them, were common amongst students. The unique educational experience that students received through the multi-day program increased students' overall awareness of astronomy and how they (and humans) fit into the bigger picture.

By being able to see these processes and fly through space, students got a better feel for the size of objects, the scale of distance between objects in our universe, and they observed phenomena from various perspectives. This allowed students to have a more clear idea of cause and effect relationships and why we experience what we do on our planet. The overlapping of digital planetarium characteristics exposes students to content differently than the classroom and strengthens how students process and think about concepts. Flight through space intersects with showing multiple perspectives, the representation of scale overlaps with different perspectives, and the ability to fly intersects with scale, which allows students to grasp astronomical concepts in a more meaningful way. In fact, the representation of scale by the planetarium was so impactful on students that it was coded more than 200 times.

The digital projection system placed students in an immersive experience where they got to observe movement and interactions between objects in space. This dynamic modeling was helpful for students to observe and make sense of these interactions between objects. As mentioned above, an overlap of planetarium capabilities (e.g. flight and dynamic modeling) strengthens students' thinking about and understanding of 
concepts. Many students also commented that just being in the planetarium, not in the classroom, was beneficial for them. In fact, some even mentioned the dim lighting, soothing background music, and that the planetarium made the material seem more real. Overall, the physical context of the planetarium had an extremely positive effect on students and their ability to learn and think about astronomy.

Sociocultural context. Traditionally, planetariums are not conducive for question and answer time or discussions between students and docent (or planetarium educator or system operator). There are a number of reasons for this lack of interaction in planetariums: (a) students are seated in rows and all facing the same direction; (b) a group could be separated across a large space; (c) the docent, educator, or system operator is located in the rear of the dome; (d) field trip time may be limited; and (e) it is dark, which makes it difficult to field questions or to call on students.

Other factors frequently minimizing the sociocultural context for visitors are that planetariums often offer pre-packaged shows (e.g. a movie and a tour of the night sky) and may be led by educators who are not particularly experienced in delivering pedagogically-targeted instruction to K-12 students. A pre-packaged show simply requires the push of a button from a system operator and students sit and watch and listen. Although these shows can be high-quality, scientifically accurate, and engaging for students, this type of field trip does not give students an opportunity to interact with peers or adults. If students are able to ask questions and interact with a docent, the level of knowledge the docent possesses and how he/she responds to student inquiries are important. Unlike using professional educators who would use questioning strategies to elicit student thinking, answer questions in an age-appropriate manner, or have specific 
expertise in teaching this subject matter, a docent may fall short by not having a background in education.

In this study, the sociocultural context was observed from the moment students entered the planetarium until they were dismissed. Students' comments, body language, questions, and answers were observed and recorded during the four-day program.

Furthermore, the program was specifically designed to include dialogue and discussion throughout and encourage teacher-student interactions when appropriate. As certain visualizations were projected onto the dome, or important DBA-related concepts were being taught, the planetarium educator would ask for student input. Students were also encouraged to ask questions, which allowed the planetarium educator to go 'off script' in order to address those areas of interest.

The storyline created and shared during the planetarium program connected to students' lived experiences. Providing rich visualizations of objects and processes in space in which students were familiar and building from the Earth-based perspective helped students connect the learning to their own experiences first, and make sense of prior thinking. The ability of the planetarium to create continuous transitions and fly students into space allowed them to extend their mental model from their own direct experiences and think about space science more comprehensively from a number of spatial and time perspectives.

Overall, the social component of the sociocultural context collected 104 coded responses, which included student-student interactions, student-teacher interactions, and student responses to the planetarium. Students seemed to enjoy the program and appreciated when the instructor asked questions. With an experienced educator leading 
the program, he was able to engage students and create a favorable atmosphere for learning. Although this context is where traditional planetariums may struggle to reach students in a meaningful way, this study did have success in promoting interactions as much as possible to create a more positive experience for students.

The cultural component of the sociocultural context was not specifically written about by students, but due to the carefully designed storyline and pre-planned visualizations, students' comments did include this aspect. Students discussed a variety of concepts where they gained better understanding, they were able to think about concepts in a new or different way, or they were able to make connections due to the planetarium. These comments supported the positive role of the planetarium and the ability of this embedded program to connect to their lived experiences and make astronomy come alive.

\section{Instruction Simultaneously Engaging Multiple Contexts}

On the final day, students reviewed a list of what digital planetariums are capable of providing that are difficult to provide while learning astronomy in a classroom. Students were asked to rank each item on the list based on how important they were in influencing their thinking and understanding of astronomical concepts. Students ranked the planetarium's ability to fly a viewer's perspective through space, as most influential, followed by the ability of the planetarium to more accurately represent the scale of size and distance, and then learning within an immersive environment. These features of the planetarium may be synergistic and provide multiple avenues for students to build conceptual understanding of astronomical concepts. 
These findings support the important overlap of the personal, physical, and sociocultural contexts when students visit a planetarium. It was possible to show continuous, coherent transitions between objects in space, which gave students a more personal connection to their surroundings. Also, the transitions helped students develop a better grasp on scale and recognize how small humans are and how big the universe is. Had this group of students not been immersed in such a physical environment, they would not have been able to think about and understand astronomy as meaningfully. Furthermore, the introduction to various perspective and flight was able to give students new things to think about and connect with everyday experiences.

Students' daily responses confirmed an overlap of the three contexts because many of them were coded into multiple context categories. In order to identify which context had the greatest influence on their experience, students were asked to place a vote into one "bucket", which forced students into a single vote. The bucket options were: (a) Understanding daily Earth observations (e.g. day/night, seasonal changes) better through flight into space (Personal context), (b) The immersive environment and the dome shape making you feel like you are in space (Physical context), and (c) Important astronomy concepts woven within a storyline (Sociocultural context). The findings from 201 student votes showed that the physical context received the most votes $(60.7 \%)$, the personal context was second (22.4\%), and the sociocultural context was third $(16.9 \%)$.

These results highlighted the absolute importance of the physical space that the planetarium offered for students. Students commented on lighting, background music, the setting in comparison to the classroom, and the planetarium's ability to project captivating visualizations. The physical structure of the dome made it possible for 
students to feel like they were flying through space and gave students greater appreciation for the scale of size and distance. The immersive environment of the planetarium was novel, it was engaging, and students voted it as the context most influential on their thinking and learning.

These findings also demonstrated the important role that the personal and sociocultural contexts have on students' thinking and learning since they both received substantial percentages of the forced vote. Students were able to make personal connections and build knowledge during the planetarium experience due to the capabilities of the planetarium. Virtual flight through space took students directly to certain planets, areas in space, and allowed them to visualize interactions between objects. Students perceived that they were able to learn by observing such things, rather than having to imagine them.

The opportunity for students to listen and learn content through a pre-planned storyline was influential on a substantial number of participants and helped them connect the shared planetarium experience with real-world happenings. Although the sociocultural context received the least amount of votes, it cannot be viewed as unimportant in the process of creating the most beneficial learning experience for students. In addition to a storyline, the need for planetariums to include discussion points and question and answer time could add value to the services they provide for visitors. This study included a co-created, well-designed program with embedded questions and discussion opportunities built in. This design had a positive influence on students' thinking and learning within their sociocultural context. 


\section{Importance of Addressing all Three Contexts Simultaneously}

Table 14 provides a review of the role of each context within the research questions guiding this study and student outcomes - attitude, learning, and thinking. This brief summation highlights the importance of overlapping contexts on students' experiences in the planetarium.

\section{Table 14}

Student Outcomes Situated Within Contexts of the CML

\begin{tabular}{|c|c|c|}
\hline RQ & Context & Student Outcomes \\
\hline \multicolumn{3}{|l|}{ Attitude } \\
\hline & \multirow[t]{2}{*}{ Personal } & $\begin{array}{l}\text { There was greater interest in learning astronomy in } \\
\text { the classroom reported by teachers. }\end{array}$ \\
\hline & & $\begin{array}{l}\text { Students expressed positive feelings when able to } \\
\text { make connections between content in the classroom } \\
\text { and the planetarium program. }\end{array}$ \\
\hline & \multirow[t]{2}{*}{ Physical } & $\begin{array}{l}\text { Students asked teachers about returning to the } \\
\text { planetarium and teachers reported that students } \\
\text { were excited to learn in the planetarium. }\end{array}$ \\
\hline & & $\begin{array}{l}\text { There were daily positive responses and comments } \\
\text { upon entering planetarium and seeing visualizations } \\
\text { and simulations on the planetarium dome. }\end{array}$ \\
\hline & \multirow[t]{2}{*}{ Sociocultural } & $\begin{array}{l}\text { Many positive interactions between students and } \\
\text { with the instructor were observed and recorded by } \\
\text { the researcher and planetarium instructor. }\end{array}$ \\
\hline & & $\begin{array}{l}\text { Student reactions to and written responses to } \\
\text { visualizations showed that connections were made } \\
\text { with the real world occurrences. }\end{array}$ \\
\hline \multirow[t]{3}{*}{ Learning } & \multirow{3}{*}{ Personal } & \\
\hline & & $\begin{array}{l}\text { There were many student comments indicating that } \\
\text { the planetarium helped them understand a concept } \\
\text { better. }\end{array}$ \\
\hline & & $\begin{array}{l}\text { Students obtained a better grasp of scale and } \\
\text { understood their place in the solar system, galaxy, } \\
\text { and universe. }\end{array}$ \\
\hline
\end{tabular}




\begin{tabular}{|c|c|c|}
\hline & Physical & $\begin{array}{l}\text { The visualizations helped students see, rather than } \\
\text { imagine what they were learning about. }\end{array}$ \\
\hline & & $\begin{array}{l}\text { Students expressed that the planetarium was a } \\
\text { different and better space to learn astronomy than } \\
\text { in the classroom. }\end{array}$ \\
\hline & Sociocultural & $\begin{array}{l}\text { Students' ability to ask questions for clarification } \\
\text { helped them build greater foundational knowledge. }\end{array}$ \\
\hline & & $\begin{array}{l}\text { Students were able to answer instructor questions } \\
\text { and display their conceptions and misconceptions } \\
\text { on various topics. }\end{array}$ \\
\hline & & $\begin{array}{l}\text { Student comments indicated that they knew things } \\
\text { happened, but now understand why those things } \\
\text { happen on Earth. }\end{array}$ \\
\hline \multicolumn{3}{|l|}{ Thinking } \\
\hline & Personal & $\begin{array}{l}\text { Students were able to think about astronomy } \\
\text { processes in a new, different, or more interesting } \\
\text { way in the planetarium and were able to make more } \\
\text { meaningful connections. }\end{array}$ \\
\hline & Physical & $\begin{array}{l}\text { The planetarium's ability to make students feel like } \\
\text { they were flying through space in an immersive } \\
\text { environment helped them think about space } \\
\text { differently. }\end{array}$ \\
\hline & Sociocultural & $\begin{array}{l}\text { The interactions that were possible and the } \\
\text { designed storyline of the planetarium program were } \\
\text { influential on students' thinking and learning. }\end{array}$ \\
\hline
\end{tabular}

\section{Implications}

The planetarium is just one example of an informal science venue (or institution) that aims to engage, explore, and expand science learning for students outside of the traditional, formal education system. This research demonstrated the importance of the planetarium on students studying astronomy during a high school science unit and could have long-lasting implications on various groups. 


\section{Planetariums and planetarium educators}

The first contribution of this study would be to planetariums and the educators they employ. The findings of this study have added to the existing data about planetariums, revealing a positive influence on students' attitudes toward science and confirming that students learn more from studying astronomy in a planetarium.

The measurement of learning included additional components that varied from previous research (i.e. retention quiz) and should encourage new studies to evaluate the retention of knowledge over time and to measure learning beyond test performance. This study found that students receiving an embedded planetarium program while learning astronomy outperformed others on a test by a statistically significant margin and exhibited an increased gap by $3.5 \%$ on the two assessments, meaning that the treatment group retained knowledge at a higher rate. Planetariums may have an increased interest in working with school groups to measure knowledge, which may lead to the redesign and improvement of field trip offerings.

In regards to capturing the process of learning, rather than learning as a product, the findings of this study indicated that each of the three contexts influenced students' thinking of astronomical concepts. Students were positively affected by the physical space of the planetarium, the activities conducted within the planetarium setting, and with the visualizations projected onto the dome. In order for planetariums to shape student thinking in a positive direction, more experiences (e.g. field trips, exhibits) that will touch each context of the CML should be considered. 


\section{Science education researchers}

By using the data from this study, science education researchers may be inspired to develop, or help in developing, a series of visualizations, accompanying questions to elicit student thinking, and an avenue to test what students learn from a visit to the planetarium. The development of rich visuals and careful planning of age-appropriate questions may help planetariums worldwide offer better programs to have more positive influences on students. In addition, placing a greater emphasis on collaborative efforts could help bridge the gap between informal science institutions and schools. This connection between in-school and out-of-school could be beneficial to all parties involved in educating students.

With the development of similar shows, standard visualizations between planetariums, and testing options, researchers could help enhance informal science education in many ways: (a) provide improved and more consistent programs for students in various geographic areas; (b) assist in designing programs to link formal and informal science education; (c) work with planetariums to conduct future research on informal science education; and (d) have the ability to conduct research and compare study outcomes in a more meaningful way.

\section{Teachers, Students, and Administrators}

The results of this study showed positive results on students' attitudes, learning, and thinking while participating in a planetarium program. These findings are beneficial for school members: teachers, students, and administration. Teachers should be aware of the role that a planetarium can have on their students and be encouraged to take more field trips to campus or community-based planetariums. In some cases, there is also the 
possibility of having a portable planetarium come to their school. Incorporating field trips would give educators an additional instructional tool, which could help students learn and gain more insight into the astronomical concepts they are teaching within the classroom.

Students may benefit by having an opportunity to be immersed into an environment that will help them visualize what they have been learning in class. The three-dimensional environment strengthens students' understanding through projecting different perspectives of astronomical phenomena, which leads to personal connections with the material. The planetarium increased interest and engagement, it contributed to higher test scores, and students genuinely felt that the planetarium added to their enjoyment and learning during this unit. It may be the perfect link between formal and informal science education for teachers and students.

Lastly, administration should take notice of the positive findings of this study, which have identified that planetariums are positive for students in many aspects. This recognition may promote support and encouragement for teachers to plan and schedule field trips to local/regional planetariums and not hinder them because of expenses or other resources (e.g. buses, time, etc...). A knowledgeable and supportive administrative team that supports teachers should result in a more positive educational experience for their students.

\section{Conclusion}

Through presenting visualizations from various perspectives and explaining cause and effect relationships, students gained a new level of comprehension for why we experience events on Earth (e.g. day/night, seasons, eclipses and Moon phases). Next, 
students began to learn more details of astronomical processes that occur (or did occur in the past) outside of the Earth, but still within our solar system. Leaving the Earth, yet remaining in our 'neighborhood' helped students formulate a greater understanding of space at a larger scale (e.g. the role of gravity, the location and size of objects, how our solar system formed).

Finally, at the largest scale, students were able to experience something that would not have been possible within the classroom. They were immersed in an environment where virtual flight through space led to a greater appreciation and understanding of the scale of distance in space. The planetarium took students to the edge of the observable universe and taught them about the origin of the universe, which placed a high cognitive demand on them. All aspects of what the planetarium offered throughout the program, from the small scale to scale on the grandest level, positively influenced students' personal, physical, and sociocultural contexts.

The teachers that participated in this study enjoyed the planetarium and it was engaging for them as well as their students. Teachers were able to take material (i.e. facts, figures, and visualizations) from the planetarium back into their classrooms when teaching. The reference to material taught in the planetarium that day (or on previous days) helped students understand and make important connections with topics from the textbook and class discussions. They also reported their satisfaction with the program because students were more interested and engaged as a result of what they experienced in the planetarium. According to one teacher, "the planetarium experience helped reveal that modern astronomy may be studied and appreciated without using an overwhelming amount of physics or formulation." 
The students in this study were fortunate to have an embedded planetarium program during their astronomy unit. The multi-day learning experience had a positive influence on students' in many ways. Students reaped the benefits of what the planetarium offered, which was evident from content assessment scores, the evaluation of daily formative assessments, and what teachers reported about interest levels and engagement with topics in the classroom.

The planetarium was able to influence the personal, physical, and sociocultural contexts for students to create a positive learning experience over the four days. Although many examples are provided in Tables 8 and 9, it is worthwhile to revisit how each context affected students. Within the personal context, students reported that they understood concepts better and the planetarium's ability to represent scale provided them with a better idea of how they fit into the grander scheme. It helped build interest and students liked learning within the planetarium better than their classroom. The program gave students a deeper way of thinking about astronomical concepts and they gained knowledge that went beyond their initial thinking, or ideas about space science. The personal context was considered most important on thinking and learning about astronomy by over $22 \%$ of students.

In regards to the physical context, students enjoyed the immersive setting and what the digital system was capable of showing them. Students appreciated the visualizations and three-dimensional environment, which meant they did not have to imagine objects and processes as they often did in the classroom. The ability of the planetarium to manipulate time (e.g. seasons, day/night, Moon phases), the size of objects (e.g. Earth or Moon enlarged for reference), show students things that are not visible (e.g. 
pole lines, equator line, rotation and revolution of objects), and taking them on virtual flights were powerful for their thinking and learning about astronomy. These were some of the reasons why over $60 \%$ of students indicated that this context was most important during their experience.

The sociocultural context, which is normally absent in planetarium settings, was included in this study and the program was designed to include interactions as often as possible. The interactive atmosphere allowed students to talk, ask questions, answer questions, and short discussions were included throughout. In this study, the sociocultural context was an important consideration even though there are obvious difficulties when teaching in a dark (and typically quiet) environment.

The instructor's background in education meant that he was able to manage questions in a thoughtful way, push students to make important connections with classroom learning, and to think about astronomical processes from different perspectives. During the program, some students made specific mention of the instructor's presentation style as being positive. Additionally, the visualizations and virtual flight helped students' cultural aspect of this context to build a greater understanding of astronomical concepts. At the conclusion of the multi-day experience, almost $17 \%$ of students thought that this context was most important for thinking and learning.

It is with great hope that this study will encourage informal science educators and researchers to continue conducting research in planetariums. The development of shows to include standard visualizations and storylines (including formative assessment questions) could lead to more interesting and educational programs for students. 
Furthermore, creating a more interactive experience while students are learning in the planetarium could have positive impacts on students' understanding and appreciation of space science.

Lastly, although studies have been conducted since the 1960s, planetarium research is still lacking consistent results due to the many differences in what planetariums offer and how success is measured. With the release of the Next Generation Science Standards (NGSS Lead States, 2013), researchers and informal science educators should be able to hone in on the most important and age appropriate concepts and design assessments to measure student knowledge and growth. The development of a standardized assessment could be helpful in refining planetarium field trips and providing students with a memorable learning experience.

This study has added to our knowledge of why a planetarium can impact learning and thinking. The importance of overlapping the personal, physical, and sociocultural contexts may be the missing piece that gives students a way to think, process, and retain information. The planetarium setting provides dynamic and compelling multiperspective visuals to impact them (personal context), it immerses students in a unique learning space (physical context), and if done within a coherent storyline (sociocultural context), the educational experience will be enhanced. 


\section{REFERENCES}

Adams, J., Gupta, P., \& DeFelice, A. (2012). Schools and informal science settings: collaborate, co-exist, or assimilate? Cultural Studies of Science Education, 7, 409416.

Adelman, L., Dierking, L., Haley Goldman, K., Coulson, D., Falk, J., \& Adams, M. (2001). Baseline impact study: Disney’s animal kingdom conservation station. Technical Report, Annapolis, MD: Institute for Learning Innovation.

Adelman, L., Falk, J., \& James, S. (2000). Assessing the National Aquarium in Baltimore's impact on visitor's conservation knowledge, attitudes and behaviors. Curator, 43(1), 33-62.

Ames, C., \& Archer, J. (1988). Achievement goals in the classroom: Students' learning strategies and motivation processes. Journal of Educational Psychology, 80(3), 260.

Anderson, D., \& Lucas, K. (1997). The effectiveness of orienting students to the physical features of a science museum prior to visitation. Research in Science Education, $27,485-495$.

Anderson, D., Lucas, K., \& Ginns, I. (2003). Theoretical perspectives on learning in an informal setting. Journal of Research in Science Teaching, 40, 177-199.

Anderson, D., Lucas, K., Ginns, I., \& Dierking, L. (2000). Development of knowledge about electricity and magnetism during a visit to a science museum and related post-visit activities. Science Education, 84, 658-679. 
Anderson, D., \& Zhang, Z. (2003). Teaching perceptions of field-trip planning and implementation. Visitor Studies Today, 6(3), 6-11.

Baxter, J., \& Preece, P. (2000). A Comparison of Dome and Computer Planetaria in the Teaching of Astronomy. Research in Science and Technological Education, 18, 63.

Bell, P., \& Bevan, B. (2015). What is the role of informal science education in supporting the vision for K-12 science education? Retrieved from http://stemteachingtools.org/brief/38

Bitgood, S., \& Patterson, D. (1995). Principles of exhibit design. Visitor Behavior, 2, 4-6.

Bitgood, S., Serrell, B., \& Thompson, D. (1994). The impact of informal education on visitors to museums. Informal Science Learning, 61-106.

Brazell, B., \& Espinoza, S. (2009). Meta-analysis of planetarium efficacy research. Astronomy education review.

Ceci, S. (1996). On intelligence: A bioecological treatise on intellectual development. Boston, MA: Harvard University Press.

Ceci, S., \& Bronfenbrenner, U. (1985). Don't forget to take the cupcakes out of the oven: Strategic time monitoring, prospective memory, and context. Child Development, 56, $175-190$.

Chartrand, M. (1973). A fifty year anniversary of a two thousand year dream: the history of the planetarium. The Planetarian, 2(3), 95-101.

Chastenay, P. (2015). From Geocentrism to Allocentrism: Teaching the phases of the Moon in a digital full-dome planetarium. Research in Science Education, 1-35.

Coe, J. (1985). Design and perception: Making the zoo experience real. Zoo Biology, 4, 
$197-208$.

Coombs, P., \& Ahmed, M. (1974). Attacking Rural Poverty: How Nonformal Education Can Help. Baltimore, MD: Johns Hopkins University Press.

Crane, V., Nicholson, H., Chen, M., \& Bitgood, S. (1994). Informal science learning. What the Research Says About Television, Science Museums and CommunityBased Projects. Dedham, MA: Research Communications, Ltd.

Creswell, J. (2009, 2013). Research design: Qualitative, Quantitative, and Mixed Methods Approaches. Sage publications.

Croft, J. (2008). Planetarium professionals: A balancing act to engage and educate. The Planetarian, 34(6), 6-16.

Dean, N., \& Lauck, G. (1972). Planetarium Instruction - Using an Open-Sky Test. The Science Teacher, 39, 54.

DeWitt, J., \& Osborne, J. (2010). Recollections of Exhibits: Stimulated-recall interviews with primary school children about science centre visits. International Journal of Science Education, 32(10), 1365-1388.

Dierking, L., Falk, J., Rennie, L., Anderson, D., \& Ellenbogen, K. (2003). Policy statement of the "informal science education" ad hoc committee. Journal of Research in Science Teaching, 40, 108-111.

Dierking, L. (1991). Learning theory and learning styles: An overview. The Journal of Museum Education, 4-6.

Dierking, L., \& Pollock, W. (1998). Questioning assumptions: An introduction to frontend studies. Washington, DC: Association of Science Technology Centers. 
Dwinal, L. (2014). Creating Successful Partnerships Between Informal and Formal Science Education. In ASTC 2014 Annual Conference.

Evans, G. (1995). Learning and the physical environment. In J. Falk \& L.Dierking (Eds.), Public institutions for personal learning (pp. 119 - 126). Washington, DC: American Association of Museums.

Falk, J. (1983). Field Trips: A look at environmental effects on learning. Journal of Biological Education, 17 (2), 134-142.

Falk, J., Moussouri, T., \& Coulson, D. (1998). The effect of visitors' agendas on museum learning. Curator, 41(2), 106-120.

Falk, J., \& Adelman, L. (2003). Investigating the impact of prior knowledge, experience and interest on aquarium visitor learning. Journal of Research in Science Teaching, 40, $163-176$.

Falk, J., \& Balling, J. (1982). The field trip milieu: Learning and behavior as a function of contextual events. Journal of Educational Research, 76(1), 22 - 28.

Falk, J., \& Dierking, L. (1992). The Museum Experience. Washington, DC: Whalesback Books.

Falk, J., \& Dierking, L. (1997). School field trips: assessing their long-term impact. Curator: The Museum Journal, 40, 211-218.

Falk, J., \& Dierking, L. (2000). Learning from museums: Visitor experiences and the making of meaning. Walnut Creek, CA: Altamira Press.

Falk, J., Koran, J., \& Dierking, L. (1986). The things of science: Assessing the learning potential of science museums. Science Education, 70, 503-508. 
Falk, J., \& Storksdieck, M. (2005). Using the contextual model of learning to understand visitor learning from a science center exhibition. Science Education, 89, 744-778.

Fallik, O., Rosenfeld, S., \& Eylon, B. (2013). School and out-of-school science: a model for bridging the gap. Studies in Science Education, 49(1), 69-91.

Fox-Turnbull, W. (2009). Stimulated recall using autophotography: A method for investigating technology education. In: A. Bekker, I. Mottier, M. J. de Vries (Eds.), Strengthening the position of technology education in the curriculum. Proceedings PATT-22 Conference: Delft, the Netherlands, August 24-28, 2009 (pp. 204-217). International Technology and Engineering Educators Association. Retrieved from http://www.iteaconnect.org/Conference/ PATT/PATT22/FoxTurnbull.pdf (date of access: Nov. 28, 2015).

Freedman, M. (1997). Relationship among laboratory instruction, attitude toward science, and achievement in science knowledge. Journal of Research in Science Teaching, $34(4), 343-357$.

Ginsburg, H. (1997). Entering the child's mind: The clinical interview in psychological research and practice. Cambridge University Press.

Glaser, B., \& Strauss, A. (2009). The discovery of grounded theory: Strategies for qualitative research. New Jersey: Transaction publishers.

Glowinski, I., \& Bayrhuber, H. (2011). Student labs on a university campus as a type of out-of-school learning environment: assessing the potential to promote students' interest in science. International Journal of Environmental \& Science Education, $6,371-392$.

Griffin, J. (2004). Research on students and museums: looking more closely at the 
students in school groups. Science Education, 88 (supplement 1): s59-s70.

Guisasola, J., Morentin, M., \& Zuza, K. (2005). School visits to science museums and learning sciences: a complex relationship. Physics Education, 40, 544.

Hedge, A. (1995). Human-factor considerations in the design of museums to optimize their impact on learning. In J. Falk \& L. Dierking (Eds.); Public Institutions for Personal Learning (pp. 105-118). Washington, DC: American Association of Museums.

Hein, G. (1998). Learning in the Museum. London: Routledge.

Hodson, D. (1998). Teaching and learning science: Towards a personalized approach. London: McGraw-Hill Education.

Hofstein, A., \& Rosenfeld, S. (1996). Bridging the gap between formal and informal science learning. Studies in Science Education, 28, 87-112.

Heppner, P., Wampold, B., \& Kivlighan, D. (2007). Research design in counseling: Research, statistics, \& program evaluation. Cengage Learning.

Itzek-Greulich, H., Flunger, B., Vollmer, C., Nagengast, B., Rehm, M., \& Trautwein, U. (2015). Effects of a science center outreach lab on school students' achievement Are student lab visits needed when they teach what students can learn at school? Learning and Instruction, 38, 43-52.

Kaiser, H. (1991). Coefficient alpha for a principal component and the Kaiser-Guttman Rule, Psychological Reports, 68(1), 855-858.

Kikas, E. (1998). The impact of teaching on students' definitions and explanations of astronomical phenomena. Learning and Instruction, 8(5), 439-454.

Kisiel, J. (2003). Revealing teacher agendas: An examination of teacher motivations and 
strategies for conducting museum fieldtrips (Doctoral dissertation, University of Southern California). Retrieved from ProQuest Dissertations and Theses database (305320337).

Knox, K., Moynihan, J., \& Markowitz, D. (2003). Evaluation of short-term impact of a high school summer science program on students' perceived knowledge and skills. Journal of Science Education and Technology, 12, 471-478.

Krepel, W., \& Durral, C. (1981). Field trips: A guideline for planning and conducting educational experiences. Washington, DC: National Science Teachers Association.

Kubota, C., \& Olstad, R. (1991). Effects of novelty-reducing preparation on exploratory behavior and cognitive learning in a science museum setting. Journal of Research in Science Teaching, 28, 225-234.

Lantz, E. (2009). The Planetarium: A Transitional Animal: a review of the history and future of planetarium technology and programming. The Planetarian, 38(2), 7-12.

Lelliott, A., \& Pendlebury, S. (2009). “A Large Object with a Small Museum”: A Narrative Analysis of Tlotlo's Experience of an Astronomy Science Center. Curator: The Museum Journal, 52, 241-260.

Lelliott, A. (2010). The concept of spatial scale in astronomy addressed by an informal learning environment. African Journal of Research in Mathematics, Science and Technology Education, 14(3), 20-33.

Littmann, M. (2009). Voices from Educational Planetariums. Sky and Telescope. Retrieved from http://www.skyandtelescope.com/sky-and-telescopemagazine/beyond-the-printed-page/voices-from-educational-planetariums/ 
Lombard, M., Reich, R., Grabe, M., Bracken, C., \& Ditton, T. (2000). Presence and television. Human Communication Research, 26(1), 75-98.

Luehmann, A. L., \& Markowitz, D. (2007). Science teachers' perceived benefits of an out-of-school enrichment programme: identity needs and university affordances. International Journal of Science Education, 29(9), 1133-1161.

Mackenzie, J. (1894). The report of the committee of ten. The School Review, 2, 146-155. Markowitz, D. (2004). Evaluation of the long-term impact of a university high school summer science program on students' interest and perceived abilities in science. Journal of Science Education and Technology, 13, 395-407.

Menke, D. (1987). The origin and evolution of the planetarium and planetarians: Phillip Fox and the Adler planetarium. The Planetarian, 16(1), 46-48.

Miles, M., \& Huberman, A. (1994). Qualitative data analysis: An expanded sourcebook. Sage publications.

Morgan, A. (2007). Using video-stimulated recall to understand young children's perceptions of learning in classroom settings. European Early Childhood Education Research Journal, 15(2), 213-226.

National Research Council. (1996). National Science Education Standards. Washington, DC: National Academy Press.

National Research Council. (2007). Taking Science to School: Learning and Teaching Science in Grades K-8. Washington, DC: National Academies Press.

National Science Foundation. (1997). Informal Science Education: Supplements to Active Research Awards. Retrieved from http://www.nsf.gov/pubs/1997/nsf9770/isesupl.htm 
National Science Teacher Association (2014). NSTA Position Statement: Early

Childhood Science Education. Retrieved from

http://www.nsta.org/about/positions/earlychildhood.aspx

NGSS Lead States (2013). Next Generation Science Standards: For States, By States.

Washington, DC: The National Academies Press.

Orion, N., \& Hofstein, A. (1994). Factors that influence learning during a scientific field trip in a natural environment. Journal of Research in Science Teaching, 31, 10971119.

Palmer, J. C. (2007). The efficacy of planetarium experiences to teach specific science concepts (Doctoral dissertation, Texas A\&M University). Retrieved from ProQuest Dissertations \& Theses Global. (304718330).

Phillips, M., Finkelstein, D., \& Wever-Frerichs, S. (2007). School site to museum floor: How informal science institutions work with schools. International Journal of Science Education, 29, 1489-1507.

Plummer, J. (2009). Early Elementary Students' Development of Astronomy Concepts in the Planetarium. Journal of Research in Science Teaching, 46(2): 192-209.

Plummer, J. (2014a). My Sky Tonight. In ASTC Annual Conference.

Plummer, J. (2014b). Spatial thinking as the dimension of progress in an astronomy learning progression. Studies in Science Education, 50, 1-45

Plummer, J., Kocareli, A., \& Slagle, C. (2014c). Learning to explain astronomy across moving frames of reference: Exploring the role of classroom and planetariumbased instructional contexts. International Journal of Science Education, 36, 1083-1106. 
Ramey-Gassert, L., \& Walberg, H. (1994). Reexamining connections: Museums as science learning environments. Science Education, 78, 345-363.

Reed, G. (1970). Is the Planetarium a more Effective Teaching Device than the Combination of the Classroom Chalkboard and Celestial Globe? School Science and Mathematics, 70, 487.

Reed, G. (1971). Inquiry Teaching and the Planetarium. Science Activities, 6(1), 15-17.

Reed, G. (1973). The Planetarium Versus the Classroom - An Inquiry into Earlier Implications. School Science and Mathematics, 553-555.

Rennie, L., Feher, E., Dierking, L., \& Falk, J. (2003). Toward an agenda for advancing research on science learning in out-of-school settings. Journal of Research in Science Teaching, 40, 112-120.

Rennie, L., \& Johnston, D. (2004). The nature of learning and its implications for research on learning from museums. Science Education, 88(S1), S4-S16.

Rennie, L., \& McClafferty, T. (1995). Using visits to interactive science and technology centers, museums, aquaria, and zoos to promote learning in science. Journal of Science Teacher Education, 6, 175-185.

Rosemergy, J. (1967). An Experimental Study of the Effectiveness of a Planetarium in Teaching Selected Astronomical Phenomena to Sixth-Grade Children. (Doctoral dissertation, University of Michigan). Retrieved from ProQuest Dissertations \& Theses Global. (302234352).

Sacco, K., Falk, J., \& Bell, J. (2014). Informal Science Education: Lifelong, Life-Wide, Life-Deep. PLoS Biol, 12(11): e1001986. doi:10.1371/journal.pbio.1001986 Sadler, P. (1998). Psychometric models of student conceptions in science: reconciling 
qualitative studies and distractor-driven assessment instruments. Journal of Research in Science Teaching, 35, 265-296.

Säljö, R. (1979). 'Learning in the learner's perspective. I. Some common-sense conceptions', Reports from the Institute of Education, University of Gothenburg, 76.

Salmi, H. (2003). Science centres as learning laboratories: experiences of Heureka, the Finnish Science Centre. International Journal of Technology Management, 25, $460-476$.

Sefton-Green, J. (2003). Informal Learning: substance or style? Teaching Education, 14(1), 37-51.

Serrell, B. (1996). Exhibit labels: An interpretive approach. Walnut Creek, CA: AltaMira.

Serrrell, B. (1998). Paying attention: Visitors and museum exhibitions. Washington, DC: American Association of Museums.

Seybold, B., Braunbeck, T., \& Randler, C. (2014). Primate conservation - an evaluation of two different educational programs in Germany. International Journal of Science and Mathematics Education, 12, 285-305.

Simon, S., Erduran, S., \& Osborne, J. (2006). Learning to teach argumentation: Research and development in the science classroom. International Journal of Science Education, 28, 235-260.

Sindorf, L. (2014). Assessing visitor engagement in science centers: An ISE research brief discussing Barriault \& Pearson, “Assessing exhibits for learning in science 
centers: A practical tool.” Retrieved from

http://relatingresearchtopractice.org/article/361

Small, K., \& Plummer, J. (2014). A longitudinal study of early elementary students' understanding of lunar phenomena after planetarium and classroom instruction. The Planetarian. 43(4), 18-21.

Smagorinsky, P. (2008). The method section as conceptual epicenter in constructing social science research reports. Written Communication, 25, 389-411.

Smith, B. (1966). “An Experimental Comparison of Two Techniques (Planetarium Lecture-Demonstration and Classroom Lecture-Demonstration) of Teaching Selected Astronomical Concepts to Sixth-Grade Students," Dissertation Abstracts International, B: The Sciences and Engineering, 27, 887.

Smith, M. (2015). What is education? A definition and discussion. The encyclopaedia of informal education. Retrieved from http://infed.org/mobi/what-is-education-adefinition-and-discussion/.

Smith, M. (2003). 'Learning theory', the encyclopedia of informal education. Retrieved from http://infed.org/mobi/learning-theory-models-product-and-process/.

Sternberg, R., \& Wagner, R. (Eds.). (1996). Practical intelligence: Nature and origins of competence in the everyday world. Cambridge: Cambridge University Press.

Stevens, J. (1996). Applied Multivariate Statistics for the Social Sciences, 4th ed., Erlbaum, Mahwah, NJ.

Storksdieck, M. (2004). Testing a model for understanding field trips in environmental education. PhD dissertation, Department of Education, Universitat Luneburg.

Sturm, H., \& Bogner, F. (2010). Learning at workstations in two different environments: 
a museum and a classroom. Studies in Educational Evaluation, 36, 14-19.

Sunal, D. (1976). Analysis of Research on the Educational Uses of a Planetarium. Journal of Research in Science Teaching, 13, 345.

Tal, R., Bamberger, Y., \& Morag, O. (2005). Guided school visits to natural history museums in Israel: Teachers' roles. Science Education, 89, 920-935.

Tavakol, M., \& Dennick, R. (2011). Making sense of Cronbach's alpha. International Journal of Medical Education, 2, 53-55.

Thompson, B. (2004). Exploratory and Confirmatory Factor Analysis, American Psychology Association, Washington, D.C.

Thompson, J. (1968). Investigating the Earth Through Student Inquiry. GLPA Projector, p. 46.

Tomlinson, G. (2011). Keeping astronomy in science education. The Planetarian, 40(3), 10-19.

Tran, L. (2007). Teaching science in museums: The pedagogy and goals of museum educators. Science Education, 91, 278-297.

Tretter, T., Jones, G., Andre, T., Negishi, A., \& Minogue, J. (2006). Conceptual boundaries and distances: Students' and experts' concepts of the scale of scientific phenomena. Journal of Research in Science Teaching, 43(3), 282-319.

Trundle, K., Atwood, R., \& Christopher, J. (2007). A longitudinal study of conceptual change: Preservice elementary teachers' conceptions of moon phases. Journal of Research in Science Teaching, 44(2), 303-326.

Türk, C., \& Kalkan, H. (2015). The effect of planetariums on teaching specific astronomy concepts. Journal of Science Education and Technology, 24(1), 1-15. 
Tuttle, D. (1966). Effects of the Use of the Planetarium upon the Development of Spatial Concepts among Selected Sixth Grade Students in Elgin.

Vadeboncoeur, J. (2006). Engaging young people: Learning in informal contexts. Review of Research in Education, 239-278.

Wellington, J. (1991). Newspaper science, school science: friends or enemies? International Journal of Science Education, 13, 363-372.

Wright, D. (1968). Effectiveness of the Planetarium and Different Methods of its Utilization in Teaching Astronomy. (Doctoral dissertation, University of Nebraska-Lincoln). Retrieved from ProQuest Dissertations \& Theses Global. (302350741).

Wulf, R., Mayhew, L., Finkelstein, N., Singh, C., Sabella, M., \& Rebello, S. (2010). Impact of informal science education on children's attitudes about science. In AIP Conference Proceedings, 1289, 1, 337.

Yin, R., Green, J., Camilli, G., \& Elmore, P. (2006). Handbook of complementary methods in education research.

Yu, K. (2009). Digital planetariums for geology and geography education: Earth visualizations at the Gates planetarium. The Planetarian, 36(3), 6-12.

Yu, K., Sahami, K., Sahami, V., \& Sessions, L. (2015). Using a digital planetarium for teaching seasons to undergraduates. Journal of Astronomy \& Earth Sciences Education, 2 (1).

Zeilik, M. (2012, March 17). Survey of Attitudes Towards Astronomy. Retrieved from http://www.pearweb.org/atis/tools/57 
Zoldosova, K. \& Prokop, P. (2006). Education in the field influences children's ideas and interest toward science. Journal of Science Education and Technology, 15, 304313. 


\section{APPENDICES}

\section{Appendix A}

\section{Earth Space Science DBA Questions}

1. ${ }^{* \wedge}$ What basic characteristic best differentiates the inner planets from the outer planets.
a. rocky composition or gaseous composition
c. presence or lack of moons

b. presence or lack of seasons

d. presence or lack of weather

2. ${ }^{* \wedge}$ What it is the initial cause of the formation of our solar system?

a. high pressure and high temperature causes nuclear fusion to occur

b. low pressure and low temperature causes nuclear fusion to occur

c. high pressure and low temperature causes nuclear fusion to occur

d. low pressure and high pressure causes nuclear fusion to occur

3. *What is the driving force in all solar system formation?
a. acceleration
c. magnetism
b. friction
d. gravity

4. ${ }^{* \wedge}$ Which of the following best explains the statement: the solar system may have formed from large rotation cloud composed of gas and dust.
a. big bang theory
c. nebular theory
b. condensation theory
d. differentiation hypothesis

5. Regarding the nebular theory, which of the following is the correct sequence of events?

a. jovian planets formed, nebula rotated and collapsed, sun formed in the center, terrestrial planets formed

b. nebula rotated and collapsed, sun formed in the center, terrestrial planets \& jovian planets formed

c. sun formed in the center, nebula rotated and collapsed, terrestrial planets \& jovian planets formed

d. nebula rotated and collapsed, jovian planets formed, sun formed in the center, terrestrial planets formed

6. ${ }^{* \wedge}$ By comparing and contrasting order the following planets from smallest to largest.
a. Mercury, Earth, Mars, Venus
c. Mars, Mercury, Venus, Earth
b. Venus, Earth, Mars, Mercury
d. Mercury, Mars, Venus, Earth 
7. By comparing the formation of the inner and outer planets choose the correct....

a. The inner planets formed from elements that resisted vaporization/the outer planets formed from rocks.

b. The inner planets from gasses left over from the suns formation/the outer planets formed from rocky material that resisted vaporization.

c. The inner planets formed from elements that resisted vaporization/the outer planets formed from gaseous and icy particles

d. The inner planets were frozen that way/the outer planets were also frozen that way

8. *By comparing \& contrasting the asteroid belt and the Kuiper belt.

a. Asteroid belt lies between the earth and the sun/Kuiper belt is between Jupiter and Saturn

b. Asteroid belt is between Jupiter and Saturn/Kuiper belt is between earth and Venus

c. Asteroid belt is outside of Uranus/Kuiper belt is between Jupiter and Saturn

d. Asteroid belt is between Mars and Jupiter/Kuiper belt is outside the orbit of Neptune

9. When comparing the planets in the night sky, which is brightest?
a. Venus
c. Jupiter
b. Mars
d. Mercury

10. *Pluto was demoted from planetary status because
a. too small
c. no atmosphere
b. too far away
d. unable to clear its orbital path

11. ${ }^{* \wedge}$ Compare the following statements and determine which is correct.
a. the distance of the sun to earth causes the seasons
b. the distance the moon to the earth in relation to the sun causes seasons
c. the tilt and orbit of our earth causes the seasons
d. the rotation of earth on its axis causes the seasons.

12. *The interaction between the sun's flares and earth's magnetic field cause the following to form
a. coal and other energy byproducts
c. el Niño
b. the aurora borealis
d. the monsoon season

13. When examining the electromagnetic spectrum, which form of electromagnetic wave that is produced by the sun is the most important to life on earth?
a. microwaves
c. gamma rays
b. visible light
d. radiowaves

14. *When explaining the power of the sun the following reaction is occurring a. fusing of lighter elements (hydrogen to helium) into heavier elements 
b. fission of lighter elements (hydrogen to helium) into heavier elements

c. fusing of heavier (helium to hydrogen) element into lighter elements

d. fission of heavier (helium to hydrogen) element into lighter elements

15. What is likely to occur to Earth as the sun enters next stellar stage (old age)?

a. The sun will expand and the Earth will heat up.

b. The sun will collapse and the Earth will cool down.

c. The sun will become white and photosynthesis won't occur.

d. The sun will last forever and never change.

16. When comparing stars, which color star would have the highest surface temperature?
a. blue
c. red
b. yellow
d. orange

17. Which type of star is the sun?
a. dwarf
c. red giant
b. main sequence
d. neutron star

18. When analyzing stars which, type is considered balanced between gravity and outward pressure?
a. dwarf
c. red giant
b. main sequence
d. protostar

19. ${ }^{* \wedge}$ When analyzing the movement of stars astronomers know that a star...

a. coming towards you will red shift, going away it will blue shift

b. coming towards you will blue shift, going away it will also blue shift

c. coming towards you will blue shift, going away it will red shift

d. stars don't move.

20. Which tool uses temperature and absolute magnitude to classify stars?
a. psychrometric chart
b. adiabatic chart
c. stellar zenithal diagram
d. H-R diagram

21. *When analyzing galaxies which type of galaxy is most like our Milky Way galaxy?
a. spiral
c. elliptical
b. hexagonal
d. irregular

22. When analyzing galaxies, where do you find the oldest stars?
a. the bulge
c. wing
b. spiral arms
d. central black hole

23. *When ordering objects in the universe from largest to smallest, the following is true...

a. universe, local group, Milky Way galaxy, solar system, planet 
b. planet, universe, Milky Way galaxy, solar system, local group

c. planet, solar system, Milky Way Galaxy, local group, universe

d. planet, local group, universe, solar system, Milky Way Galaxy

24. Select the following sentence which best summarizes Hubble's Law.

a. The greater the distance to a galaxy, the greater its velocity.

b. The greater the distance to a galaxy, the brighter its halo.

c. The greater the distance to a galaxy, the greater its age.

$\mathrm{d}$. The greater the distance to a galaxy, the greater its mass.

25. Which of the following is the closest to the distance across the Milky Way galaxy?
a. 25 thousand light years
b. 50 thousand light years
c. 75 thousand light years
d. 100 thousand light years

Note. $*=$ same questions included in analysis of subset of 13 questions. ${ }^{\wedge}=$ same questions included in retention quiz 


\section{Appendix B}

Daily student formative assessments

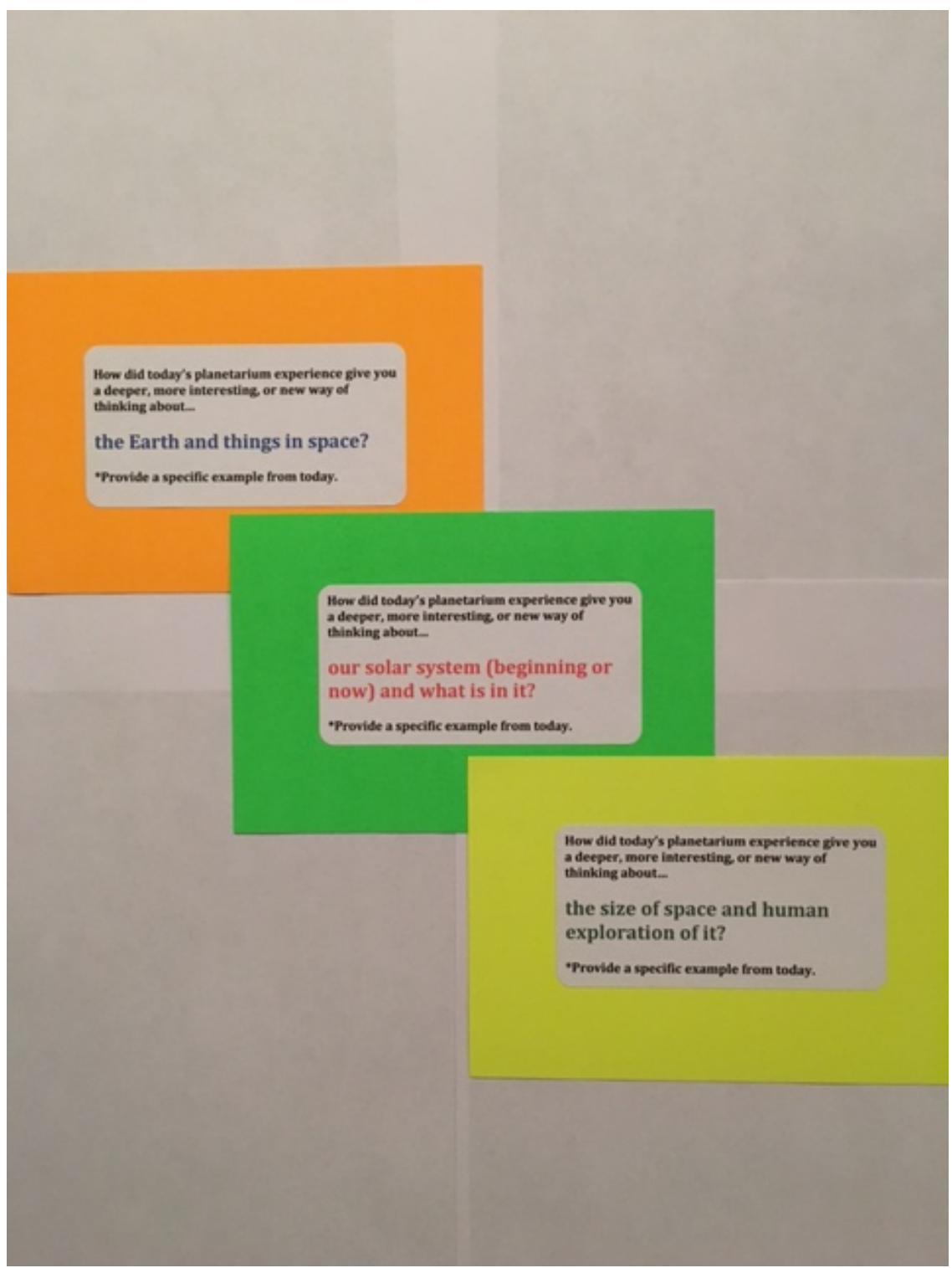




\section{Appendix C}

Planetarium Script

\section{"The Sun, Stars, and Galaxies" Hickory High School \\ 2016-17}

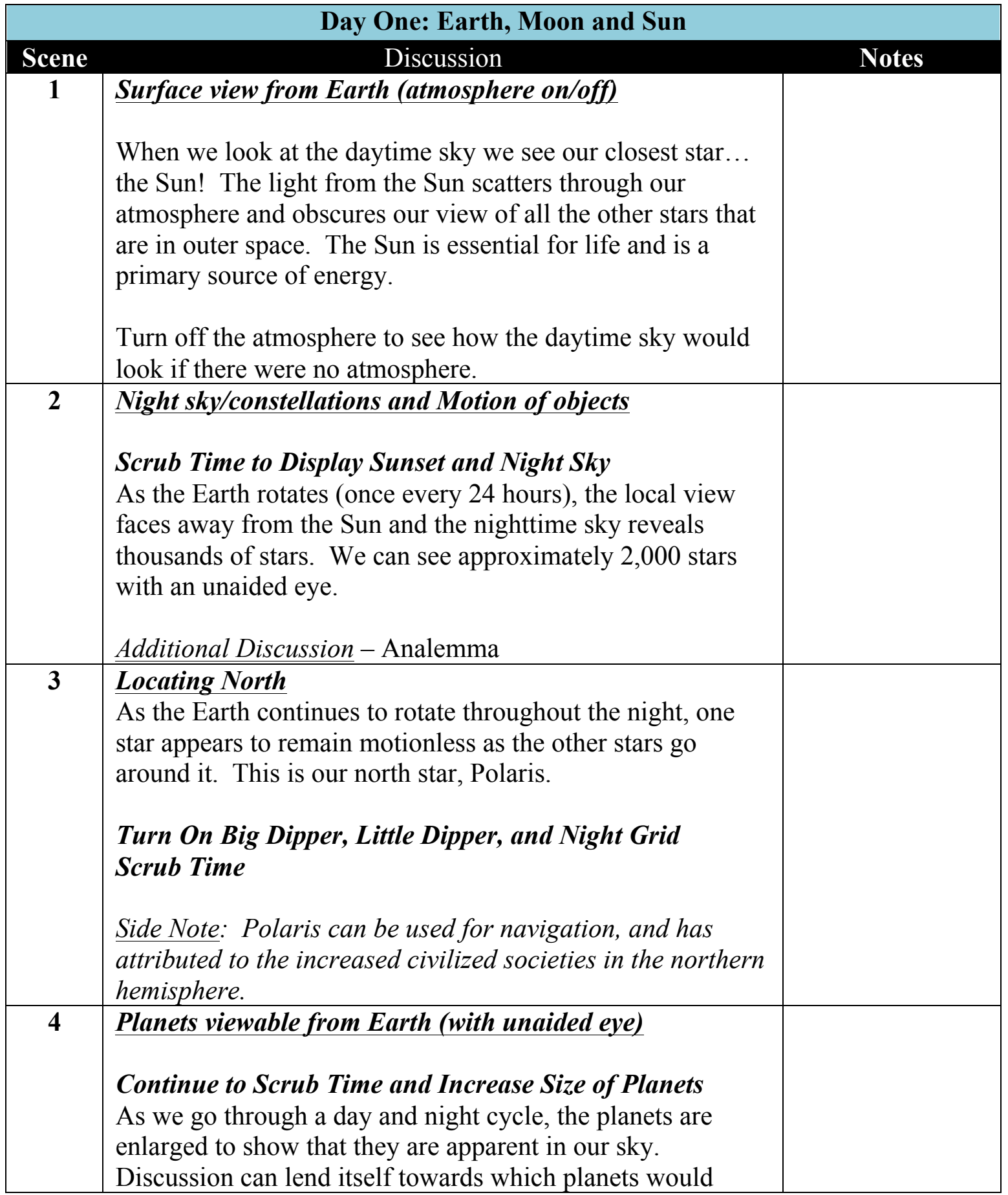




\begin{tabular}{|c|c|c|}
\hline & $\begin{array}{l}\text { appear to be brightest and why? (e.g. Venus brighter than } \\
\text { Mars, because of Size and Distance.) Also, various color of } \\
\text { stars and their temperatures }\end{array}$ & \\
\hline 5 & $\begin{array}{l}\text { Color/temperature of stars (HR Diagram) } \\
\text { Point out that the stars vary in size and color. Some stars } \\
\text { are much larger than our Sun, while others are smaller. The } \\
\text { Sun is an average star. } \\
\text { What color is the Sun? Yellow, which gives it an average } \\
\text { temperature. Blue stars are much hotter and Red stars are } \\
\text { cooler... though all stars are extremely hot. } \\
\text { Sun Temperature: Core }=27 \text { million degrees F; } \\
\text { Photosphere }=10,000 \mathrm{~F}\end{array}$ & \\
\hline 6 & $\begin{array}{l}\text { Lift Off from Surface of Earth and Hover Over Planet } \\
\text { Turn On Poles and Equatorial Line } \\
\text { Do you remember how Polaris appeared to remain still in } \\
\text { the night sky? If one examines the North Pole, one can see } \\
\text { that it points to Polaris. }\end{array}$ & \\
\hline 7 & $\begin{array}{l}\text { Seasons/Tilt of Earth (Theia) } \\
\text { 3.5 billion years ago, a Mars sized planet impacted the } \\
\text { Earth. This impact occurred before the Earth's crust had } \\
\text { become rigid and solid. The tilt of the Earth, a thin crust for } \\
\text { plate tectonics, a larger core and our Moon were products of } \\
\text { this collision. } \\
\text { Turn on Poles } \\
\text { Fly to view the Earth's orbital path. Enlarge the size of } \\
\text { the Earth and extend the poles of the planet. Scrub time to } \\
\text { display the revolution of the Earth. } \\
\text { If we watch the Earth complete a revolution around the Sun, } \\
\text { we can see that the North Pole is always pointing to Polaris } \\
\text { every second of the year. } \\
\text { We can also see that the Earth is tilted on its axis ( } 23.5 \\
\text { degrees). This tilt is the reason for our seasons. } \\
\text { Scrub Time to Dec. } 21^{\text {st }}-\text { Winter Solstice - Zoom to Earth } \\
\text { Looking at the tilt of the Earth, we see that the North Pole is } \\
\text { in } 24 \text { hours of darkness, and the northern hemisphere is } \\
\text { experiencing longer nights... which means less time to be }\end{array}$ & $\begin{array}{l}\text { *BEST VISUAL } \\
\text { Bookmark for } \\
\text { End of } \\
\text { Experience }\end{array}$ \\
\hline
\end{tabular}




\begin{tabular}{|c|c|c|}
\hline & $\begin{array}{l}\text { warmed by the Sun, and more time to cool off at night. } \\
\text { There is also the light being dispersed over a larger area. } \\
\text { Scrub to June } 2 \mathbf{1}^{\text {st }}-\text { Summer Solstice - Zoom to Earth } \\
\text { Here you see the northern hemisphere in the summer. The } \\
\text { north pole is tilted toward the Sun. More time during the } \\
\text { day to soak up the more direct sunlight. Less time to cool } \\
\text { off, because of shortened nights. } \\
\text { Scrub time and have students watch the shadow and its } \\
\text { relationship with the north pole. Identify season during } \\
\text { random times of the revolution. } \\
\text { Reset Options/Scale and Return to the Earth }\end{array}$ & \\
\hline 8 & $\begin{array}{l}\text { Structure of Earth (Layers) and Magnetosphere } \\
\text { Discuss the layers of the Earth (crust, mantle, outer/inner } \\
\text { core). The metallic inner core's spinning motion created a } \\
\text { magnetic field around the Earth, called the magnetosphere. } \\
\text { This magnetosphere protects the Earth from harmful } \\
\text { radiation and solar winds. } \\
\text { If the Earth did not have a magnetosphere, life would not be } \\
\text { able to exist. The atmosphere and water would be blasted } \\
\text { into space and the Earth would be much like Mercury. }\end{array}$ & \\
\hline 9 & Moon Formation (Theia) & \\
\hline 10 & Rotation and Revolution of the Moon (Phasing) & \\
\hline $\begin{array}{l}\text { END } \\
\text { DAY }\end{array}$ & $\begin{array}{l}\text { Sun } \\
\text { Equator }=24.47 \text { days } \\
\text { Poles }=38 \text { days }\end{array}$ & \\
\hline & $\begin{array}{l}\text { Day } 1 \text { stimulus - BEST visual - focus on Earth-Sun. Sun } \\
\text { centered (center of our solar system, Earth enlarged (for } \\
\text { better visual of our planet (globe like rather than a point in } \\
\text { space), poles turned on (good for tilt b/c attached to patterns } \\
\text { in the sky and tilt/seasons), and having Earth revolve around } \\
\text { the Sun. } \\
\text { Script: "You all have a clipboard under your chair. Please } \\
\text { get your clipboard and let's read the question on the index } \\
\text { card together (I will read aloud while students look at index } \\
\text { card). We are going to fly back toward the Earth and then } \\
\text { I'd like you to write your answer on the back of the card". } \\
\text { "Turn your attention to the dome and observe the flight back }\end{array}$ & $\begin{array}{l}* * \text { NOTE - NO } \\
\text { pole pointed } \\
\text { toward Polaris } \\
\text { b/c we don't } \\
\text { want to suggest } \\
\text { that students } \\
\text { should only talk } \\
\text { about seasons } \\
\\
\text { *Note - The } \\
\text { visual will be }\end{array}$ \\
\hline
\end{tabular}




\begin{tabular}{|c|c|c|}
\hline & $\begin{array}{l}\text { toward the Earth". } \\
\text { Question on index card: } \\
\text { How did today's planetarium experience give you } \\
\text { a deeper, more interesting, or new way of } \\
\text { thinking about... } \\
\text { Our Earth and things in space? } \\
\text { *Provide a specific example from today. }\end{array}$ & $\begin{array}{l}\text { moving } \\
\text { dynamically } \\
\text { while students } \\
\text { have time to } \\
\text { answer the } \\
\text { questions. }\end{array}$ \\
\hline \multicolumn{3}{|c|}{ Day Two: Formation of the Solar System } \\
\hline Scene & Discussion & Notes \\
\hline 1 & Start at Sun & \\
\hline 2 & $\begin{array}{l}\text { Nebular Theory - Video Clip } \\
\text { Our Sun was born like any other star. Its birth occurred in a } \\
\text { nebula. } \\
\text { The Sun was made from the gas within the nebula that was } \\
\text { brought together by gravity, which resulted in high pressure } \\
\text { and immense temperature. } \\
\text { Once the temperature reached } 10 \text { million degrees Kelvin (or } \\
10 \text { million degrees above absolute zero), the process of } \\
\text { fusion can begin... and a star is born. }\end{array}$ & \\
\hline 3 & $\begin{array}{l}\text { Revolution of Planets - Newton's Laws of Motion } \\
\text { Increase Size of Planets and Turn on the Asteroid Belt w/ } \\
\text { Hazardous } \\
\text { Remind Students that Size of Planets is } 2000 X \\
\text { Let's examine the order and size of the inner planets. } \\
\text { Mercury, Venus, Earth, and Mars... Size: Mercury, Mars, } \\
\text { Venus, Earth }\end{array}$ & \\
\hline 4 & $\begin{array}{l}\text { Life Cycle of the Sun } \\
\text { Fusion continues in a star making larger and larger elements } \\
\text { from hydrogen and the other elements it is producing. The } \\
\text { largest element made by our Sun is Iron (Fe). } \\
\text { So what makes elements larger than Iron? More energy is } \\
\text { needed for those elements to be formed... and the death of a } \\
\text { star, in a process called a supernova, provides that energy. } \\
\text { When a star dies it creates the other elements in a supernova } \\
\text { and then releases all of those elements into space. } \\
\text { Those elements then become other stars, planets, moons, } \\
\text { and even us. We are made from stars! }\end{array}$ & \\
\hline
\end{tabular}




\begin{tabular}{|c|c|}
\hline & $\begin{array}{l}\text { Switch back to Uniview and Fly to Inner Planet View } \\
\text { Life Cycle of our Sun } \\
\text { 4.6 billion years old } \\
\text { Another } 4 \text { billion years of main sequence } \\
\text { After all of the H is exhausted the Sun will fuse He into } \\
\text { Carbon and become a Red Giant. The Sun will then begin } \\
\text { to release its gases into space and collapse upon itself } \\
\text { creating a white dwarf star, cooling to the background } \\
\text { temperature of space. }\end{array}$ \\
\hline 5 & $\begin{array}{l}\text { Composition, Rotation, Revolution } \\
\text { Scrub Time to display Rotation and Revolution } \\
\text { Discuss elliptical path of planets, and how the gravity of the } \\
\text { Sun keeps them in orbit. What would happen if the Sun's } \\
\text { gravity did not exist? Answer: The planets would continue } \\
\text { to move in a straight line and leave the solar system, until } \\
\text { acted upon by another external force ( } 1{ }^{\text {st }} \text { Law of Motion). }\end{array}$ \\
\hline 6 & $\begin{array}{l}\text { Habitable Zone } \\
\text { Turn On the Solar System's Habitable Zone } \\
\text { Here we see the Habitable Zone of our Sun. It is an area } \\
\text { that has been determined to have the ability for liquid water, } \\
\text { and where there is liquid water there exists the ability for } \\
\text { life (as we know it). }\end{array}$ \\
\hline 7 & $\begin{array}{l}\text { Dwarf Planets } \\
\text { Turn On the Dwarf Planets and Fly to Ecliptic } \\
\text { Often people ask about Pluto and why it is categorized as a } \\
\text { dwarf planet. There are a few reasons for this: To small to } \\
\text { maintain a consistent round shape, does not clear its own } \\
\text { path in the Kuiper Belt, and it is not on the plane of the } \\
\text { ecliptic with the } 8 \text { major planets. } \\
\text { *Pluto and New Horizons }\end{array}$ \\
\hline 8 & $\begin{array}{l}\text { Asteroid Belt, Kuiper Belt } \\
\text { Fly Out and Turn on the Kuiper Belt } \\
\text { This outer region is known as the Kuiper Belt. It is } 20 \text { times } \\
\text { wider than the asteroid belt and between } 20-200 \mathrm{X} \text { as } \\
\text { massive. } \\
\text { It is composed of frozen volatiles ("ices" of methane, } \\
\text { ammonia, and water). Extends from Neptune (about } 5.5 \\
\text { light hours from the Earth) to } 50 \text { AU from the Sun. } \\
\text { Let's compare the Kuiper Belt and the Asteroid Belt. } \\
\text { Discuss location and what each is composed. }\end{array}$ \\
\hline 9 & $\begin{array}{l}\text { Jupiter (Compare to a mini solar system) } \\
\text { If we look closely at the Jovian planets, we know that they } \\
\text { are gaseous. The much larger outer planets also have many }\end{array}$ \\
\hline
\end{tabular}




\begin{tabular}{|c|c|}
\hline & $\begin{array}{l}\text { more moons than the small, rocky inner planets. } \\
\text { Fly into Jupiter } \\
\text { As we approach Jupiter, look at the purple orbits around the } \\
\text { planet... there are over } 60 \text { identified moons. Neat Fact: If } \\
\text { Jupiter were } 100 \text { times larger during the formation of the } \\
\text { solar system, it would have had enough mass and } \\
\text { temperature to become a star. } \\
\text { Jupiter also has a small ring system, and magnetosphere. } \\
\text { The magnetosphere is created by the outer core, which is } \\
\text { composed of liquid metallic hydrogen (the inner core is } \\
\text { possibly silicate rock/ice). Mass ejections of sulfur dioxide } \\
\text { from Io, this gas cloud (torus) around Jupiter loads with } \\
\text { plasma. The shape of the magnetosphere is caused by Io's } \\
\text { plasma and the planet's rotation. } \\
\text { Fly out to Solar System View } \\
\text { Reinforce the Nebular Theory and Gravity's importance }\end{array}$ \\
\hline $\begin{array}{l}\text { END } \\
\text { DAY }\end{array}$ & $\begin{array}{l}\text { Oort Cloud } \\
\text { Fly to Oort Cloud } \\
\text { As we travel within our galaxy we see that stars are different } \\
\text { colors (temperature) and sizes. } \\
\text { Does anyone recall what the smallest stars are called? } \\
\text { Answer: Neutron } \\
\text { What about the largest stars? Supergiant } \\
\text { Which color is the hottest, red or blue? Answer: Blue } \\
\text { Play Video Clip of Star Comparison } \\
\text { As we approach the edge of the Oort Cloud (the extent of } \\
\text { our Sun's gravitational attraction), we notice something } \\
\text { strange happening to the constellation lines. } \\
\text { They have changed because we have changed position in } \\
\text { space; we are now } 1 \text { Light Year from the Earth! }\end{array}$ \\
\hline
\end{tabular}




\begin{tabular}{|c|c|c|}
\hline & $\begin{array}{l}\text { Question on index card } \\
\text { How did today's planetarium experience give you } \\
\text { a deeper, more interesting, or new way of } \\
\text { thinking about... } \\
\text { Our solar system (beginning or now) and what is } \\
\text { in it? } \\
\text { * Provide a specific example from today. }\end{array}$ & $\begin{array}{l}\text { Day 2 stimulus - } \\
\text { BEST visual - } \\
\text { Sun enlarged (to } \\
\text { suggest Nebular } \\
\text { theory), can be } \\
\text { top view or } \\
\text { oblique (better } \\
\text { option), if planets } \\
\text { are enlarged } \\
\text { (how much?), } \\
\text { show asteroids in } \\
\text { motion, show } \\
\text { Kuiper belt (if } \\
\text { possible), include } \\
\text { dwarf planets } \\
\text { (optional), } \\
\text { everything in } \\
\text { motion }\end{array}$ \\
\hline \multicolumn{3}{|c|}{ Day Three: Size and Scale } \\
\hline Scene & Discussion & Notes \\
\hline 1 & $\begin{array}{l}\text { Begin on Earth - } \\
\text { Quickly takeoff and slowly hover over a rotating Earth }\end{array}$ & \\
\hline 2 & $\begin{array}{l}\text { Scale } \\
\text { ISS - } \\
\text { Discuss the "falling" around the Earth and Newton's laws of } \\
\text { motion. Orbital Velocity (ISS }=17,100 \mathrm{mph}) \mathrm{vs.} \mathrm{Escape} \\
\text { Velocity ( } 25,000 \mathrm{mph}) \\
\sim 230 \text { miles above the Earth's surface } \\
\text { Other Satellites } \\
\text { Turn on the orbital paths of all of the Earth's manmade } \\
\text { satellites to see the impact of man in space }\end{array}$ & \\
\hline 3 & $\begin{array}{l}\text { Moon } \\
238,000 \text { miles away, } \sim 1 \text { light second } \\
\text { Light speed }=186,000 \text { miles per second }=671 \text { million } \mathrm{mph}\end{array}$ & \\
\hline 4 & $\begin{array}{l}\text { Sun } \\
93 \text { million miles from the Earth, } \sim 8 \text { light minutes } \\
\text { How long would it take to reach the Sun - } \\
\text { Apollo } 10=24,790 \mathrm{mph}=156 \text { days }\end{array}$ & \\
\hline 5 & $\begin{array}{l}\text { Mars } \\
48 \text { million miles from Earth } \\
\sim 9 \text { months for humans to travel to Mars from the Earth }\end{array}$ & \\
\hline
\end{tabular}




\begin{tabular}{|c|c|}
\hline & $\begin{array}{l}\text { Ramp up the speed of revolution to show an approximate } \\
\text { takeoff point from the Earth. Display with laser pointer how } \\
\text { Mars will meet up with the spacecraft as it revolves around } \\
\text { the Sun. }\end{array}$ \\
\hline 6 & $\begin{array}{l}\text { Jupiter } \\
390 \text { million miles from Earth } \\
43 \text { light minutes from Sun } \\
\text { Flyby: Voyager } 1=546 \text { days } \text { /Voyager } 2=688 \text { days } \\
\text { Shuttle = } 2 \text { years } \\
\text { Get into Orbit: } \sim 2000 \text { days (because you could not approach } \\
\text { the planet at extreme speeds or you would just 'flyby') } \\
\text { Neptune (Outermost Planet) } \\
4.1 \text { light hours from Sun } \\
2.7 \text { billion miles from Earth } \\
\text { Voyager } 2=12 \text { years } \\
\text { Shuttle = } 11 \text { years }\end{array}$ \\
\hline 7 & $\begin{array}{l}\text { Pluto (Dwarf Planet) } \\
5.5 \text { light hours } \\
\text { New Horizon }=\sim 9 \text { years } \\
\text { Shuttle }=15 \text { years }\end{array}$ \\
\hline 8 & $\begin{array}{l}\text { Voyager Missions } \\
\text { Travelling through space at } \sim 35,000 \mathrm{mph} \text { for } 39 \text { years } \\
\text { Investigated the gas giant planets before leaving our solar } \\
\text { system } \\
\text { Last photons from the Sun were received in } 2012 \\
\text { Enlarge Voyagers to show detail of the unmanned probes. } \\
\text { They are still operational and sending back information. } \\
\text { Though unmanned to reach this point in space it would take } \\
40 \text { years. If an astronaut were } 20 \text { years old when they left } \\
\text { the Earth, he/she would be } 60 \text { years old at this point. If he } \\
\text { wanted to return to Earth, he/she would arrive at the age of } \\
100 \text { years. } \\
\text { Continue to travel... it will take them } \sim 40,000 \text { years to } \\
\text { reach the Oort Cloud } \\
\text { Info from NASA: The twin Voyager } 1 \text { and } 2 \text { spacecraft are } \\
\text { exploring where nothing from Earth has flown before. } \\
\text { Continuing on their more-than-37-year journey since their } \\
1977 \text { launches, they each are much farther away from Earth } \\
\text { and the sun than Pluto. In August } 2012 \text {, Voyager } 1 \text { made the }\end{array}$ \\
\hline
\end{tabular}




\begin{tabular}{|c|c|}
\hline & $\begin{array}{l}\text { historic entry into interstellar space, the region between } \\
\text { stars, filled with material ejected by the death of nearby } \\
\text { stars millions of years ago. Scientists hope to learn more } \\
\text { about this region when Voyager 2, in the "heliosheath" -- } \\
\text { the outermost layer of the heliosphere where the solar wind } \\
\text { is slowed by the pressure of interstellar medium -- also } \\
\text { reaches interstellar space. Both spacecraft are still sending } \\
\text { scientific information about their surroundings through the } \\
\text { Deep Space Network, or DSN. } \\
\text { The primary mission was the exploration of Jupiter and } \\
\text { Saturn. After making a string of discoveries there -- such as } \\
\text { active volcanoes on Jupiter's moon Io and intricacies of } \\
\text { Saturn's rings -- the mission was extended. Voyager } 2 \text { went } \\
\text { on to explore Uranus and Neptune, and is still the only } \\
\text { spacecraft to have visited those outer planets. The } \\
\text { adventurers' current mission, the Voyager Interstellar } \\
\text { Mission (VIM), will explore the outermost edge of the Sun's } \\
\text { domain... and beyond. }\end{array}$ \\
\hline 9 & $\begin{array}{l}\text { Oort Cloud } \\
8 \text { light months from Sun } \\
\sim 40,000 \text { years via Voyager Missions } \\
\end{array}$ \\
\hline 10 & $\begin{array}{l}\text { Proxima Centauri } \\
4.2 \text { light years }=\sim 25 \text { trillion miles away } \\
\text { Space Shuttle (Humans) }=17,600 \mathrm{mph}=165,000 \text { years } \\
\text { Voyager }=35,000 \mathrm{mph}=10 \text { 's of thousands of years } \\
\text { New Horizons }=\sim 36,000 \mathrm{mph}=78,000 \text { years }\end{array}$ \\
\hline 11 & $\begin{array}{l}\text { Milky Way } \\
\text { Sun to Edge }=\sim 20,000 \text { light years } \\
\text { Sun to Center }=\sim 30,000 \text { light years } \\
\text { Milky Way Across }=\sim 100,000 \text { light years (Show the orbit } \\
\text { of the Sun within the Milky Way to display that it is not } \\
\text { stationary. It's revolution takes } \sim 240 \text { million years) }\end{array}$ \\
\hline 12 & $\begin{array}{l}\text { Local Group (Green cluster of dots within Uniview } \\
\text { surrounding the Milky Way Galaxy Model) } \\
\text { Group of galaxies near us that we are gravitationally } \\
\text { attracted to } \\
\text { Andromeda } \\
2.3 \text { million light years away. We are on a collision course - } \\
\text { mention red and blue shift (will discuss on day } 4 \text { in more } \\
\text { detail). }\end{array}$ \\
\hline 13 & $\begin{array}{l}\text { Cosmic Microwave Background Radiation } \\
13.8 \text { billion years old, but } \\
46 \text { billion light years away, because of accelerated } \\
\text { expansion }>\text { the speed of light }\end{array}$ \\
\hline
\end{tabular}




\begin{tabular}{|c|c|c|}
\hline END & $\begin{array}{l}\text { Edge of Observable Universe } \\
\text { At the "edge" of the observable universe, this is the extent } \\
\text { of our technological capabilities. It does not mean that there } \\
\text { is nothing beyond this point... we just can't see it, because } \\
\text { this is as fast as light can travel back to us. }\end{array}$ & \\
\hline & $\begin{array}{l}\text { Question on index card } \\
\text { How did today's planetarium experience give you } \\
\text { a deeper, more interesting, or new way of } \\
\text { thinking about... } \\
\text { The size of space and human exploration of it } \\
\text { *Provide a specific example from today. }\end{array}$ & $\begin{array}{l}\text { Day 3 Stimulus - } \\
\text { BEST visual - } \\
\text { Constellations } \\
\text { (from Earth), } \\
\text { then flying } \\
\text { through solar } \\
\text { system, and } \\
\text { breaking as you } \\
\text { move beyond } \\
\text { Oort cloud all the } \\
\text { way to observing } \\
\text { the Milky Way } \\
\text { (at oblique angle } \\
\text { with slow } \\
\text { rotation) }\end{array}$ \\
\hline \multicolumn{3}{|c|}{ Day Four: Big Bang and Search for Life } \\
\hline Scene & Discussion & Notes \\
\hline 1 & $\begin{array}{l}\text { Begin at Earth from Space Perspective } \\
\text { Beginning reference as the only place where life (as we } \\
\text { know it) exists } \\
\text { Humans have only: Traveled as far as the Moon and Live on } \\
\text { the ISS }\end{array}$ & \\
\hline 2 & $\begin{array}{l}\text { Fly Out to Edge of Observable Universe } \\
\text { Fast Flight to the edge of the observable universe } \\
\text { Reminder of waypoints on the trip to reinforce vast } \\
\text { distances }\end{array}$ & \\
\hline 3 & $\begin{array}{l}\text { Create a Single Point of Energy (visually) flying as far as } \\
\text { one can within Uniview } \\
\text { This represents the beginning of the universe } \\
\text { From this single point of infinite energy everything was } \\
\text { made }\end{array}$ & \\
\hline 4 & $\begin{array}{l}\text { Big Bang Theory (Expansion) } \\
\text { We will now simulate the Big Bang... the process that } \\
\text { began it all. } \\
\text { If we look at the equation } E=\mathrm{mc}^{2} \text {, we understand that } \\
\text { energy can be made by multiplying the mass of an object by } \\
\text { a constant (the speed of light) squared. So if we manipulate }\end{array}$ & \\
\hline
\end{tabular}




\begin{tabular}{|c|l|l|}
\hline $\mathbf{5}$ & the equation... then mass/matter can be made from energy. & $\begin{array}{l}\text { CMBR and Cooling to Create first Atoms } \\
\text { After the "bang" the universe was composed of matter and } \\
\text { antimatter. When these two came into contact they } \\
\text { destroyed one another. Luckily for us there was more } \\
\text { matter. This matter is the building blocks of everything } \\
\text { around you. }\end{array}$ \\
$\begin{array}{l}\text { The CMBR is the evidence used by scientists to show that } \\
\text { this destructive battle released massive amounts of energy } \\
\text { during the birth of our universe. }\end{array}$ \\
\hline $\mathbf{6}$ & $\begin{array}{l}\text { The pattern displays varied amounts of the released energy. } \\
\text { Notice that it is all around you. } \\
\text { First Stars and Nucleosynthesis } \\
\text { As the matter began to cool, subatomic particles began to } \\
\text { form and those particles organized themselves into the first } \\
\text { element. } \\
\text { Which element do you believe is the easiest and simplest to } \\
\text { create? Answer = Hydrogen }\end{array}$ \\
$\begin{array}{l}\text { The hydrogen atoms were brought together into dense } \\
\text { clouds by gravity. As these clouds became denser the } \\
\text { temperature increased and the first stars were formed. } \\
\text { Inside of these stars, fusion began to create larger elements. } \\
\text { What is fusion? Answer = fusing of smaller atoms to form } \\
\text { new, more massive elements. } \\
\text { These stars did not live for very long and would supernova, } \\
\text { expelling the newly formed elements into space. That } \\
\text { expelled dust and gas, composed of the new elements, } \\
\text { would come together once again to create new stars and } \\
\text { eventually planets and moons. }\end{array}$ \\
$\begin{array}{l}\text { Local Group of Galaxies (Red Shift/Blue Shift) } \\
\text { As we travel toward our Earth, we begin to see our galaxy. } \\
\text { Within Uniview it is a dot that is surrounded by billions of } \\
\text { other dots. These dots are not stars. Each dot represents a } \\
\text { galaxy. } \\
\text { We are now just outside of our galaxy. Does anyone recall } \\
\text { the name of our galaxy? Answer: Milky Way } \\
\text { Does anyone know how many stars are in our galaxy? } \\
\text { Answer: Over 200 billion } \\
\text { Our galaxy has a distinctive shape. Can you classify which }\end{array}$ \\
\hline
\end{tabular} \mid




\begin{tabular}{|c|c|}
\hline & $\begin{array}{l}\text { type of galaxy we live in? Answer: Spiral (the other types } \\
\text { are irregular and elliptical) } \\
\text { Each galaxy contains between } 100 \text { - } 400 \text { billion stars. So if } \\
\text { you are attempting to wrap your mind around how many } \\
\text { stars are in the entire universe... there are more stars in the } \\
\text { universe than there are grains of sand on all of the beaches } \\
\text { of planet Earth. } \\
\text { The varying colors of the galaxies represent the gravitational } \\
\text { attraction to one another. } \\
\text { For example, our local group is colored green, because we } \\
\text { are attracted to one another. The Milky Way Galaxy and } \\
\text { Andromeda (m31) are on a collision course with one } \\
\text { another... in about } 4 \text { billion years. } \\
\text { Some may ask, "How do we know if objects are moving } \\
\text { towards or away from us in space?"... these objects are so } \\
\text { far away. The answer is to look at the photon/light } \\
\text { information and see if there is a blue or red shift in the } \\
\text { spectral analysis. The light waves give us two different types } \\
\text { of information: elemental composition and radial velocity. } \\
\text { Display Static, Red-Shift, Blue-Shift (Use of laser pointer) } \\
\text { Approaching objects have shorter blue waves, compressed } \\
\text { just like sound waves of the Doppler Effect. } \\
\text { Objects that are receding have longer red waves. } \\
\text { Display quick movie clip: "Collision of Milky Way and } \\
\text { Andromeda" } \\
\text { Within this clip discuss that Andromeda and the Milky Way } \\
\text { will collide to create a super galaxy in approximately } 3.5 \\
\text { billion years. This collision will not be destructive. There } \\
\text { is so much space in space that all of the star will find their } \\
\text { new niche and the massive black holes at the center of each } \\
\text { galaxy will combine into one. }\end{array}$ \\
\hline 8 & $\begin{array}{l}\text { Milky Way Galaxy Habitable Zone and Orbit of the Sun } \\
\text { Turn On Galactic Habitable Zone } \\
\text { The Milky Way Galaxy also has a habitable zone. Luckily } \\
\text { for us our Sun resides within that habitable zone. } \\
\text { Turn On the Sun's Revolutionary Orbit } \\
\text { Our Sun is in an area that is stable enough for life to exist. } \\
\text { Revolution is } 225 \text { million years. }\end{array}$ \\
\hline
\end{tabular}




\begin{tabular}{|c|c|}
\hline & $\begin{array}{l}\text { If we where in the red area, there is too much radiation and } \\
\text { instability because of larger, coolest, aging stars and the } \\
\text { tremendous black hole that is at our galactic center. } \\
\text { Looking at the blue area of the galaxy, stars are too young } \\
\text { and supernovas have not expelled enough heavy elements } \\
\text { into space to create rocky planets. }\end{array}$ \\
\hline $\begin{array}{l}9 \\
\end{array}$ & $\begin{array}{l}\text { Exoplanets and Radiosphere } \\
\text { Fly to Radiosphere } \\
\text { This blue sphere is our radiosphere. Humans have been } \\
\text { transmitting television signals for approximately } 80 \text { years, } \\
\text { so this sphere has a radius of } 80 \text { light years (diameter of } 160 \\
\text { ly). } \\
\text { Turn On Exoplanets } \\
\text { The blue sprites/asterisks that surround you are stars with } \\
\text { known exoplanets. When scientists search for life they look } \\
\text { for the two habitable zones (galactic and solar system). } \\
\text { How do we find these exoplanets? } \\
\text { Play the video: "Exoplanet Discovery" } \\
\text { Discuss the following while video is playing: All stars give } \\
\text { off light that enters telescopes on Earth. This light can be } \\
\text { graphed and analyzed to find out extreme amounts of } \\
\text { information. The most basic is to see if a planet is orbiting } \\
\text { the star. Discuss graph on right. The graph begins at a } \\
\text { baseline reading and then it drops. This drop coincides with } \\
\text { a planet transiting the star and blocking a portion of that } \\
\text { light. When the planet revolves to the opposite side of the } \\
\text { star, the graph returns to baseline. Looking at spectral } \\
\text { analysis scientists can also determine characteristics of the } \\
\text { planet's elements and composition. } \\
\\
\text { Let's fly to one of these exoplanets }\end{array}$ \\
\hline 10 & $\begin{array}{l}\text { Proxima Centauri B around a Red Dwarf Star } \\
\text { Proxima Centauri is a red dwarf star that resides } \sim 4.3 \text { light } \\
\text { years from the Earth. Revolving around this star scientists } \\
\text { have discovered the nearest earthlike planet, Proxima } \\
\text { Centarui B. } \\
\sim 0.05 \text { AU from Proxima Centarui } \\
\text { Revolution: } 11.2 \text { Earth days } \\
\text { Rotation: Tidally locked } \\
\text { The area between day and night may be the most } \\
\text { Earthlike... a blend of the extreme cold on the dark side and } \\
\text { the eternal scorching on the dayside. }\end{array}$ \\
\hline
\end{tabular}




\begin{tabular}{|c|c|c|}
\hline & $\begin{array}{l}\text { The planet is believed to be located within the habitable } \\
\text { zone of the star. } \\
\text { Life may not be able to exist around this star because of the } \\
\text { amount of radiation that it expels into space. }\end{array}$ & \\
\hline 11 & $\begin{array}{l}\text { Search for Life within our Solar System } \\
\text { Most likely, any life we find outside of the Earth will be } \\
\text { extreme (extremophile). } \\
\text { Titan - Methane based life } \\
\text { Europa - Water shooting from its cracks } 125 \text { miles into } \\
\text { space } \\
\text { Io - Volcanic activity (life on Earth's ocean trenches) } \\
\text { Mars - Liquid water }\end{array}$ & \\
\hline END & $\begin{array}{l}\text { Fly back to Earth } \\
\text { This is the only place where we have found life to exist, and } \\
\text { we have not even identified all of the various life forms. }\end{array}$ & \\
\hline & $\begin{array}{l}\text { Question on paper } \\
\text { What about the planetarium has helped you in } \\
\text { thinking about or understanding astronomical } \\
\text { concepts (rank in order from most to least } \\
\text { important)? } \\
\text { 1. Flying through and around space } \\
\text { 2. Dynamic modeling of space phenomena } \\
\text { (e.g. showing the Earth as is, ability to } \\
\text { enlarge, can add poles, and show motion of } \\
\text { the Earth and in relation to other objects) } \\
\text { 3. Immersive environment (feeling like being } \\
\text { in space) } \\
\text { 4. Scale of the size of objects } \\
\text { 5. Scale of distance between objects } \\
\text { 6. Different perspectives of same concept } \\
\text { (e.g. Earth day from surface of planet vs. } \\
\text { seeing Earth rotate from space) } \\
\text { 7. Manipulation of time (e.g. day-night, yearly } \\
\text { patterns, etc...) } \\
\text { These } 7 \text { are things that a planetarium can do well... better } \\
\text { than classrooms, textbooks, computer screens, etc... }\end{array}$ & $\begin{array}{l}\text { Day 4 Stimulus - } \\
\text { BEST visual - } \\
\text { Milky Way with } \\
\text { our Sun's orbit } \\
\text { visible (without } \\
\text { habitable zone) }\end{array}$ \\
\hline & $\begin{array}{l}\text { Provide bingo chips and } 3 \text { buckets - all students given a } \\
\text { bingo chip when they enter and will place it in the bucket } \\
\text { they feel was most helpful in helping them think about (or } \\
\text { learn) astronomy. } \\
\text { "Over the last } 4 \text { days, which aspect of the } \\
\text { planetarium experience was most impactful for } \\
\text { you? Please vote by placing your bingo chip in }\end{array}$ & \\
\hline
\end{tabular}




\begin{tabular}{|l|l|}
\hline $\begin{array}{l}\text { the appropriate bucket (1 bucket for SC, } \\
\text { personal, and physical)." } \\
\text { - Important concepts woven within a storyline } \\
\text { (SC) } \\
\text { The immersive environment/the dome shape } \\
\text { making you feel like in space (physical) } \\
\text { Understanding daily Earth observations (e.g. } \\
\text { day/night, seasonal changes) better through } \\
\text { flight into space. }\end{array}$ \\
\hline
\end{tabular}

Note. Information gathered from: NASA, CNN, Space.com, Earthsky.org 


\section{Appendix D}

\section{Survey of Attitudes Toward Astronomy}

The questions below are designed to identify your attitudes about astronomy and science. The item scale has 5 possible responses; the responses range from 1 (strongly disagree) through 3 (neither agree nor disagree) to 5 (strongly agree). Please read each question. From the 5-point scale mark the response that most clearly represents your agreement.

\begin{tabular}{|c|c|c|c|c|c|}
\hline $\begin{array}{l}\text { 1. Astronomy is a subject learned quickly by most } \\
\text { people. }\end{array}$ & 1 & 2 & 3 & 4 & 5 \\
\hline $\begin{array}{l}\text { 2. I will have trouble understanding astronomy because } \\
\text { of how I think. }\end{array}$ & 1 & 2 & 3 & 4 & 5 \\
\hline 3. Astronomy concepts are easy to understand. & 1 & 2 & 3 & 4 & 5 \\
\hline 4. Astronomy is irrelevant to my life. & 1 & 2 & 3 & 4 & 5 \\
\hline $\begin{array}{l}\text { 5. I will get frustrated going over astronomy tests in } \\
\text { class. }\end{array}$ & 1 & 2 & 3 & 4 & 5 \\
\hline 6. I will be under stress during astronomy class. & 1 & 2 & 3 & 4 & 5 \\
\hline $\begin{array}{l}\text { 7. I will understand how to apply analytical reasoning to } \\
\text { astronomy. }\end{array}$ & 1 & 2 & 3 & 4 & 5 \\
\hline 8. Learning astronomy requires a great deal of discipline. & 1 & 2 & 3 & 4 & 5 \\
\hline 9. I will have no idea of what's going on in astronomy. & 1 & 2 & 3 & 4 & 5 \\
\hline 10. I will like astronomy. & 1 & 2 & 3 & 4 & 5 \\
\hline $\begin{array}{l}\text { 11. What I learn in astronomy will not be useful in my } \\
\text { career. }\end{array}$ & 1 & 2 & 3 & 4 & 5 \\
\hline $\begin{array}{l}\text { 12. Most people have to learn a new way of thinking to } \\
\text { do astronomy. }\end{array}$ & 1 & 2 & 3 & 4 & 5 \\
\hline 13. Astronomy is highly technical. & 1 & 2 & 3 & 4 & 5 \\
\hline $\begin{array}{l}\text { 14. I will feel insecure when I have to do astronomy } \\
\text { homework. }\end{array}$ & 1 & 2 & 3 & 4 & 5 \\
\hline $\begin{array}{l}\text { 15. I will find it difficult to understand astronomy } \\
\text { concepts. }\end{array}$ & 1 & 2 & 3 & 4 & 5 \\
\hline 16. I will enjoy taking this astronomy course. & 1 & 2 & 3 & 4 & 5 \\
\hline $\begin{array}{l}\text { 17. I will make a lot of errors applying concepts in } \\
\text { astronomy. }\end{array}$ & 1 & 2 & 3 & 4 & 5 \\
\hline $\begin{array}{l}\text { 18. Astronomy involves memorizing a massive } \\
\text { collection of facts. }\end{array}$ & 1 & 2 & 3 & 4 & 5 \\
\hline 19. Astronomy is a complicated subject. & 1 & 2 & 3 & 4 & 5 \\
\hline 20. I can learn astronomy. & 1 & 2 & 3 & 4 & 5 \\
\hline 21. Astronomy is worthless. & 1 & 2 & 3 & 4 & 5 \\
\hline 22. I am scared of astronomy. & 1 & 2 & 3 & 4 & 5 \\
\hline $\begin{array}{l}\text { 23. Scientific conclusions are rarely presented in } \\
\text { everyday life. }\end{array}$ & 1 & 2 & 3 & 4 & 5 \\
\hline 24. Scientific concepts are easy to understand. & 1 & 2 & 3 & 4 & 5 \\
\hline
\end{tabular}




\begin{tabular}{|l|l|l|l|l|l|}
\hline 25. Science is not useful to the typical professional. & 1 & 2 & 3 & 4 & 5 \\
\hline 26. The thought of taking a science course scares me. & 1 & 2 & 3 & 4 & 5 \\
\hline 27. I like science. & 1 & 2 & 3 & 4 & 5 \\
\hline 28. I find it difficult to understand scientific concepts. & 1 & 2 & 3 & 4 & 5 \\
\hline 29. I can learn science. & 1 & 2 & 3 & 4 & 5 \\
\hline 30. Scientific skills will make me more employable. & 1 & 2 & 3 & 4 & 5 \\
\hline 31. Science is a complicated subject. & 1 & 2 & 3 & 4 & 5 \\
\hline 32. I use science in my everyday life. & 1 & 2 & 3 & 4 & 5 \\
\hline $\begin{array}{l}\text { 33. Scientific thinking is not applicable to my life } \\
\text { outside my job. }\end{array}$ & 1 & 2 & 3 & 4 & 5 \\
\hline $\begin{array}{l}\text { 34. Science should be a required part of my professional } \\
\text { training. }\end{array}$ & 1 & 2 & 3 & 4 & 5 \\
\hline
\end{tabular}

Note. Post-SATA included the same questions with changes in verb tense 


\section{Appendix E}

\section{Pre-Astronomy Content Assessment}

Please answer the following questions about astronomy. You may or may not know the correct answer, but please do your best to make an educated guess. This assessment will not be graded, rather used to measure your entry knowledge and progression during the course.

1. In addition to dwarf planets (like Pluto), there are two main classifications of planets in our solar system. Which answer is correct?
a. Rocky planets and Gaseous planets
b. Rocky planets and Circumbinary planets
c. Gaseous planets and Coreless planets
d. Circumbinary planets and Coreless planets

2. What force has been most important in the formation of objects in space?
a. Electromagnetic forces
b. Nuclear forces
c. Gravitational forces
d. Friction forces

3. How do scientists explain the initial formation of our solar system?

a. The solar system formed after the initial expansion of material from the Big Bang.

b. The solar system formed after nuclear fusion began at the core of our star.

c. The solar system formed once the 8 planets and dwarf planets began orbiting in a predictable pattern around the Sun.

d. Scientists have yet to explain the formation of our solar system.

4. Nebular theory states...

a. that nebula are responsible for the differences between planets in our solar system.

b. that a nebula is responsible for planets of different sizes revolving at varying distances around a star.

c. that the solar system exists because it is in a part of our galaxy not close enough to be pulled in by a massive black hole.

d. that the solar system formed from a swirling cloud of gas and dust.

5. The correct order of planets (starting closest to the Sun and working out) is:

a. Mercury, Venus, Mars, Earth, Jupiter, Saturn, Neptune, Uranus

b. Mercury, Venus, Earth, Mars, Jupiter, Saturn, Neptune, Uranus

c. Mercury, Venus, Earth, Mars, Jupiter, Saturn, Uranus, Neptune

d. Mercury, Venus, Mars, Earth, Jupiter, Saturn, Uranus, Neptune

6. What is the best explanation for having different seasons throughout the year? 
a. The Earth has seasons because it is cold in the winter and hot in the summer.

b. The Earth has seasons because the planet is at different distances from the Sun throughout the year.

c. The Earth has seasons because it is tilted and its orbital path around the Sun is elliptical.

d. The Earth has seasons because it is tilted and absorbs different amounts of energy throughout the year.

7. When scientists study distant objects in space, something called red shift can occur. What does red shift mean?

a. Objects in space have extremely high temperatures.

b. Objects in space are moving away from us.

c. Objects in space are on a possible collision course.

d. Objects in space have shifted into a new solar system or galaxy.

8. There are many different types of stars in space. Which stars have the hottest temperature?
a. Yellow
b. Red
c. Blue
d. White

9. Objects in space vary tremendously in size. Which choice is the correct order of objects from smallest to largest in regards to size.

a. The Moon, Earth, Jupiter, Solar System, Milky Way Galaxy, the Local Group

b. The Moon, Earth, the Local Group, Jupiter, Solar System, Milky Way Galaxy

c. The Moon, Earth, Jupiter, Solar System, the Local Group, Solar System, Milky Way Galaxy

d. The Moon, Earth, Jupiter, Solar System, the Local Group, Milky Way Galaxy

10. Objects in space are separated by extreme distances. Which of the following is furthest from the Earth?
a. The Kuiper belt
b. The planet Neptune
c. The asteroid belt
d. The Oort cloud 


\section{Appendix F}

Final day ranking of planetarium characteristics

The list below includes 7 things that a planetarium can do well... better than classrooms, textbooks, and computer screens.

What about the planetarium has helped you in thinking about or understanding astronomical concepts? Rank in order from most important (1) to least important (7).

Flying through and around space

Dynamic modeling of space phenomena (e.g. showing the Earth as is, ability to enlarge, can add poles, and show motion of the Earth and in relation to other objects)

Immersive environment (feeling like being in space)

Scale of the size of objects (e.g. Earth compared to other planets)

Scale of distance between objects in space

Different perspectives of same concept (e.g. Earth day from surface of planet vs. seeing Earth rotate from space)

Manipulation of time (e.g. day-night, yearly patterns, etc...) 


\section{Appendix G}

Bucket voting - each representing a context of the CML

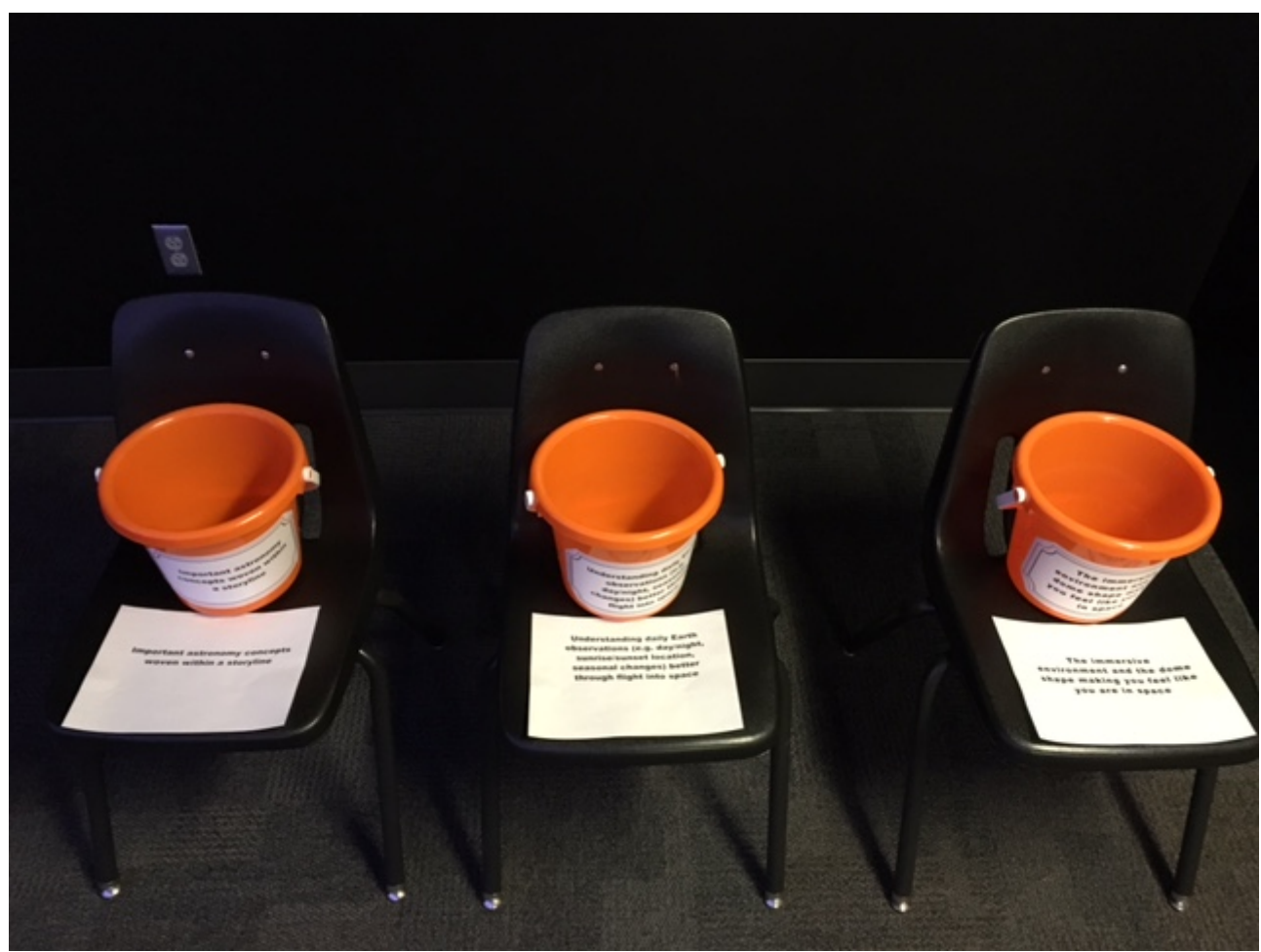

Personal context - Understanding daily Earth observations (e.g. day/night, seasonal changes) better through flight into space.

Physical context - The immersive environment and the dome shape making you feel like you are in space.

Sociocultural context - Important astronomy concepts woven within a storyline. 


\section{Appendix H}

Survey - Do You Remember the Planetarium?

Reflect back to earlier in the year when you studied astronomy. Do you feel that the 4 days in the planetarium helped you learn and enjoy astronomy?

1. The planetarium helped me learn astronomy.
a. Strongly disagree
b. Disagree
c. Neutral
d. Agree
e. Strongly disagree

2. I enjoyed astronomy because of our time in the planetarium.
a. Strongly disagree
b. Disagree
c. Neutral
d. Agree
e. Strongly disagree 


\section{Appendix I}

Teacher interview questions

1. Did students talk positively about the planetarium - when they left the daily show, the next day, or anytime since you finished that unit? Can you provide examples to support this?

2. Did students learn from the planetarium program? What support do you have for this?

3. Did students have positive attitudes during the time they were going to the planetarium? How do you know?

4. Were you able to use planetarium show material to teach or connect concepts for students? What and how did you do so and did the reference back to the planetarium help them? 


\section{Appendix J}

\section{Observation protocol}

Location - Sat at control console or stood near the doorway to count students entering. At the beginning of each show, started the audio-recorder to capture topics covered, questions asked, and answers given. During the show, stood behind students to gather interactions, or reactions, to certain visuals and topics. At the end of each day, moved to the front to assist students in obtaining formative assessment and a writing utensil, then moved around to gather cards before they exited.

Field notebook recordings - Recorded day, class number, number of students (males \& females), topics taught, questions from educator, answers from students, questions from students, comments/reactions from students, interactions between students, group dynamics (when differences existed).

Key words or phrases (upon entry and during show) - Since it was dark and interactions were typically limited to question-answer format, these were recorded. Additionally, it was noted whether boys or girls were answering, asking, or commenting. Any pointing to things shown on dome or displays of interest (e.g. whistles, wows, and whispers) in the physical space or visualizations were recorded.

Key words and phrases (at the conclusion of or after show) - As students answered formative assessment questions, or once they completed, asked questions these were recorded. Also, any questions asked as students left the planetarium or if students stayed behind to discuss certain topics, these were recorded.

Key words and phrases (used to code formative assessments) Personal context: 
Examples: 'I didn't know', 'It helped me understand', 'It gave or showed me', 'It made me think', 'I learned', 'It impacted or affected me'

\section{Physical context:}

Examples: 'The visuals or visualizations', 'Size and/or distance (scale)', 'Gave a new and/or different perspective', 'The 3-D view', 'Allowed us to see or showed us', 'Faster speed, movement, or enlarging of objects'

\section{Sociocultural context:}

Examples: Questions or answers from students, Questions or answers from planetarium educator, Context of the planetarium in science, Interactions or collaboration inside the planetarium between students

\section{Individual concepts:}

Each day included a variety of topics and students were free to mention anything of their choice. In addition to the context(s) that the quote fit into, any mention of certain words, or student ideas about a topic, led to categorizing student quotes into these codes:

$\underline{\text { Stars }}-$ constellations, North Star/Polaris, stars, Sun

Seasons - Tilt of Earth, interactions between Earth and Sun, revolution during the year, connection of North Pole-North Star

Earth motion or position - rotation, revolution, tilt

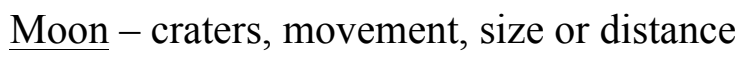

Scale - enlarging an object for comparison, size of objects, distance between objects, size of space, feeling small in comparison to objects, massive or miniscule in size Day/night - day/night, light lines at polar regions, Earth rotation Flight through space - flying in and out, the flight through space, flying between objects 
Interactions - between Sun-Earth, Earth-Moon, Earth-Moon-Sun, between Earth and other objects in space, or interactions between other objects

Magnetosphere - Earth's or Jupiter's magnetosphere, magnetic field

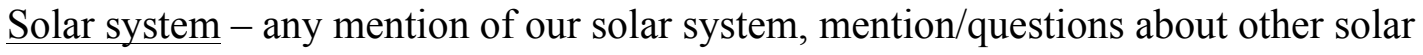
systems

Dwarf planets - mention of dwarf planets, planets with different orbits, mention of Pluto Oort cloud - any mention of presence of Oort cloud, distance of Oort cloud, or Sun's influence to this area of space

Gravity - any mention of gravity within the solar system or beyond, certain interactions between objects in space, absence of and what would happen

Galaxy/Universe - any mention of the Milky Way, Andromeda, other neighboring galaxies, the universe, possibility of other universes

Positive - 'It was cool', 'It's good for visual learners', 'A more realistic view', 'It was very interesting'. These comments went beyond the basic student answer and provided solid evidence that the planetarium played an important role in their learning/understanding. Negative - 'My neck hurt', 'I didn't learn anything', 'It didn't change my perspective'. These small group of comments represented student thoughts that included anything negative (comfort or learning). 


\section{Appendix K}

Qualitative Data Coding and Student Responses

\begin{tabular}{|c|c|c|c|}
\hline Code & Male & Female & Total \\
\hline Personal context & 162 & 155 & 374 \\
\hline Physical context & 110 & 90 & 233 \\
\hline Sociocultural context & 10 & 7 & 134 \\
\hline Stars & 22 & 24 & 52 \\
\hline Seasons & 13 & 13 & 26 \\
\hline Earth & 17 & 12 & 31 \\
\hline Moon & 12 & 10 & 25 \\
\hline Scale & 99 & 72 & 208 \\
\hline Day/night & 2 & 0 & 2 \\
\hline Flight & 6 & 3 & 9 \\
\hline Interactions & 11 & 3 & 15 \\
\hline Magnetosphere & 7 & 6 & 14 \\
\hline Solar system & 11 & 10 & 32 \\
\hline Dwarf planets & 11 & 11 & 26 \\
\hline Oort Cloud & 16 & 6 & 23 \\
\hline Gravity & 8 & 9 & 18 \\
\hline Galaxy/universe & 25 & 23 & 63 \\
\hline Manipulation & 15 & 17 & 43 \\
\hline No specific content mentioned & 11 & 5 & 20 \\
\hline Positive comments & 40 & 50 & 101 \\
\hline Negative comments & 5 & 0 & 5 \\
\hline
\end{tabular}


Note: Only students at Hickory H.S. $(n=1007)$, total codes are greater than sample size because of responses being placed into multiple categories, the variation in male and female sample size compared to the grand total is due to not knowing students' gender from third period responses. 


\section{CURRICULUM VITA}

William R. Thornburgh

\section{OFFICE:}

University of Louisville

College of Education and Human Development

1905 S. ${ }^{\text {st }}$ St. Louisville, KY 40292

wrthor01@louisville.edu

\section{EDUCATION:}

Doctor of Philosophy

April 2017
University of Louisville

Major: Curriculum and Instruction Dissertation: The Role of the

Planetarium in Students' Attitudes, Learning, and Thinking about Astronomical Concepts

Chair: Dr. Tom Tretter

Montana State University

Major: Science Education

Butler University

Major: Chemistry

1998

\section{PUBLICATIONS:}

Thornburgh, W., \& Tretter, T. (2017). Modeling the eclipse. The Science Teacher, $84(3), 47-52$.

Tretter, T., Thornburgh, W. \& Duckwall, M. (2016). Seeing The Solar System Through Two Perspectives. Science and Children, 53(5), 60-70.

Thornburgh, W., Tretter, T. \& Duckwall, M. (2015). Seeing The Solar System Through Two Perspectives. Science and Children, 53(4), 42-51.

Thornburgh, W., \& Tretter, T. (In press). Explaining Patterns in Our Solar System and The Role of Gravity in Space Science.. Science Scope 


\section{PROFESSIONAL SOCIETIES:}

Association for Science Teacher Educators (ASTE)

Mid-Atlantic ASTE

Kentucky Academy of Science

National Science Teachers Association (NSTA)

American Modeling Teachers Association (AMTA)

INTERNATIONAL AND NATIONAL MEETING PRESENTATIONS:

AERA, 2015 - Chicago, IL

NSTA, 2016 - Nashville, TN

ASTE, 2016 - Reno, NV

ASTE, 2017 - Des Moines, IA

\section{GRANTS}

2017 Junior Science and Humanities Symposium, \$12,000

2016 Junior Science and Humanities Symposium, \$12,000

2015 Junior Science and Humanities Symposium, \$12,000

2014 Junior Science and Humanities Symposium, \$15,000 